\title{
Elaboration during problem-based, small group discussion : a new approach to study collaborative learning
}

Citation for published version (APA):

van Blankenstein, F. M. (2011). Elaboration during problem-based, small group discussion : a new approach to study collaborative learning. [Doctoral Thesis, Maastricht University]. Maastricht University. https://doi.org/10.26481/dis.20110518fb

Document status and date:

Published: 01/01/2011

DOI:

10.26481/dis.20110518fb

Document Version:

Publisher's PDF, also known as Version of record

\section{Please check the document version of this publication:}

- A submitted manuscript is the version of the article upon submission and before peer-review. There can be important differences between the submitted version and the official published version of record.

People interested in the research are advised to contact the author for the final version of the publication, or visit the DOI to the publisher's website.

- The final author version and the galley proof are versions of the publication after peer review.

- The final published version features the final layout of the paper including the volume, issue and page numbers.

Link to publication

\footnotetext{
General rights rights.

- You may freely distribute the URL identifying the publication in the public portal. please follow below link for the End User Agreement:

www.umlib.nl/taverne-license

Take down policy

If you believe that this document breaches copyright please contact us at:

repository@maastrichtuniversity.nl

providing details and we will investigate your claim.
}

Copyright and moral rights for the publications made accessible in the public portal are retained by the authors and/or other copyright owners and it is a condition of accessing publications that users recognise and abide by the legal requirements associated with these

- Users may download and print one copy of any publication from the public portal for the purpose of private study or research.

- You may not further distribute the material or use it for any profit-making activity or commercial gain

If the publication is distributed under the terms of Article $25 \mathrm{fa}$ of the Dutch Copyright Act, indicated by the "Taverne" license above, 


\title{
Elaboration during problem-based, small group discussion
}

\author{
A new approach to study \\ collaborative learning
}


The research reported here was carried out at

Maastricht University

in the School of Health Professions Education

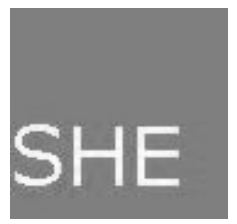

in the context of the research school

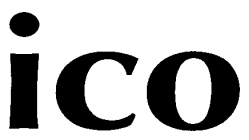

(Interuniversity Center for Educational Research)

(C) Floris van Blankenstein, Maastricht, the Netherlands, 2011 ISBN-13978908666 1947

Cover design: Jaro Wetzer

All rights reserved

Printed by: Boekenplan 


\section{Elaboration during problem-based, small group discussion}

\section{A new approach to study collaborative learning}

\section{Proefschrift}

ter verkrijging van de graad van doctor aan de Universiteit Maastricht op gezag van de Rector Magnificus, Prof. Mr. G. P. M. F. Mols, volgens het besluit van het College van Decanen

in het openbaar te verdedigen op woensdag 18 mei 2011 om 16:00 uur

$$
\text { door }
$$

Floris Matthias van Blankenstein Geboren op 9 januari 1980 te Den Haag 


\section{Promotores:}

Prof. dr. H. G. Schmidt, Erasmus Universiteit Rotterdam

Prof. dr. C. P. M. van der Vleuten

\section{Co-promotor:}

Dr. D. H. J. M. Dolmans

Leden beoordelingscommissie:

Prof. dr. J. J. G. van Merriënboer (voorzitter)

Dr. A. B. H. de Bruin

Dr. G. Erkens, Universiteit Utrecht

Prof. dr. G. W. C. Paas, Erasmus Universiteit Rotterdam

Prof. dr. A. J. J. A. Scherpbier 


\section{Contents}

\section{Chapter 1:}

Introduction

The role of providing explanations and listening to others during small group discussion

Published in Instructional Science, 39(2), 189-204.

Does explanation to others improve learning after small group discussion? 35 Presented at the annual meeting of the American Educational Research Association, Denver, CO. Under editorial review.

Can a teacher who promotes elaboration during small group discussion improve academic achievement?

Under editorial review.

Relevant prior knowledge moderates the effect of elaboration during small group discussion on academic achievement Under editorial review.

General discussion

Appendices

Summary

Samenvatting

Dankwoord (Acknowledgements)

Curriculum Vitae

SHE dissertation series 



\section{Chapter 1}

\section{Introduction}

Collaborative learning is being applied more and more often, but the cognitive processes that make it effective remain ill-understood. This also accounts for problem-based learning (PBL), a collaborative learning approach in which students discuss real-world scenarios in small groups. PBL is used at many universities across the globe and its' effectiveness has been evaluated repeatedly (Albanese, 1993; Colliver, 2000; Dochy, Segers, Van den Bossche, \& Gijbels, 2003; Schmidt, Van der Molen, Te Winkel, \& Wijnen, 2009; Vernon \& Blake, 1993). However, it remains unclear which cognitive processes boost academic achievement in PBL. Although there seems to be a consensus that cognitive elaboration is one beneficial element of collaborative learning (O'Donnell, 2006; Slavin, Hurley, \& Chamberlain, 2003; Springer, Stanne, \& Donovan, 1999), previous research has not confirmed that it enhances achievement in PBL. This dissertation aimed at examining the effect of elaboration in PBL on achievement.

The introduction will start with some background information about cognitive elaboration. It will then focus on elaboration during collaborative learning. Subsequently, it will explain how elaboration is expected to enhance learning in PBL. It shall become clear that research to collaborative learning comes with some problems, which can be solved by adjusting the research method. Therefore, a new method to study collaborative learning will be presented. All this will result in some specific research questions that conclude the introduction.

\section{Cognitive elaboration}

Elaboration occurs when students add meaningful relationships to something they learn (Levin, 1988). By doing this, they create new and meaningful connections between the new information and their own prior knowledge. The resulting knowledge base contains more interconnections, which serve as retrieval cues at the time information must be recalled from memory. Therefore, elaboration should facilitate recall (Reder, 1980). This explanation is referred to as the richness hypothesis (Hamilton, 2004), because elaboration enriches the knowledge base. Elaboration can be triggered by learning materials, but students can also generate the new relations themselves. According to the generative model for learning (Wittrock, 1992), students come to a fuller understanding of new knowledge when they meaningfully connect it to prior knowledge. Therefore, the generation of elaborations is expected to enhance the recall and comprehension of new knowledge. 
Support for the effectiveness of generating elaborations has been reported frequently in the research literature. Initially, elaboration was tested with relatively simple learning tasks, like word-pairing tasks (Bobrow \& Bower, 1969; Slamecka \& Graf, 1978). Generating connective sentences between two words, or completing incomplete word-pairings, proved to enhance the recall of those words. Later experiments included more complex learning tasks and found positive effects of self-generated elaborations on recall and application of knowledge (Johnsey, Morrison, \& Ross, 1992; Mayer, 1980; Pressley, Symons, McDaniel, Snyder, \& Turnure, 1988; Pressley et al., 1992). In Mayer's (1980) experiments, participants learned a lesson about computer programming. During the lesson, they elaborated by comparing different parts of the lesson with each other or by actively relating the parts with their own prior knowledge. After the lesson, they tended to solve complex problems more often than read-only controls. Also, they recalled more conceptual information than reading controls. Johnsey et al. (1992) reported similar findings. Pressley and colleagues (1988) discovered that students recalled more facts after they came up with meaningful reasons for why the facts were true. It may therefore be concluded that generating elaborations is conducive to learning.

The positive effect of elaboration can be moderated by students' level of prior knowledge. That is, elaboration increases recall especially (or only) when participants have relevant prior knowledge about the study topic, whereas it has a smaller (or no) effect on recall when participants have virtually no prior knowledge (Willoughby, Waller, Wood, \& MacKinnon, 1993; Woloshyn, Pressley, \& Schneider, 1992). It thus seems that relevant prior knowledge facilitates the generation of new connections when students are encouraged to elaborate. Without prior knowledge, students may have insufficient background information to elaborate on.

Prior knowledge in itself may actually guide new learning. It has been shown that students recall more information from a text when they have read the text from a certain perspective (Pichert \& Anderson, 1977). Other findings suggest that the activation of prior knowledge determines which information is recalled best (Machiels-Bongaerts, Schmidt, \& Boshuizen, 1995; Peeck, 1982). Machiels-Bongaerts et al. let one group of participants activate prior knowledge about the fishery policy of the European Union, a topic that was often in the news at that time. Other participants activated common knowledge about tourism and control participants activated knowledge about an irrelevant topic. Then, all participants studied a text with information about: (1) the fishery policy; (2) tourism; (3) an alternative to fishing (i.e. putting up fish farms). Participants who activated knowledge about the policy recalled more policy and fish farm information than those who activated knowledge about tourism or the irrelevant topic. Participants who activated tourism information recalled more tourism information than those in the other two groups (Machiels-Bongaerts et al., 1995). Apparently, the nature of the 
activated prior knowledge guided which information students recalled from the text. Prior knowledge activation can therefore have a stage-setting function for new learning (Wetzels, Kester, \& van Merriënboer, 2011), in which the activated prior knowledge provides a contextual framework for new learning.

\section{Elaboration during collaborative learning}

Cognitive elaboration has not only been studied in individual learning. Its' importance has also been acknowledged in the realm of collaborative learning (O'Donnell, 2006; Slavin et al., 2003; Springer et al., 1999). Therefore, it has been applied in various collaborative learning programs (Dansereau, 1988; King, 2007; King, Staffieri, \& Adelgais, 1998). Collaboration is said to promote active learning (O'Donnell, 2006; Veenman, Denessen, Van den Akker, \& Van der Rijt, 2005) and moreover, the co-construction of knowledge (Chi, 2009; Van Boxtel, Van der Linden, \& Kanselaar, 2000). According to Chi (2009), learning during collaboration is not only active, but constructive and interactive as well. Constructive learning occurs when students add new meaning to something they learn, for example by self-explaining the material or explaining it to someone else. Self-explanation occurs when students verbally explain why some new information makes sense (Chi, 2000). This activity has shown to improve learning achievement in a variety of learning tasks (Chi, De Leeuw, Chiu, \& La Vancher, 1994; De Bruin, Rikers, \& Schmidt, 2007; Renkl, Stark, Gruber, \& Mandl, 1998).

Students can also construct new knowledge when they explain something to other students. Explanation to others has been proposed an important activity that promotes elaboration during collaborative discussion (Krol, Janssen, Veenman, \& Van der Linden, 2004; Nussbaum, 2008; Slavin et al., 2003). As some authors put it, "Giving explanations may encourage explainers to clarify or reorganize materials in new ways, recognize and fill gaps in understanding, recognize and resolve inconsistencies, develop new perspectives, and construct more elaborate conceptualizations than they would by learning themselves (Webb, Troper, \& Fall, 1995)." Explanation to others can thus be an important 'working ingredient' for the effectiveness of collaborative learning. Support for this notion comes from a review of studies by Webb (1989), in which various activities during collaboration in the classroom were correlated with achievement. Providing elaborative explanations, explanations that described a whole reasoning process, correlated consistently positive with achievement, whereas providing short answers was virtually unrelated to achievement. A positive relation between elaborative explanation and achievement has also been found in later studies (Van Boxtel et al., 2000; Webb et al., 2008).

Although providing explanations related consistently positive with achievement, listening to explanations only correlated positively with achievement in some of the reviewed studies (Webb, 1989). Providing 
elaborative explanations might therefore be more effective than listening to such explanations, perhaps because explaining a process leads to more elaboration than listening. Further indications for the benefits of explaining come from experiments that compared talking students with either listening students or students collaborating silently (Spurlin, Dansereau, Larson, \& Brooks, 1984; Teasley, 1995). Spurlin et al. (1984) compared the free recall scores of students who verbally summarized a text with the recall scores of students who listened to those summaries. The summarizers recalled more from the text than the listeners. Teasley (1995) discovered that students who interacted verbally while working on a computer task came up with better hypothesis than students who collaborated silently. In another experiment, students discussed a lecture in small groups. Half of the students had been trained to ask question to evoke the generation of new relations. These students asked such elaborative questions during the discussion, whereas the other half of the students came up with their own questions. The groups that used the elaborative questions produced more explanations and showed a better comprehension of the lecture (King, 1990). Together, these findings signify that explanation can promote elaboration and improve learning achievement.

\section{Problems with studies to collaborative learning}

The study of collaborative learning faces the problem that collaboration is a very dynamic process, in which many variables can influence final learning outcomes. In other words, there are many confounders to final achievement. These confounding variables can be external - coming from outside the group - or internal, coming from within the group. External confounders can be defined as influences from outside the group (i.e. factors that are not part of the collaboration but nevertheless influence learning outcomes, such as changes in a curriculum, important tests, etc.). Internal confounders are defined as influences from within the group (i.e. factors that are part of the collaboration and influence learning outcomes, like a higher quality of information exchange in one group than in another, etc.). External confounders may emerge during long-term programs for collaborative learning in classrooms, which can last for several weeks up till a few years. Nussbaum (2008) argues that the effects of such programs on individual learning outcomes are not always clear. Indeed, only some of them reported positive effects of elaborative discussion on academic achievement (King et al., 1998; Krol et al., 2004; Mercer \& Sams, 2006), whereas other studies revealed ambiguous (Krol et al., 2004) or no effects (Veenman et al., 2005). There might ne external confounders that influence the final results. For example, Veenman et al. (2005) found that an important nationwide test confounded the final learning outcomes. In between a pre- and a posttest, students took a national test, for which they were highly motivated to learn. After the test, their motivation dropped and this negatively affected the posttest results. 
According to the investigators, this contributed to a lack of pre- to posttest improvement.

Next to external confounders, there can also be internal confounders, influences from within the group process that affect learning. It is possible that students in one group elaborate more than students in other groups. This depends for instance on the ability level of the students in the group (Webb, Nemer, Chizhik, \& Sugrue, 1998). In other words, the exchange of information - or the quality of the group discussion - can vary across groups. Students may also engage in off-task behavior during their conversation (Dansereau, 1988). Therefore, all kinds of factors inside the group influence the quality of the discussion when students collaborate. If investigators want to test the 'pure' effect of elaboration during small group discussion on learning achievement, both external and internal confounders must be eliminated. For this purpose, the present thesis developed a new experimental approach. More details about this new approach will follow.

\section{Elaboration in problem-based learning}

Up till now, the impact of elaboration during collaborative learning has been discussed in general. Because of the great diversity in collaborative learning approaches, it might be valuable to illuminate the educational context of the present thesis, which is problem-based learning (PBL). Even PBL has been called 'a coat of many colors' (Lloyd, Margetson, \& Bligh, 1998), meaning that it comes in many forms. Nevertheless, Schmidt, Van der Molen, Te Winkel \& Wijnen (2009) defined six general principles of PBL. First of all, PBL uses a problem as the starting point for new learning. Second, it supports collaboration, namely through a small group discussion about the problem. Third, a teacher (also called a tutor) guides the group discussion. Fourth, a PBL program contains fewer lectures than conventional curricula, because the problem is the predominant incentive for new learning. Fifth, students actively seek new information about the problem after the small group discussion. And finally, they receive sufficient time for this period of self-study.

The group size in PBL can range from five up till 10 students (HmeloSilver \& Barrows, 2008; Schmidt et al., 2009). During a problem-based group discussion, students can activate their prior knowledge about the problem and elaborate by generating explanations for the problem (Schmidt, 1993). This can lead to the discovery of gaps in knowledge, which form the basis of new learning. The role of the teacher is to facilitate the discussion instead of lecture the students (Hmelo-Silver, 2004; Neville, 1999). Stimulating elaboration is one of the core tasks of this facilitation (De Grave, Dolmans, \& Van der Vleuten, 1999). The teacher can promote elaboration by relating the discussion to prior knowledge from previous literature (Lee, Lin, Tsou, Shiau, \& Lin, 2009), stimulating the exploration of ideas, and motivating the students to evaluate their explanations critically (Wilkerson, 1994). In order to 
achieve this, PBL teachers should not only be good content experts, but also good process facilitators (Dolmans et al., 2002).

Although Schmidt (1993) identified prior knowledge activation and elaboration as the most important cognitive underpinnings of $\mathrm{PBL}$, there is little evidence supporting the effectiveness of these processes during PBL group meetings. There is no unequivocal evidence that students learn more from PBL than from conventional education (Albanese, 1993; Colliver, 2000; Vernon \& Blake, 1993). However, there are indications that PBL students recall more knowledge over time than conventional students, suggesting that students elaborate more often, namely during the PBL group meetings, than students in conventional learning programs (Dochy et al., 2003). Unfortunately, these macro-level comparisons do not clarify the cognitive processes at the group level that are responsible for this improved long-term recall. Some studies have shown that students recalled more information from a text when they collaboratively discussed a problem before studying the text (De Grave, Schmidt, \& Boshuizen, 2001; Schmidt, 1984; Schmidt, De Volder, De Grave, Moust, \& Patel, 1989). Furthermore, Capon and Kuhn (2004) revealed that PBL students showed a better conceptual understanding of course materials than students who were taught with lectures. Still, none of these studies identified elaboration as the working ingredient for improved achievement.

Moreover, there seems to be no evidence that elaboration during problem-based discussion promotes achievement. Moust, De Volder, Belien and De Grave (1987) found no positive correlation between elaboration during problem-based discussion and achievement. That is, the number of generated elaborations during a problem-based discussion did not correlate positively with the amount of recall from a text studied after the discussion. This contradicts the findings from other studies to collaborative learning (Van Boxtel et al., 2000; Webb, 1989; Webb et al., 2008), which usually did report a positive correlation between elaborative explanations and achievement. Therefore, elaboration during the PBL group process needs to be studied in more detail.

Besides, the few PBL experiments that have been conducted (Schmidt, 1984; Schmidt et al., 1989; De Grave et al., 2001) did not control how much students learned from each other during the group discussion (Capon \& Kuhn, 2004; Wetzels et al., 2011). In other words, the internal confounders were not eliminated. Controlling the quality of the discussion requires a new experimental approach, which will be unfolded next.

\section{A new approach to study collaborative learning}

The quality of the discussion, or the exchange of knowledge during the group discussion, can be controlled by exposing all research participants in a study to a similar group discussion. This can be accomplished by simulating the discussion in some sort of way. The most realistic and efficient method for doing this might be showing the discussion on video. Showing a video will expose all research participants to exactly the same 
discussion. Furthermore, this eliminates the drawback of performing a discussion many times. The study will need only one recording, which makes the method efficient in terms of costs and labor. Moreover, the video can be presented in a controlled experiment, which can be replicated easily and at any time. But the most important advantage is that elaboration can be tested separately, as an independent variable unaffected by internal confounders. For instance, participants in an experimental group can contribute to the discussion by generating explanations that relate to the problem. Participants in a control group can then e.g. listen to explanations from others, resulting in one group that generates elaborations and one group that receives elaborations. In sum, showing a group discussion on video allows investigators to examine the role of elaboration without other, random influences from within the group.

Figure 1. Conceptual framework of the experiments

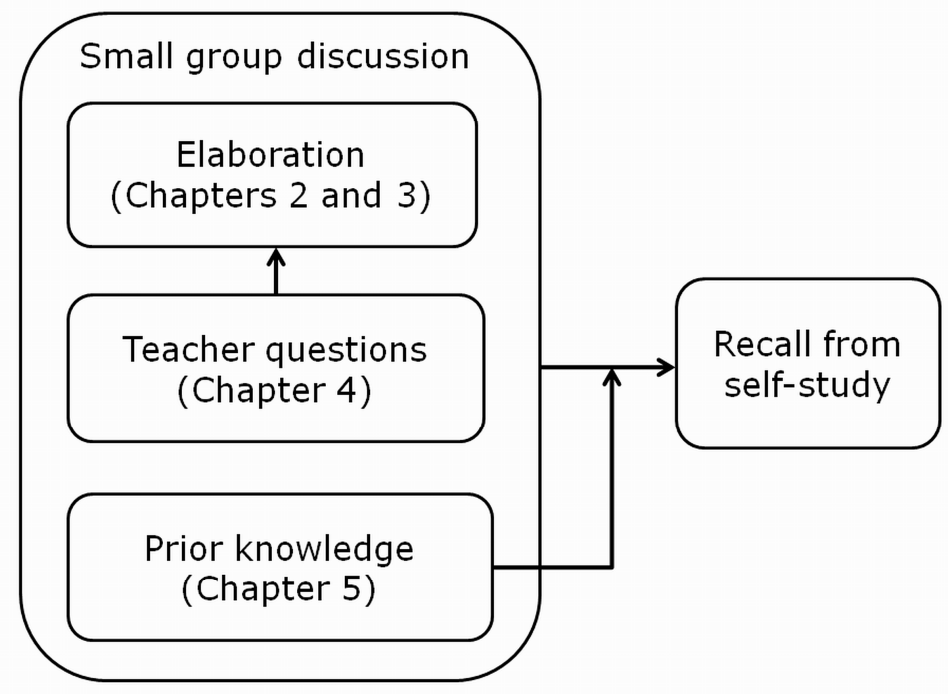

\section{Overview and research questions}

This dissertation applied the aforementioned new research method in four experiments, using a PBL context. Figure 1 illustrates a conceptual framework of the experiments. Chapters 2 and 3 will describe the first and second experiment, which aimed at testing whether elaboration facilitated recall. Research participants observed a group discussion that was presented on video. Some participants elaborated by providing explanations to other students in the group, while other participants only received explanations. After the discussion, all participants studied a text that explained the phenomena in the problem. The first experiment 
comprised a first implementation of the new research method, which was fine-tuned in experiment 2.

Chapters 4 and 5 will deal with the third and fourth experiment. These studies extended the new method by testing two hypothetical improvers of elaboration. Experiment 3 tested the effect of elaborative questions by a teacher during the group discussion. In doing this, experiment 3 examined the teacher's role of learning facilitator (Hmelo-Silver, 2004; Neville, 1999). Half of the research participants answered elaborative questions, while the other half answered superficial questions. The expectation was that responding to the elaborative questions would improve recall as compared to answering the superficial questions. Experiment 4 added the influence of relevant prior knowledge to that of elaboration. Since relevant prior knowledge has shown to moderate the effect of elaboration on recall (Willoughby et al., 1993; Woloshyn et al., 1992), a similar moderating influence was expected during a problembased discussion. Therefore, one group of participants received relevant prior knowledge before the discussion, whereas another group received irrelevant prior knowledge. Taken together, the research questions can be summarized as follows:

- Does elaboration during small group discussion increase recall from self-study after the discussion (experiment 1 and 2)?

- Do certain variables, i.e. a teacher's elaborative questions and relevant prior knowledge, promote elaboration and recall (experiment 3 and 4$)$ ?

\section{References}

Albanese, M. A. (1993). Problem-based learning: A review of literature on its outcomes and implementation issues. Academic Medicine, 68(1), 52-81.

Bobrow, S. A., \& Bower, G. H. (1969). Comprehension and recall of sentences. Journal of Experimental Psychology, 80(3), 455-461.

Capon, N., \& Kuhn, D. (2004). What's so good about problem-based learning? Cognition and Instruction, 22(1), 61-79.

Chi, M. T. H. (2000). Self-explaining expository texts: The dual processes of generating inference and repairing mental models. In R. Glaser (Ed.), Advances in Instructional Psychology (Vol. 5, pp. 161-238). Mahwah, NJ, US: Erlbaum.

Chi, M. T. H. (2009). Active-constructive-interactive: A conceptual framework for differentiating learning activities. Topics in Cognitive Science, 1(1), 73-105.

Chi, M. T. H., De Leeuw, N., Chiu, M. H., \& La Vancher, C. (1994). Eliciting selfexplanations improves understanding. Cognitive Science, 18(3), 439-477.

Colliver, J. A. (2000). Effectiveness of problem-based learning curricula: Research and theory. Academic Medicine, 75(3), 259-266.

Dansereau, D. F. (1988). Cooperative learning strategies. In C. E. Weinstein, E. T. Goetz \& P. A. Alexander (Eds.), Learning and study strategies: Issues in assessment, instruction, and evaluation (pp. 103-120). San Diego, CA: Academic Press.

De Bruin, A. B. H., Rikers, R. M. J. P., \& Schmidt, H. G. (2007). The effect of selfexplanation and prediction on the development of principled understanding of chess in novices. Contemporary Educational Psychology, 32(2), 188-205. 
De Grave, W. S., Dolmans, D. H. J. M., \& Van der Vleuten, C. P. M. (1999). Profiles of effective tutors in problem-based learning: Scaffolding student learning. Medical Education, 33(12), 901-906.

De Grave, W. S., Schmidt, H. G., \& Boshuizen, H. P. A. (2001). Effects of problembased discussion on studying a subsequent text: A randomized trial among first year medical students. Instructional Science, 29(1), 33-44.

Dochy, F., Segers, M., Van den Bossche, P., \& Gijbels, D. (2003). Effects of problem-based learning: A meta-analysis. Learning and Instruction, 13(5), 533-568.

Dolmans, D. H. J. M., Gijselaers, W. H., Moust, J. H. C., De Grave, W. S., Wolfhagen, I. H. A. P., \& Van der Vleuten, C. P. M. (2002). Trends in research on the tutor in problem-based learning: Conclusions and implications for educational practice and research. Medical Teacher, 24(2), 173-180.

Hamilton, R. J. (2004). Material appropriate processing and elaboration: The impact of balanced and complementary types of processing on learning concepts from text. British Journal of Educational Psychology, 74(2), 221-237.

Hmelo-Silver, C. E. (2004). Problem-based learning: What and how do students learn? Educational Psychology Review, 16(3), 235-266.

Hmelo-Silver, C. E., \& Barrows, H. S. (2008). Facilitating collaborative knowledge building. Cognition and Instruction, 26, 48-94.

Johnsey, A., Morrison, G. R., \& Ross, S. M. (1992). Using elaboration strategies training in computer-based instruction to promote generative learning. Contemporary Educational Psychology, 17(2), 125-135.

King, A. (1990). Enhancing peer interaction and learning in the classroom through reciprocal questioning. American Educational Research Journal, 27(4), 664687.

King, A. (2007). Beyond literal comprehension: A strategy to promote deep understanding of text. In D. S. McNamara (Ed.), Reading comprehension strategies: Theories, interventions, and technologies (pp. 267-290). Mahwah, NJ: Erlbaum.

King, A., Staffieri, A., \& Adelgais, A. (1998). Mutual peer tutoring: Effects of structuring tutorial interaction to scaffold peer learning. Journal of Educational Psychology, 90(1), 134-152.

Krol, K., Janssen, J., Veenman, S., \& Van der Linden, J. (2004). Effects of a cooperative learning program on the elaborations of students working in dyads. Educational Research and Evaluation, 10(3), 205-237.

Lee, G.-H., Lin, Y.-H., Tsou, K.-I., Shiau, S.-J., \& Lin, C.-S. (2009). When a problem-based learning tutor decides to intervene. Academic Medicine, 84(10), 1406-1410.

Levin, J. R. (1988). Elaboration-based learning strategies: Powerful theory=powerful application. Contemporary Educational Psychology, 13(3), 191-205.

Lloyd, J., Margetson, D., \& Bligh, J. G. (1998). Problem-based learning: A coat of many colours. Medical Education, 32(5), 492-494.

Machiels-Bongaerts, M., Schmidt, H. G., \& Boshuizen, H. P. A. (1995). The effect of prior knowledge activation on text recall: An investigation of two conflicting hypotheses. British Journal of Educational Psychology, 65(4), 409-423.

Mayer, R. E. (1980). Elaboration techniques that increase the meaningfulness of technical text: An experimental test of the learning strategy hypothesis. Journal of Educational Psychology, 72(6), 770-784.

Mercer, N., \& Sams, C. (2006). Teaching children how to use language to solve maths problems. Language and Education, 20(6), 507-528.

Neville, A. J. (1999). The problem-based learning tutor: Teacher? Facilitator? Evaluator? Medical Teacher, 21(4), 393-401.

Nussbaum, E. M. (2008). Collaborative discourse, argumentation, and learning: Preface and literature review. Contemporary Educational Psychology, 33, 345359. 
O'Donnell, A. M. (2006). The role of peers and group learning. In P. H. Winne \& P. A. Alexander (Eds.), Handbook of educational psychology (pp. 781-802). Mahwah, NJ: Erlbaum.

Peeck, J. (1982). Effects of mobilization of prior knowledge on free recall. Journal of Experimental Psychology: Learning, Memory, and Cognition, 8(6), 608-612.

Pichert, J. W., \& Anderson, R. C. (1977). Taking different perspectives on a story. Journal of Educational Psychology, 69(4), 309-315.

Pressley, M., Symons, S., McDaniel, M. A., Snyder, B. L., \& Turnure, J. E. (1988). Elaborative interrogation facilitates acquisition of confusing facts. Journal of Educational Psychology, 80(3), 268-278.

Pressley, M., Wood, E., Woloshyn, V. E., Martin, V., King, A., \& Menke, D. (1992). Encouraging mindful use of prior knowledge: Attempting to construct explanatory answers facilitates learning. Educational Psychologist, 27(1), 91109.

Reder, L. M. (1980). The role of elaboration in the comprehension and retention of prose: A critical review. Review of Educational Research, 50(1), 5-53.

Renkl, A., Stark, R., Gruber, H., \& Mandl, H. (1998). Learning from worked-out examples: The effects of example variability and elicited self-explanations. Contemporary Educational Psychology, 23(1), 90-108.

Schmidt, H. G. (1984). Activatie van voorkennis en tekstverwerking / Activation of prior knowledge and text processing. Nederlands Tijdschrift voor de Psychologie en haar Grensgebieden, 39(6), 335-347.

Schmidt, H. G. (1993). Foundation of problem-based learning: Some explanatory notes. Medical Education, 27(5), 422-432.

Schmidt, H. G., De Volder, M. L., De Grave, W. S., Moust, J. H. C., \& Patel, V. L. (1989). Explanatory models in the processing of science text: The role of prior knowledge activation through small-group discussion. Journal of Educational Psychology, 81(4), 610-619.

Schmidt, H. G., Van der Molen, H. T., Te Winkel, W. W. R., \& Wijnen, W. H. F. W. (2009). Constructivist, problem-based learning does work: A meta-analysis of curricular comparisons involving a single medical school. Educational Psychologist, 44(4), 227-249.

Slamecka, N. J., \& Graf, P. (1978). The generation effect: Delineation of a phenomenon. Journal of Experimental Psychology: Human Learning and Memory, 4(6), 592-604.

Slavin, R. E., Hurley, E. A., \& Chamberlain, A. (2003). Cooperative learning and achievement: Theory and research. In G. E. Miller \& W. M. Reynolds (Eds.), Handbook of psychology: Educational psychology (Vol. 7, pp. 177-198). Hoboken, NJ: John Wiley \& Sons.

Springer, L., Stanne, M. E., \& Donovan, S. S. (1999). Effects of small-group learning on undergraduates in science, mathematics, engineering, and technology: A meta-analysis. Review of Educational Research, 69(1), 21-51.

Spurlin, J. E., Dansereau, D. F., Larson, C. O., \& Brooks, L. W. (1984). Cooperative learning strategies in processing descriptive text: Effects of role and activity level of the learner. Cognition and Instruction, 1(4), 451-463.

Teasley, S. D. (1995). The role of talk in children's peer collaborations. Developmental Psychology, 31(2), 207-220.

Van Boxtel, C., Van der Linden, J., \& Kanselaar, G. (2000). Collaborative learning tasks and the elaboration of conceptual knowledge. Learning and Instruction, $10,311-330$.

Veenman, S., Denessen, E., Van den Akker, A., \& Van der Rijt, J. (2005). Effects of a cooperative learning program on the elaborations of students during help seeking and help giving. American Educational Research Journal, 42(1), 115151.

Vernon, D. T., \& Blake, R. L. (1993). Does problem-based learning work? A metaanalysis of evaluative research. Academic Medicine, 68(7), 550-563.

Webb, N. M. (1989). Peer interaction and learning in small groups. International Journal of Educational Research, 13(1), 21-39. 
Webb, N. M., Franke, M. L., Ing, M., Chan, A., De, T., Freund, D., et al. (2008). The role of teacher instructional practices in student collaboration. Contemporary Educational Psychology, 33(3), 360-381.

Webb, N. M., Nemer, K. M., Chizhik, A. W., \& Sugrue, B. (1998). Equity issues in collaborative group assessment: Group composition and performance. American Educational Research Journal, 35(4), 607-651.

Webb, N. M., Troper, J. D., \& Fall, R. (1995). Constructive activity and learning in collaborative small groups. Journal of Educational Psychology, 87(3), 406-423.

Wetzels, S. A. J., Kester, L., \& van Merriënboer, J. J. G. (2011). Adapting prior knowledge activation: Mobilisation, perspective taking, and learners' prior knowledge. Computers in Human Behavior, 27(1), 16-21.

Wilkerson, L. (1994). Identification of skills for the problem-based tutor: Student and faculty perspectives. Instructional Science, 22(4), 303-315.

Willoughby, T., Waller, T. G., Wood, E., \& MacKinnon, G. E. (1993). The effect of prior knowledge on an immediate and delayed associative learning task following elaborative interrogation. Contemporary Educational Psychology, 18(1), 36-46.

Wittrock, M. C. (1992). Generative learning processes of the brain. Educational Psychologist, 27(4), 531-541.

Woloshyn, V. E., Pressley, M., \& Schneider, W. (1992). Elaborative-interrogation and prior-knowledge effects on learning of facts. Journal of Educational Psychology, 84(1), 115-124. 


\section{Chapter 2}

\section{The role of providing explanations and listening to others during small group discussion ${ }^{1}$}

This experiment measured the effect of providing explanations during a small group discussion on recall of subsequently studied text. Seventy participants watched a video of a small group discussion. In a first experimental condition, the participants were encouraged to verbally participate in the discussion. In a second experimental condition, they merely observed the discussion. In a control condition, they observed a discussion that was unrelated to the text. This text was studied by all participants after the discussion. They received a test about the text both directly and after four weeks. During the second test, the participants who had provided explanations recalled more information than those who had observed. Thus, providing explanations during a discussion might positively affect long-term memory.

${ }^{1}$ Van Blankenstein, F.M., Dolmans, D.H.J.M., Van der Vleuten, C.P.M., \& Schmidt, H.G. (2009). Which cognitive processes support learning during small-group discussion? The role of providing explanations and listening to others. Instructional Science, 39(2), 189-204. 


\section{Introduction}

Small group collaboration has been widely recognized as a factor that is conducive to learning (Cohen 1994; Johnson, Johnson, \& Smith, 2007). Several review studies have shown that working together in small groups has a positive effect on learning achievement (Roseth, Johnson, \& Johnson, 2008; Slavin, 1983; Springer, Stanne, \& Donovan, 1999). Springer et al. (1999) pointed to the phenomenon that differing theoretical assumptions have been put forward to explain this effect. Indeed, widely differing explanations of the effectiveness of collaborative learning have been proposed (Slavin, Hurley, \& Chamberlain, 2003). O'Donnell (2006) distinguishes two major theoretical perspectives on collaborative learning: a sociobehavioral and a cognitive one. From the socio-behavioral perspective motivation, social cohesion and positive sociocultural values are considered conducive to learning, whereas the cognitive perspective stresses elaboration and recourse to prior knowledge and experiences. The idea underpinning the cognitive elaborative perspective on collaborative learning is that students process information at deeper levels when they learn collaboratively (O'Donnell, 2006). The current study tested the assumptions underlying this perspective.

Elaboration is a form of higher-order thinking in which new ideas are generated by connecting new information with knowledge already present in memory and by combining new ideas. Elaboration leads to deep levels of information processing (Craik \& Lockhart, 1972) and is assumed to inhibit forgetting, because it produces a richer, more redundant memory structure (Reder, 1980).

In collaborative settings, several learning strategies that promote elaboration have been shown to enhance academic achievement. Some of these strategies involved measures to stimulate elaboration when collaborating students were communicating. That this can be effective appeared from a sequence of intervention studies which showed that scripting collaborative talk enhanced learning (see Dansereau 1988, for an overview). In scripted cooperation (O'Donnell, 1996) a predetermined structure guided the way dyads studied a text. The text was broken up into sections and pairs of students studied the sections one by one, switching the roles of recaller and listener for each section. After the students had read one section, they put it away and the recaller reproduced as much information from the text as possible while the listener concentrated on detecting errors and omissions. Next, the two students produced ideas that might help them memorize the material, such as analogies. This strategy resulted in better achievement than did either collaborative learning without a strategy or individual learning. (McDonald, Larson, Dansereau, \& Spurlin, 1985; O’Donnell et al., 1985). One study found similar results in small study groups of four to five students (Yager, Johnson, \& Johnson, 1985) but Rewey, Dansereau, Skaggs, Hall, and Pitre (1989) found no significant effect of scripted cooperation on achievement in small groups, although the trend was 
positive. The broad trend that seems to emerge from the above findings on collaborative learning is that learning can benefit from elaborative communication during cooperative discourse.

Another series of intervention studies used a procedure called guided peer questioning to enhance comprehension of new material (King, 2007). In one of these studies, students were trained to ask thought-provoking questions before engaging in small group discussions. The questions were specifically designed to elicit answers that related (old and) new information. For example: "Why are ... and ... similar," or "How does ... relate to ...?" (King, 1990). In a later study, students were also trained to provide elaborated explanations in response to these questions (King et al. 1998). These interventions generally increased participating students' academic achievement.

Finally, there are indications that the amount of exploratory talk used by children enhances their ability to solve problems on the Raven test (Wegerif, Mercer, \& Dawes, 1999). Exploratory talk is a constructive form of collaborative communication, in which participants reach consensus by presenting and listening to carefully balanced arguments and counterarguments (Mercer, 1996). Training children to use this form of talk has been found to have a positive effect on their learning (Mercer \& Sams, 2006; Mercer, Wegerif, \& Sams, 2004).

In most of the studies that involved manipulation of elaborative communication, group discussions either took place while people were processing new information, or after they had done so (King, 1991; Larson, Dansereau, O'Donnell, et al., 1985; McDonald et al., 1985; O'Donnell et al., 1985; O'Donnell 1996; Webb \& Farivar, 1999; Webb, Troper, \& Fall, 1995; Yager et al., 1985). Interestingly, elaborative discourse has also been shown to be beneficial when it precedes learning (De Grave, Schmidt, \& Boshuizen, 2001; O'Donnell et al., 1990; Schmidt, De Volder, De Grave, Moust, \& Patel, 1989). In a study by Schmidt et al. (1989), small groups of students discussed a problem illustrating the osmosis process in cells before studying a text about osmosis and diffusion. These students recalled more information from the text than students who had discussed a non-relevant problem, about airplanes taking off, before studying the same text. De Grave et al. (2001) reported similar results. Apparently, discussing the problem facilitated learning from the text that was studied immediately afterwards. In summary, it seems that learning is facilitated by elaborative discourse regardless of whether this occurs before, during or after the actual learning task.

Based on the literature discussed so far it seems safe to assume that attempts to stimulate elaborative communication in small study groups or dyads are beneficial to individual group members' academic achievement, whether elaborative communication precedes, follows or coincides with studying new material.

Unfortunately, studies have provided scant information about why students benefit from group discussion and what cognitive activities play a 
role. For instance, it could be the act of listening carefully to what others say that aids learning the most. On the other hand, the act of explaining something to someone else might also be productive for one's own learning. This is in agreement with Slavin's (1996) argument that explaining something to others is a cognitive process that evokes elaboration during small group work. Explaining requires structuring of knowledge as well as restructuring of knowledge when inconsistencies in one's reasoning are revealed (Webb, 1989). So, providing explanations during small group discussions stimulates elaboration, which, in turn, is expected to foster learning.

Studies have indicated that providing explanations with the aim to elaborate (i.e. creating connections between newly studied information) can increase retention of information. For instance, individuals who had to guess the second word of word-pairings remembered more words than individuals who studied the same words without having to guess (Slamecka \& Graf, 1978). Also, generating self-explanations while studying a text increased achievement on various post-test measures (Chi, De Leeuw, Chiu, \& La Vancher, 1994; Roscoe \& Chi, 2007). However, these results were found in individuals who were not studying in a collaborative setting and consequently were unable to learn by listening to the input of others.

Still, a review study of small group learning of mathematics and computer sciences also showed that the relationship between engaging in explaining things to others and learning outcomes was predominantly positive (Webb, 1989). Here, it needs to be mentioned that some positive relationships were found between listening to explanations from others and learning achievement. For instance, Peterson and Swing (1985) found that both listening and explaining were positively related to final group achievement when students cooperatively tried to solve math problems in small groups. The more mixed results from these small group studies may be attributable to the more dynamic circumstances under which these studies took place. The small groups were observed in classrooms, which allowed for a variety of influences on learning. By contrast, some studies with cooperative dyads showed that dyad members who provided oral summaries recalled more information than their listening counterparts (Ross \& DiVesta, 1976; Spurlin et al., 1984). Thus, the general impression from prior studies is that, when students collaborate, explaining yields a stronger positive effect than listening.

The preceding has shown that providing explanations may be a pivotal process for the effectiveness of learning in small groups. Therefore it is well worth investigating but researchers have to face the problem that explaining and its role and effects cannot always be disentangled from the myriad of other factors that impact on learning in group processes. First, group members' differing levels of prior knowledge may affect the ease of learning new information. This was shown by a study where one of the major predictors of final math achievement of collaborating school children 
proved to be their general math achievement before the study (Webb \& Farivar, 1999; Webb et al., 1995). Perhaps the children with superior prior achievement had more relevant prior knowledge, which they could relate to new information, which led to better results. Second, it cannot be ruled out that the quality of small group discussions affects individual learning outcomes. That is, some group discussions may be more productive than others, perhaps because they contain more exploratory talk. Other group discussions may me less productive, for instance when group members engage in off-task behavior. This was illustrated by Dansereau (1988), who noted in studies of scripted cooperation that some dyads talked about unnecessary details and irrelevant subjects, which may well have impaired their learning. However, this was not taken into account as a confounding variable, which is not surprising seeing that this was probably impossible due to random group dynamics. From an example like this, it is easy to understand why some authors call for more controlled, experimental research in order to improve understanding of collaborative learning (Springer et al., 1999). Controlled conditions will lend greater robustness to research into cognitive processes that may contribute to learning in small groups.

To summarize: studies have usually found positive effects of elaborative communication on individual learning achievement and there are strong indications that explaining things to others is an important cognitive process that accounts for this effect, although this notion has never been tested in a controlled, experimental study. Studying effects of explaining in a laboratory setting gives researchers greater control over individual differences in prior knowledge and the quality of the group discussion. Hence it enables evaluation of the differential effects of explaining on learning compared to that of other forms of participation in group discussions. In order to study explanation in isolation, we developed a new research method which aimed to let participants enter a group discussion with the same level of prior knowledge. Also, they were exposed to the same simulated group process. This was done by presenting the group discussion on a video. The effects of explanation on learning could be studied by stopping the video at various points in time and instructing the participants to respond to the discussion during these 'gaps'. This way, an important contribution could be made to the existing literature about small group learning, for the research method allowed us to study one cognitive activity (i.e. providing explanations) and to compare the learning-effects of this activity with those of other cognitive activities (i.e. listening to relevant or irrelevant information).

While the main aim of this study was to examine the effects of explaining during small group discussion while controlling for confounding effects of individual prior knowledge and random group processes, the specific aim was to determine whether students who actively explained issues had better recall of a text that was studied after the group discussion. As mentioned earlier, the results of some studies suggested 
that collective elaborative activities can improve the processing of new information, so information that is studied after the elaborative activities took place (O'Donnell et al., 1990; Schmidt et al., 1989; De Grave et al., 2001). This study aimed to replicate these findings, while zooming in on the role of providing explanations versus listening. Therefore, the main hypothesis was that providing explanations during a small group discussion would lead to a better recall of subsequently studied information than merely listening to a group discussion. Since the important role of listening during a group discussion has not been ruled out (see Peterson \& Swing, 1985) and group discussion in general has been found to facilitate subsequent learning (Schmidt et al., 1989; De Grave et al., 2001), a second hypothesis was included as well. This one stated that participation in a relevant group discussion, regardless of providing explanations or listening, would increase the recall of subsequently studied information. In order to test this second hypothesis, the learning results of students who participated in a relevant discussion were compared with the results of students who participated in an irrelevant group discussion.

\section{Method}

Overview

Undergraduate students took part in simulated group discussions after receiving instruction on a topic. They were assigned to one of three conditions. In the explanation condition, they were encouraged to verbally participate in the group discussion, using knowledge from the preexperiment instruction. The discussion was based on a problem, which provided a contextual cue for elaboration (Schmidt, 1993). Participants in the listening condition took part in the same group discussion but they were instructed not to contribute actively but only listen to the other group members, while keeping in mind the information from the instruction. In the control condition, participants attended a group discussion about an unrelated problem, which precluded activating and elaborating on relevant prior knowledge. This condition was included to compare the effects of attending and of not-attending a discussion about a relevant problem. After participating in the simulated discussion, all the participating students studied the same text about a topic related to the problem discussed in the group viewed by the students in the explaining and listening condition. The participants' recall of this text was tested by thirteen open-ended questions both immediately after the experiment and one month later.

\section{Participants}

The participants were 70 students at the Faculties of Health, Medicine and Life Sciences, Psychology, Cultural Sciences, and Economics and Business Administration, Maastricht University, the Netherlands. They were recruited with advertisements and received a financial compensation 
for their participation. At Maastricht University, group discussions are the main educational format, so all participants in this study were used to taking part in such discussions. Their average age was 21.04 years $(S D=$ 2.21). None of the participants reported having taken their final secondary school examination in physics. This implied that they had not studied physics in school after the third grade of secondary education, so approximately after the age of 15 years.

\section{Materials}

Excerpts from the materials can be found in Appendix A. Based on Mayer and Cook (1981; also see Mayer, 1985) and a Dutch physics textbook used in secondary education (Middelink, 1991), two texts were written aimed at providing a very basic understanding of waves and radar systems, respectively. The first text explained the physical principles of waves and was aimed at creating a basic understanding of waves, which could be used during the simulated group discussion. It also explained how sound waves can be used to measure distance. The text was tailored to the highest level of mandatory physics education in the Netherlands, which is third grade in secondary education. The text was reviewed by a secondary education physics teacher. The second text explained how radar works, the parts of a radar system, the types of wave it uses (electromagnetic waves) and why this is so. It also explained attenuation of electromagnetic waves and how this can be prevented. The contents were reviewed by a radar specialist of the Royal Dutch Meteorological Institute.

The first text consisted of nine sections. Three multiple choice questions were constructed for each section to assess participants' conceptual knowledge of the contents. This resulted in a test consisting of 27 multiple choice questions. For the post-experiment test thirteen openended questions about radar were constructed. These questions generally introduced one topic from the text and asked participants to give an indepth explanation about this topic. For example, the first question gave the names of various radar parts and asked participants to explain how these parts constitute a radar system.

For the explanation and listening conditions one problem was written, describing an air traffic controller who managed the radar system of Amsterdam Airport Schiphol, the Netherlands. The problem for the control condition was taken from the Maastricht medical curriculum and described neurological symptoms after drinking alcohol.

Before the actual experiment started, two group discussions were digitally recorded in a studio: one about the radar problem and one about the alcohol problem. Four students, all members of a drama club, participated in both discussions. In several rehearsal sessions, they first familiarized themselves with the contents of the text for the preexperiment instruction and they then discussed the radar problem based on their prior knowledge. They also discussed the alcohol problem during 
these sessions. Based on the videotaped rehearsal sessions two written scripts were produced, one for the radar problem and one for the alcohol problem. In a studio, these scripts were performed by the same student actors and recorded.

Figure 1. Screen shot of the group discussion

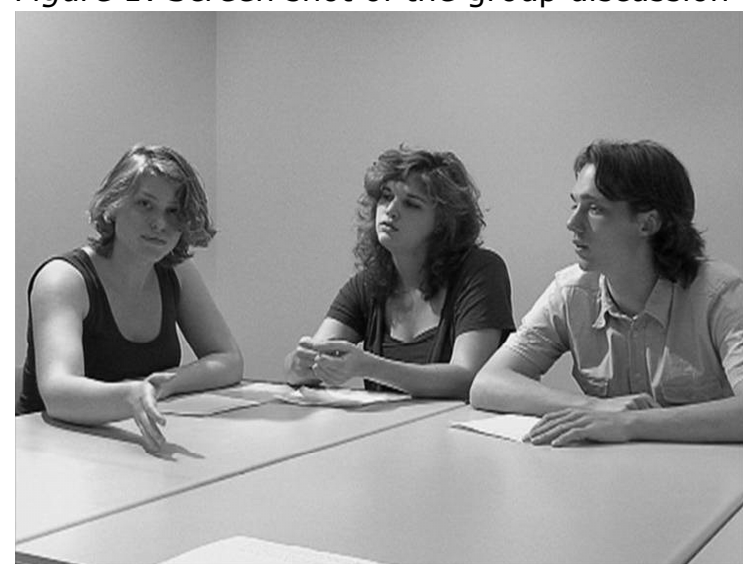

In both simulated discussions one actor did most of the explaining. The other actors asked him for explanations, for he was obviously the most knowledgeable student of the group. Of the radar discussion, two versions were prepared: an unedited version showing the integral discussion and an edited version from which the part of the actor who did most of the explaining was removed. The unedited version was used for the listening condition and the edited version for the explanation condition. For the control condition the integral recording of the alcohol discussion was used. Figure 1 shows a screen shot of the radar discussion.

The students who participated in the experimental study viewed one of the video recorded group discussions on a computer screen. The first text and the nine sets of three multiple choice questions relating to this text were available on a webpage designed by Maastricht University Department of Educational Development and Research, using RP's httpserver. The two problems, the videotaped discussions and the second text with its accompanying open-ended questions were presented on a website constructed with Macromedia Flash Professional by the first author (FvB).

\section{Procedure}

During the pre-experimental instruction phase all the participants studied the first text, which provided them with relevant prior knowledge about waves. In a large computer room the participants individually studied the first text for ten minutes and then answered nine multiple choice questions about the contents of each of the nine paragraphs. Based on a procedure by Chi et al. (1994), the students who did not get all the 
questions right during the first time were given seven minutes to reread the text and then took a retest consisting of new multiple choice questions covering the contents of the paragraphs that had yielded wrong answers. This procedure was repeated and after the third round of questions, $89 \%$ of the participants answered all questions correctly. All participants continued with the next stages of the experiment.

One week after the pre-experimental instruction, all participants returned for the experimental phase. They were randomly assigned to the explanation ( $n=24)$, listening $(n=24)$, or control condition $(n=22)$. Participants from different faculties and different years of study were equally distributed over the three conditions. Because the participants in the explanation condition had to speak out loud, the experimental task was performed in isolated computer rooms.

The participants in the explanation condition sat at a desk in front of a computer screen that was approximately 70 centimeters away from them. They were told that they were going to participate in a simulated group discussion about radar and that they could use their knowledge from the pre-experimental session to explain what they knew about radar to the other group members, just as if they were a member of the simulated group. They were also instructed to explain as much as possible. After these instructions, the participants read the radar problem and then observed a small part of the edited recording of the radar discussion, in order to familiarize themselves with the setting and the actors. They could hear the simulated group members via two speakers on either side of the computer screen and they were encouraged to answer a question from the group during this practice phase. After again being instructed to explain as much as possible, the edited video was started. At different points during the simulated discussion, the actors asked questions to which the participants could respond. The actors asked about factual knowledge from the pre-experimental instruction session, such as "How does a bat know that a wall is nearby?", but they also asked for more elaborate explanations ("Wait, I don't understand. Why not?").

One participant's response to the question how a bat knows that a wall is nearby is presented below. This participant correctly explained, after a few tries, how sound waves are used to estimate distance:

That's because it emits waves that go to the walls, and the number of seconds, so the time it takes for the waves to go to the wall and back, if it multiplies this by the...hey... Ah! So if you multiply time by the... distance? No. Yes, if it multiplies the speed of the sound by the time. What was it again? Yes, if it multiplies speed by the time it takes, then... you get the distance and the bat can estimate the distance to the wall.

When the simulated group discussion about radar was finished, the participants were given twenty minutes to read the text about radar, 
which answered the questions that had been raised during the discussion. Immediately after that, they answered thirteen open-ended questions. One month later they returned and answered the same sequence of thirteen open-ended questions.

The procedure for the participants in the listening condition was identical, except that they watched the integral group discussion, in which the questions were answered by one of the actors. They were instructed to listen carefully and keep in mind what they had learned during the preexperimental session. The participants in the control condition read the alcohol problem and watched the simulated discussion about this problem. They were only instructed to listen carefully.

\section{Analyses}

Following Mayer (1985), FvB parsed the text about radar into propositions, i.e. units that constitute a subject-verb clause. The answers to the open-ended questions were parsed into propositions by four judges, i.e. FvB and three student assistants. Two pairs of judges parsed the answers given by six randomly selected participants, i.e. each pair parsed the answers from three students. Combined average inter-judge agreement was $89 \%$. Next, the two pairs of judges matched the parsed answers of the three participants to propositions from the radar text. Combined average inter-judge agreement on these matches was $79 \%$. Differences were resolved by discussion, resulting in some additional agreements (e.g. not to analyze text that concerned paraphrasing questions or repeating answers).

After this, the judges used the same procedure to individually analyze the remaining answers. Each judge generated propositions and matched these to the propositions from the radar text. A match yielded one point and the summed points for all questions were a participant's cumulative recall score. Since there were two measurements, there were two cumulative recall scores, one for immediate recall and one for delayed recall.

A one-way analysis of variance (ANOVA) with planned contrasts was performed with condition as the independent variable and immediate and delayed recall as the dependent variables. One planned contrast tested the hypothesis of better recall of participants in the explanation condition compared to those in the listening condition. The second planned contrast tested the hypothesis of better recall by participants in the explanation and listening condition compared to those in the control condition. Effect sizes $r$ for the contrast analysis were calculated according to Rosnow and Rosenthal (2008, pp. 325-326). That is, the $t$-statistics of the contrast analyses were squared and then divided by this same squared $t$-value, plus the sum of the within-group degrees of freedom. Then, the square root of this result was taken. In general, an effect size of .10 is considered a small effect, an effect size of .30 medium and an effect size of .50 large (Rosnow \& Rosenthal, 2008, p. 278). 


\section{Results}

The mean scores per condition are presented in Table 1 . There was no significant difference between the three conditions on immediate recall, $F(2,67)=2.80, p=.07$. Planned contrasts revealed that, directly after the group discussion, the participants who had given explanations ( $M=$ $57.50, S D=22.72)$ or listened $(M=54.63, S D=15.01)$ had higher recall scores than the participants in the control condition $(M=44.86, S D=$ 17.99), $t(67)=2.31, p=.02$ (two-tailed), $r=0.27$. However, participants who had given explanations did not recall more than those who had listened, $t(67)=.53, p=.60, r=0.08$.

Table 1. Recall after two measurement intervals as a function of condition

\begin{tabular}{lcc}
\hline Condition & Immediate recall & Delayed recall \\
\hline Explanation $(n=24)$ & $57.50(22.72)$ & $49.29(19.71)$ \\
Listening $(n=24)$ & $54.63(15.01)$ & $39.04(13.56)$ \\
Control $(n=22)$ & $44.86(17.99)$ & $38.05(13.72)$
\end{tabular}

Note: The values represent the mean number (standard deviation) of recalled propositions.

Immediate recall: $p=.07$

Delayed recall: $p=.03$

After one month, there was a significant between-conditions difference in recall scores, $F(2,67)=3.57, p=.03$. Planned contrasts indicated that, during this second measurement interval, the participants who had provided explanations $(M=49.29, S D=19.71)$ or listened during the radar discussion $(M=39.04, S D=13.56)$ had no higher recall scores than the participants in the control condition $(M=38.05, S D=13.72)$, $t(67)=1.49, p=.14, r=0.18$. In contrast, participants who had explained during the discussion one month before recalled more than the participants who had listened, $t(67)=2.22, p=.03$ (two-tailed), $r=$ 0.31 .

\section{Discussion}

The aim of this study was to explore the effects of explaining on learning during collaborative small group discussions, while controlling for the effects of random group processes. To meet this objective, the group process was controlled by using a video-recorded, simulated group discussion. The conditions for the two experimental groups and the control group differed in that participants in the experimental conditions were asked to either participate in the group discussion or to listen only, while the participants in the control group watched a discussion on a topic with no relevance to the topic of the post-experimental text. The hypothesis that providing explanations during a relevant discussion would lead to 
better recall of a related text than only listening to a relevant discussion appears to be confirmed by the measurement after one month but not by the measurement immediately following the discussion. The hypothesis that participation in a relevant group discussion would lead to increased recall compared to participation in an irrelevant discussion was only confirmed immediately after the group discussion and not after one month. Our results suggest a delayed positive effect of providing explanations and an immediate positive effect of participation in a relevant discussion. In other words, taking part in a relevant group discussion had a direct positive impact on recall, whilst this positive effect persisted over a longer period only for those who had given explanations during the discussion.

These findings fit theoretical assumptions about elaboration during small group learning, such as Slavin's (1996) view that learning in small groups is successful in part because students are able to elaborate by explaining to each other. More specifically, explaining may increase learning because it requires students to structure or restructure their knowledge before they can verbalize it (Webb, 1989). The need to resolve inconsistencies during this process may trigger new ideas, which may lead to a more elaborate knowledge structure, which may militate against forgetting and facilitate retention of information (Reder, 1980).

Furthermore, our findings are consistent with earlier empirical evidence. One review study found that giving elaborate explanations during cooperative group work had a consistent beneficial effect on learning achievement (Webb, 1989). Other studies found that although students who engaged in problem-based discussions did not outperform students who learned from lectures, they did retain more knowledge over longer periods of time (Capon \& Kuhn 1994; Dochy, Segers, Van den Bossche, \& Gijbels, 2003; Eisenstaedt, Barry, \& Glanz, 1990; Tans, Schmidt, Schade-Hoogeveen, \& Gijselaers, 1986). This is in line with the expectations that verbal explanations increase elaboration and elaboration increases long-term recall. More specifically, Tans et al. (1986) hypothesized that students who discussed problems did not acquire more information than those listening to lectures, but stored what they learned in a well-structured manner, which facilitated retrieval after longer periods of time. The current experiment cannot reject this hypothesis. Moreover, it specifies that especially producing explanations is beneficial to postdiscussion learning.

The findings of this study are unique because the learning of individual participants was not affected by arbitrary effects from varying group processes. As far as we know, no other studies have controlled for this factor. Moreover, other studies did not allow a clear distinction to be made between the effects of explaining and listening (Peterson \& Swing 1985). By standardizing the group process, we were able to compare the effects of providing explanations with those of only listening to others during group work. 
This study has some limitations. First, in the explanation condition there was more variance in the recalled propositions, indicating that in this condition a larger part of the variance remained unexplained than in the other conditions. This may be associated with factors that were not analyzed, such as motivation and students' verbal ability. However, it seems even more striking that a long-term effect of producing explanations was found, despite the fact that other factors were not included in the analysis.

Second, it is debatable whether processes induced by watching a video recording of a simulated group discussion are equivalent to processes during a real group discussion. Real discussions may be more dynamic. For instance, during real discussions, students are more likely to engage in irrelevant, off topic talk. Also, the artificial environment of the current experiment may have confused some of the participants, because it was entirely new to them. So, despite their familiarity with group discussions, the participants may have behaved differently in the experiment than they would have in a real group. However, this potential bias appears to be outweighed by the advantage of stable independent variables for the group discussion. Moreover, it is commonly acknowledged that laboratory experiments are conducted at the cost of at least some ecological validity. In all, the current approach seems fit for the purposes of this study. Nevertheless, future experiments should always aim to minimize discrepancies between artificial and real group discussions.

In sum, the findings indicate that providing explanations as well as listening to others during a small group discussion benefit short-term recall, while producing explanations increases retention of knowledge during one month. These findings are supported by the theoretical assumptions about elaboration during small group learning and consistent with earlier empirical findings. Moreover, the results suggest that providing explanations is effective for long-term retention of information, regardless of the group process in which one participates.

The approach to studying small group discussions used in this study has some implications for future research. Based on the methods of this experiment, other processes can be studied as well. For instance, one could vary the quality of the group discussion, resulting in a condition with a high-quality discussion and one with a low-quality discussion, and look for effects on short-term and long-term recall. Earlier studies have shown that certain types of discourse are probably more productive for individual learning than other types of talk (Wegerif et al., 1999). These successful types of discourse might be simulated in an experimental design in order to investigate their effects on individual learning. The method we developed appears to be promising for empirical studies to test other theoretical assumptions about the success of collaborative, small group learning. 


\section{References}

Capon, N. and Kuhn, D. (2004). What's so good about problem-based learning? Cognition and Instruction 22(1), 61-79.

Chi, M. T. H., DeLeeuw, N., Chiu, M. H., \& LaVancher, C. (1994). Eliciting selfexplanations improves understanding. Cognitive Science, 18, 439-477.

Cohen, J. (1992). A power primer. Psychological Bulletin, 112(1), 155-159.

Cohen, E. G. (1994). Restructuring the classroom: Conditions for productive small groups. Review of Educational Research, 64(1), 1-35.

Craik, F. I., \& Lockhart, R. S. (1972). Levels of processing: A framework for memory research. Journal of Verbal Learning and Verbal Behavior, 11(6), 671-684.

Dansereau, D. F. (1988). Cooperative learning strategies. In A. Patricia, C. E. Weinstein, \& E. T. Goetz (Eds.), Learning and study strategies: Issues in assessment, instruction, and evaluation (pp. 103-120). San Diego, CA: Academic Press.

De Grave, W. S., Schmidt, H. G., \& Boshuizen, H. P. A. (2001). Effects of problembased learning on studying a subsequent text: A randomized trial among first year medical students. Instructional Science, 29, 33-44.

Eisenstaedt, R. S., Barry, W. E., \& Glanz, K. (1990). Problem-based learning: Cognitive retention and cohort traits of randomly selected participants and decliners. Academic Medicine, 65(9), 511-512.

Dochy, F., Segers, M., Van den Bossche, P., \& Gijbels, D. (2003). Effects of problem-based learning: A meta-analysis. Learning and Instruction, 13(5), 533-568.

Johnson, D. W., Johnson, T. T., \& Smith, K. (2007). The state of cooperative learning in postsecondary and professional settings. Educational Psychology Review, 19(1), 15-29.

King, A. (1990). Enhancing peer interaction and learning in the classroom through reciprocal learning. American Educational Research Journal, 27(4), 664-687.

King, A. (1991). Effects of training in strategic questioning on children's problemsolving achievement. Journal of Educational Psychology, 83(3), 307-317.

King, A. (2007). Beyond literal comprehension: A strategy to promote deep understanding of text. In D. S. McNamara (Ed.), Reading comprehension strategies (pp. 267-290). Mahwah, NJ: Erlbaum.

King, A., Staffieri, A., \& Adelgais, A. (1998). Mutual peer tutoring: Effects of structuring tutorial interaction to scaffold peer learning. Journal of Educational Psychology, 90(1), 134-152.

Larson, C. O., Dansereau, D. F., O'Donnell, A. M., Hythecker, V. I., Lambiotte, J. G., \& Rocklin, T. R. (1985). Effects of metacognitive and elaborative activity on cooperative learning and transfer. Contemporary Educational Psychology, 10(4), 342-348.

Mayer, R. E. (1985). Structural analysis of science prose: Can we increase problemsolving achievement? In B. K. B. Britton, \& J. B. Black (Eds.), Understanding expository text: A theoretical and practical handbook for analyzing explanatory text (pp. 65-87). Hillsdale, NJ: Erlbaum.

Mayer, R.E., \& Cook, L.K. (1981). Effects of shadowing and prose comprehension. Learning and Cognition, 9(1), 101-109.

McDonald, B. A., Larson, C. O., Dansereau, D. F., \& Spurlin, J. E. (1985). Cooperative dyads: Impact on text learning and transfer. Contemporary Educational Psychology 10(4), 369-377.

Mercer, N. (1996). The quality of talk in children's collaborative activity in the classroom. Learning and Instruction, 6(4), 359-377.

Mercer, N., L. Dawes, L., Wegerif, R., \& Sams, C. (2004). Reasoning as a scientist: Ways of helping children to use language to learn science. British Educational Research Journal, 30(3), 359-377.

Mercer, N., \& Sams, C. (2006). Teaching children how to use language to solve maths problems. Language and Education, 20(6), 507-528. 
Middelink, J. W. (1991). Systematische natuurkunde voor bovenbouw VWO. Apeldoorn: Van Walraven.

O'Donnell, A. M. (1996). Effects of explicit incentives on scripted and unscripted cooperation. Journal of Educational Psychology, 88(1), 74-86.

O'Donnell, A. M. (2006). The role of peers and group learning. In P. H. E. A. Winne, \& A. Patricia (Eds.), Handbook of educational psychology (pp. 781-802). Mahwah, NJ: Erlbaum.

O'Donnell, A. M., Dansereau, D. F., Hall, R. H., Skaggs, L. P., Hythecker, V. I., Peel, J. L., \& Rewey, K. L. (1990). Learning concrete procedures: Effects of processing strategies and cooperative learning. Journal of Educational Psychology, 82(1), 171-177.

O'Donnell, A. M., Dansereau, D. F., Rocklin, T. R., Hythecker, V. I., Lambiotte, J. G., Larson, C. O., \& Young, M. D. (1985). Effects of elaboration frequency on cooperative learning. Journal of Educational Psychology, 77(5), 572-580.

Peterson, P. L., \& Swing, S. R. (1985). Students' cognitions as mediators of the effectiveness of small group learning. Journal of Educational Psychology, 77(3), 299-312.

Reder, L. M. (1980). The role of elaboration in the comprehension and recall of prose. Review of Educational Research, 50, 5-53.

Rewey, K. L., Dansereau, D. F., Skaggs, L. P., Hall, R. H., \& Pitre, U. (1989). Effects of scripted cooperation and knowledge maps on the processing of technical material. Journal of Educational Psychology, 81(4), 604-609.

Roscoe, R. D., \& Chi, M. T. H. (2007). Understanding tutor learning: Knowledgebuilding and knowledge-telling in peer tutors' explanations and questions. Review of Educational Research, 77(4), 534-574.

Rosnow, R., \& Rosenthal, R. L. (2008). Beginning behavioral research: A conceptual primer (6th ed.). Upper Saddle River, NJ: Pearson/Prentice Hall.

Roseth, C. J., Johnson, D. W., \& Johnson, R. T. (2008). Promoting early adolescents' achievement and peer relationships: The effects of cooperative, competitive, and individualistic goal structures. Psychological Bulletin, 134(2), 223-246.

Ross, S. M., \& F. J. DiVesta (1976). Oral summary as a review strategy for enhancing recall of textual material. Journal of Educational Psychology, 68(6), 689-695.

Schmidt, H. G. (1993). Foundations of problem-based learning: Some explanatory notes. Medical Education, 27, 422-432.

Schmidt, H. G., De Volder, M. L., De Grave, W. S., Moust, J. H. C., \& Patel, V. C. (1989). Explanatory models in the processing of science text: The role of prior knowledge activation through small group discussion. Journal of Educational Psychology, 81, 610-619.

Slamecka, N. J., \& Graf, P. (1978). The generation effect: Delineation and phenomenon. Journal of Experimental Psychology: Human Learning and Memory, 4, 592-604.

Slavin, R. E. (1983). When does cooperative learning increase student achievement? Psychological Bulletin, 94(3), 429-445.

Slavin, R. E. (1996). Research on collaborative learning and achievement: What we know, what we need to know. Contemporary Educational Psychology, 21(1), 43-69.

Slavin, R. E., Hurley, E. A., \& Chamberlain, A. (2003). Cooperative learning and achievement: Theory and research. In G. E. Miller, \& W. M. Reynolds (Eds.), Handbook of psychology: Educational psychology (Vol. 7, pp. 177-198). Hoboken, NJ: John Wiley \& Sons.

Springer, L., Stanne, M. E., \& Donovan, S. S. (1999). Effects of small group learning on undergraduates in science, mathematics, engineering, and technology: A meta-analysis. Review of Educational Research, 69(1), 21-51.

Spurlin, J. E., Dansereau, D. F., Larson, C. O., \& Brooks, L. W. (1984). Cooperative learning strategies in processing descriptive text: Effects of role and activity level of the learner. Cognition and Instruction, 1(4), 451-463. 
Tans, R. W., Schmidt, H. G., Schade-Hoogeveen, B. E. J., \& Gijselaers, W. H. (1986). Sturing van het onderwijsleerproces door middel van problemen: een veldexperiment. Tijdschrift voor Onderwijsresearch, 11(1), 35-46.

Webb, N. M. (1989). Peer interaction and learning in small groups. International Journal of Educational research, 13, 21-40.

Webb, N. M., \& Farivar, S. (1999). Developing productive group interaction in middle school mathematics. In: A. King and A. O'Donnell (Eds.), Cognitive perspectives on peer learning (pp. 117-149). Mahwah, NJ: Erlbaum.

Webb, N. M., Troper, J. D., \& Fall, R. (1995). Constructive activity and learning in collaborative small groups. Journal of Educational Psychology, 87(3), 406-423.

Wegerif, R., N. Mercer, \& Dawes, L. (1999). From social interaction to individual reasoning: An empirical investigation of a possible sociocultural model of cognitive development. Learning and Instruction, 9(6), 493-516.

Yager, S., Johnson, D. W., \& Johnson, J. T. (1985). Oral discussion, group-toindividual transfer and achievement in cooperative learning groups. Journal of Educational Psychology, 77(1), 60-66. 


\section{Chapter 3}

\section{Does explanation to others improve learning after small group discussion? ${ }^{2}$}

An experiment tested the effect of elaboration during problem-based discussion on recall of textual information. Seventy-one participants observed a video-recorded group discussion about radar. In the explanation condition, participants elaborated by providing explanations to other group members during pauses in the video. In the listening condition, they listened to the same discussion, without providing explanations. In a control condition, they listened to a different discussion. Next, all participants studied a text about radar and answered questions that tested their recall of information from this text. Both the explanation and the listening condition recalled significantly more than the control condition. The results suggest that problem-based discussion facilitates new learning, but raise questions about the benefits of providing explanations.

\footnotetext{
${ }^{2}$ Van Blankenstein, F.M., Dolmans, D.H.J.M., Van der Vleuten, C.P.M., \& Schmidt, H.G. (2010). The effect of small group discussion and explaining on subsequent learning: An experimental approach. Paper presented at the annual meeting of the American Educational Research Association, Denver, CO.
} 


\section{Introduction}

Although there has been a lot of research to small group learning (Roseth, Johnson, \& Johnson, 2008; Springer, Stanne, \& Donovan, 1999), there is a lack of controlled, experimental research that determines which cognitive processes are responsible for this effect. The present study presents an experiment that tested the hypothesis that elaboration during a small group discussion would improve the recall of information. Experimental control was increased by letting all research participants take part in exactly the same small group discussion. This way, there were no uncontrolled influences from the group discussion that could confound the effect of elaboration on recall.

\section{Elaboration in small group learning}

Small group, collaborative learning may foster academic achievement because it promotes cognitive elaboration (O'Donnell, 2006; Slavin, Hurley, \& Chamberlain, 2003; Springer, et al., 1999). Elaboration occurs when students generate meaningful new relations, either between materials they are studying or between those new materials and knowledge from their own long-term memory (Wittrock, 1992). Elaboration enriches the memory structure with more connections between concepts. These connections provide extra retrieval cues and should therefore facilitate the recall of information (Reder, 1980).

Elaboration has been studied quite extensively in dyads (i.e. pairs) or small groups of students (Dansereau, 1988; King, Staffieri, \& Adelgais, 1998; Krol, Janssen, Veenman, \& Van der Linden, 2004; Webb \& Farivar, 1999). These studies generally show that elaboration during the collaboration promotes the conceptual understanding and recall of information. For instance, a series of experimental studies showed that collaborative elaborative activities, like summarising text passages and searching for errors and omissions in these summaries, improved recall compared to individual learning (Dansereau, 1988; Larson, et al., 1985; McDonald, Larson, Dansereau, \& Spurlin, 1985; O'Donnell, et al., 1985; Spurlin, Dansereau, Larson, \& Brooks, 1984).

One way students can elaborate in a small group is by providing explanations to other group members (Slavin, et al., 2003). Explanation promotes elaboration because it can lead to the discovery of gaps in knowledge and the construction of new relations to fill these gaps (Webb, 1989). A review of studies to small group learning shows that the number of elaborative explanations in a small group discussion correlates positively with quantitative measures of achievement (Webb, 1989). Elaborative explanations are explanations that contain the reason behind a concept and not merely a short answer to a question. Webb's (1989) review also shows that listening to elaborative explanations correlates positively with achievement in only some studies (Webb, 1989). These findings suggest that elaboration during small group discussion, through giving explanations to other students, has a higher impact on 
achievement than listening. Several experimental studies confirm this hypothesis, although these experiments usually tested the role of explanation to others in dyads instead of small groups (Durling \& Schick, 1976; Ross \& Di Vesta, 1976; Spurlin, et al., 1984; Teasley, 1995).

It thus seems that elaboration, especially by providing explanations to others, is one components of small group learning that fosters achievement. However, research faces the problem that the effect of elaboration cannot always be disentangled from the myriad of other variables that affect learning during the dynamic group process. More specifically, it is possible that the quality of the group discussion affects individual learning outcomes. The quality of the discussion may differ from group to group. Some groups may be more focused on relevant tasks and produce many elaborative explanations, whereas other groups could be less productive. Controlled, experimental research can decrease these random influences from the group and test the effects of independent variables like elaboration with more precision. The present study aimed at doing this by studying the effect of elaboration during a small group discussion on the recall of information. It used a controlled experimental setting to standardise the quality of the group discussion. All research participants were exposed to the same group process and either elaborated by providing explanations or listened to explanations from other group members.

\section{Context of the study}

The present study dealt with a specific type of small group discussion, namely problem-based discussion. Problem-based discussion is applied in problem-based learning (PBL), a method in which students discuss problems in small groups. PBL has been called 'a coat of many colours' (Lloyd, Margetson, \& Bligh, 1998), meaning that is can be implemented in different ways. However, there is general consensus that in PBL, learning starts with a problem. The problem describes a real-world scenario, including various phenomena that can be related to each other by means of discussion (Schmidt, Van der Molen, Te Winkel, \& Wijnen, 2009). During the discussion, students activate their prior knowledge, share their knowledge with each other and elaborate on it by generating new relations between this shared knowledge (Schmidt, 1993). The goal of the problem-based discussion is to create a tentative theory to explain the phenomena in the problem. With this first theory in mind, students perform self-study in order to gain more knowledge about the problem. After a few days or one week they gather again to report their findings. During this follow-up meeting, they can elaborate on their findings and correct possible misconceptions they had about the problem (Schmidt, et al., 2009).

Research has shown that students recall more information from a study text after discussing a problem about the study topic beforehand (De Grave, Schmidt, \& Boshuizen, 2001; Schmidt, De Volder, De Grave, 
Moust, \& Patel, 1989). A similar finding is that students recall more information from a study text after they have activated prior knowledge about the study topic (Machiels-Bongaerts, Schmidt, \& Boshuizen, 1995). Therefore, it seems that activation of prior knowledge and elaboration on that knowledge (through problem-based discussion) are two activities that improve recall.

\section{Summary and hypotheses}

The effectiveness of small group learning can be attributed to elaboration. However, there have not been attempts to study the effect of elaboration regardless of random influences from the group. The quality of the group discussion may vary from group to group and affect learning outcomes in countless many ways. Therefore, it is important to study small group learning in controlled, experimental settings. The purpose of this study is to test the effect of elaboration during small group discussion on the recall of information, regardless of random influences from the group. The educational context is PBL, an educational method that aims at the activation of prior knowledge and challenges students to elaborate on that knowledge by engaging in a problem-based discussion.

The first hypothesis is that problem-based discussion in general, so both providing explanations and listening to explanations from others, will improve recall. This hypothesis is included to see if earlier findings in PBL studies (De Grave et al., 2001; Schmidt et al., 1989) can be replicated with the new research methods. The second hypothesis is that that explanation to others will improve the recall of information studied after the discussion. Explanation to others is compared to listening to explanations from other group members.

\section{Methods}

Participants

The experiment included three experimental conditions, being the explanation condition, the listening condition and a control condition. Participants were 71 undergraduate students in psychology, health sciences, cultural sciences, law, economics and liberal arts, who were all familiar with PBL. None of them had chosen coursework in the sciences during secondary school. In the Netherlands, secondary school students can choose between four graduation programs. Two of these put an emphasis on coursework in the sciences, with subjects like biology, physics and chemistry. The other two programs put an emphasis on languages and the social sciences, including coursework in history, geography and economy. In the present experiment, the problem that was used for the discussion contained many elements from physics, like the propagation and extinction of waves. In order to reduce individual differences in prior knowledge, the experiment used only participants who graduated in one of the social sciences and language programs. All 
participants were recruited with advertisements and received $€ 20$,- for their participation.

\section{Materials}

Study materials and tests. Two problems were used, one about the functioning of radar and one about alcohol intoxication. The radar problem was written by the first author and used for the explanation and listening condition. The alcohol problem was adopted from a teacher training program and used for the control condition.

Two texts were devised; one to provide participants with some relevant prior knowledge for the small group discussion (prior knowledge text) and one that they studied after the group discussion (study text). The prior knowledge text contained 1068 words and described some features about the propagation and extinction of waves. It also described how waves can be used to measure the distance to an object. Three sets of nine multiplechoice questions (MCQs) were devised to test participants' mastery of this text. The study text was longer (1794 words) and offered to the participants after the group discussion. This text described the basic functioning of radar, including its use of electromagnetic waves. The study text was used to evaluate participants' recall of information. For this purpose, 10 open-ended questions were constructed that asked to explain various features about the functioning of radar. Each of these questions was based on the study text. The open-ended questions were used for immediate and delayed testing of recall.

Problem-based discussions. During preparatory rehearsal sessions, four student-actors freely discussed the radar and the alcohol problem. These actors attended the same university as the research participants and were therefore familiar with PBL. The rehearsal sessions were recorded on video and the first author used the resulting videos to write two scripts: one for the discussion about radar (radar discussion) one for the discussion about alcohol (alcohol discussion). These scripts included questions that students raised spontaneously during the rehearsal sessions. Their questions were rephrased in the script so that they would refer to the prior knowledge text and ask for reasons behind certain principles. For instance, one question from a group member was: "How can a bat calculate the distance to the wall of a cave?" This question referred to the mechanism of measuring distance with time, which was presented briefly in the prior knowledge text and returned in more detail in the study text. In short, the questions from the group members were meant to evoke elaborative explanations.

After the rehearsal sessions, both the radar and the alcohol discussion were recorded on final videos in a professional studio. The radar discussion was used for the explanation and listening condition and the alcohol discussion for the control condition. One student was the discussion leader and also acted as an 'all knowing student', one who provided explanations for the questions by the other group members in 
the listening condition. The explanations from the discussion leader were cut out in the video for the explanation condition, so that research participants could provide explanations themselves instead of listen to explanations from the discussion leader.

The discussion leader or 'all knowing student' was only visible at the beginning of the videos. Shortly after the start, the camera zoomed in on the other three students. As a consequence, only three students were visible most of the time (see Figure 1).

\section{Figure 1 . Screen shot of the group discussion}

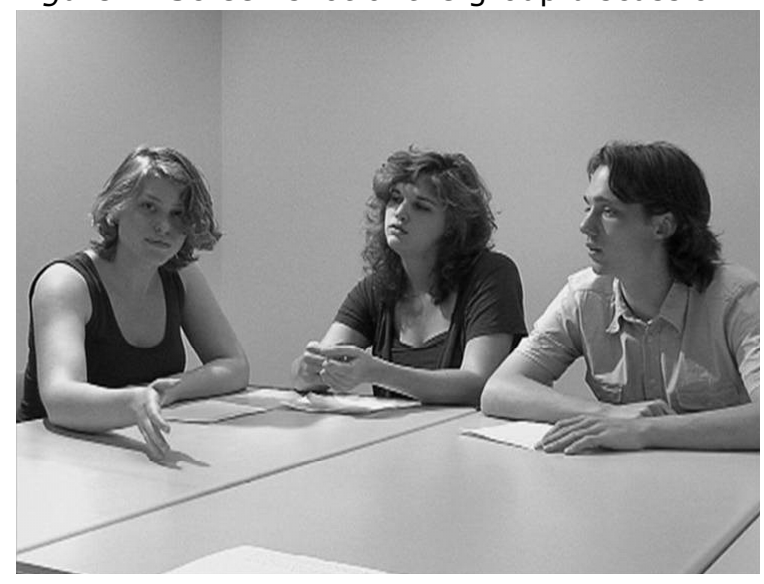

\section{Procedure}

Pre-experimental phase. Participants came to a psychological research laboratory and were seated in separate, single-person rooms with a computer. The reading distance to the computer screen was approximately $70 \mathrm{~cm}$. All materials were presented in a computer task constructed with RP's HTTP server and Macromedia Flash 8.0. The sound came from two speakers at both sides of the screen. Participants studied the prior knowledge text for 10 minutes and completed the first set of MCQs. If they made no errors, they continued to the experimental phase. If they made errors, they studied the prior knowledge text again for 7 minutes and completed the second set of MCQs. This was done to make sure that every participant mastered the prior knowledge text. Participants who made no more errors continued to the experimental phase, while those who still made errors studied the text again. This time, they only studied passages that corresponded to their errors on the last test. Questions from the third set of MCQs followed, but only those questions that corresponded to the restudied passages. After three rounds, four of the 71 participants $(5.63 \%)$ still made one or more errors on the prior knowledge test. The computer task monitored the total number of errors on the prior knowledge test, so the sum of all errors across the three rounds. 
Experimental phase. The explanation condition $(n=25)$ observed the radar discussion without the explanations from discussion leader. The discussion leader appeared briefly at the beginning of the video though. The participants received the following instructions:

You are going to meet a group of students. One of them [note: this was the discussion leader] is on your side of the table, so you will not be able to see him. Together, you form a small group that discusses a problem about radar. As a preparation, you just learned all sorts of things about waves. Waves are also used in radar systems. However, it appears that your fellow students have not remembered this information as well as you. They are therefore going to ask you questions. It is your task to explain to them as clearly as possible what you still remember. Provide them with clear formulations, so that you and your fellow students understand what you mean. Make sure the others understand everything, because they need your knowledge for further self-study. After the discussion, you will study a text about radar and you will be tested on this text.

After reading these instructions, the discussion about the radar problem appeared on the screen. The video stopped after each question from a group member and participants explained their answer verbally to the group (recall that the explanations by the discussion leader were cut out in the video for the explanation condition). Participants could explain for as long as they wanted and continue the video by pressing a button on the screen. The total time spent on the discussion was recorded and the average time ( $M=12$ minutes, 33 seconds, $S D=4$ minutes, 34 seconds) was used to set the time for the listening and control conditions. Therefore, the time spent on the discussion was equal across each condition. This manipulation was included to avoid a relevant time-on-task effect.

The listening condition $(n=23)$ observed the whole radar discussion, so with the explanations from the discussion leader. The duration of the video was 'stretched out' by adding a blank screen after each explanation by the discussion leader. The listening condition received the same instructions as the explanation condition, but the following instructions:

However, it appears that your fellow students have not remembered this information as well as you. They are therefore going to ask you questions. It is your task to explain to them as clearly as possible what you still remember. Provide them with clear formulations, so that you and your fellow students understand what you mean. Make sure the others understand everything, because they need your knowledge for further selfstudy. 
were replaced by:

Listen carefully to what the others say. There will be breaks in between that allow you to digest the information.

Participants were thus not asked to provide explanations, but to listen carefully to what the other group members had to say.

Participants in the control condition $(n=23)$ observed the alcohol discussion and received the same instructions as the listening condition, but the following sentence:

Together, you form a small group that discusses a problem about radar.

was replaced by:

Together, you form a small group that discusses a problem about alcohol.

Also, the next sentence was removed:

As a preparation, you just learned all sorts of things about waves, which are also used in a radar system.

After the discussion, all participants processed the study text for 15 minutes and answered the 10 open-ended questions about this text. This constituted the immediate recall test. After four weeks, they completed these 10 questions again as the delayed recall test.

\section{Analyses}

MEPA (Multiple Episode Protocol Analysis) was used to analyze achievement on the immediate and delayed recall test. The answers were segmented automatically into propositions, which were defined as subjectverb clauses. The boundaries of the propositions were determined by punctuations (dots, comma's, etcetera) and conjunctions (words like 'and', 'but', 'therefore, 'because', etcetera). The first author and an independent coder scored three answer protocols from the immediate recall test and three protocols from the delayed recall test. The coders assigned $\mathrm{a}$ ' 1 ' to a proposition recalled correctly and a ' 0 ' to a proposition recalled incorrectly. A segmented version of the study text was used as the answer key. For this purpose, the first author segmented the study text in propositions. MEPA was also used to calculate the inter-coder reliability (Cohen's $\kappa$ ). Values under .40 indicate poor reliability, values from .40 to .75 intermediate to good reliability, and values over .75 excellent reliability. Cohen's $\kappa$ was .79 for both the immediate and the 
delayed recall test results, thus signalling reliable inter-coder agreement. Each coder continued to score a part of the remaining answers.

The sum scores for each participant on each test were included in an analysis of covariance (ANCOVA). The number of errors on the MCQ test about the prior knowledge text was included as the covariate. The effect sizes of main effects were calculated with $\eta^{2}$. For $\eta^{2}$, a value of .01 signifies a small effect, a value of .06 a medium effect and a value of .14 a large effect (Cohen, 1988). The effect sizes of pairwise comparisons were calculated with Cohen's $d$, for which a value of 0.2 is considered a small effect, a value of 0.5 a medium effect and a value of and 0.8 a large effect (Cohen, 1992).

Table 1

Means scores and standard deviations on the immediate and delayed recall test

\begin{tabular}{lcccc}
\hline Condition & \multicolumn{2}{c}{ Immediate Recall * } & \multicolumn{2}{c}{ Delayed Recall ** } \\
\cline { 2 - 5 } & \multicolumn{1}{c}{$M$} & $S D$ & \multicolumn{1}{c}{ * } & SD \\
\hline $\begin{array}{l}\text { Explanation } \\
(n=25)\end{array}$ & 46.48 & 14.59 & 29.32 & 15.55 \\
$\begin{array}{l}\text { Listening } \\
(n=23)\end{array}$ & 47.30 & 14.28 & 26.78 & 9.03 \\
$\begin{array}{l}\text { Control } \\
(n=23)\end{array}$ & 35.61 & 15.21 & 25.52 & 12.28 \\
\hline$* F(2,67)=5.452, p=.006, \eta^{2}=.140$ & & \\
$* * F(2,67)=.653, p=.524, \eta^{2}=.019$ & & \\
\end{tabular}

\section{Results}

Table 1 presents the means and standard deviations on the immediate and delayed recall test. The ANCOVA revealed a significant overall effect of the model on immediate recall, $F(3,67)=4.887, p=.004, \eta^{2}=.180$, and a near-significant overall effect on delayed recall, $F(3,67)=2.244, p$ $=.091, \eta^{2}=.091$. The experimental treatment had a significant effect on immediate recall, $F(2,67)=5.452, p=.006, \eta^{2}=.140$, but no significant effect on delayed recall, $F(2,67)=.653, p=.524, \eta^{2}=.019$. Pairwise comparisons with Bonferroni corrections made clear that both the explanation, $t(1,67)=11.148, p=.026$, Cohen's $d=.737$, and the listening condition, $t(1,67)=12.777, p=.011$, Cohen's $d=.792$, outperformed the control condition on the immediate recall test. The results of the explanation and listening condition did differ significantly, $t(1,67)=1.640, p=1.000$, Cohen's $d=.057$. On the delayed recall test, there were no significant differences between the three conditions. 


\section{Discussion}

\section{Interpretation of the results}

The present experiment aimed at testing the effect of elaboration during small group learning on the recall of information, regardless of random influences from the group process. The context of small group learning was PBL and participants elaborated by providing explanations for a problem that described the functioning of radar.

The first hypothesis was that problem-based discussion in general, so both providing explanations and listening to explanations from others, would improve recall. Earlier experiments with real-life settings discovered that problem-based discussion facilitated the recall of information studied after the discussion (De Grave, et al., 2001; Schmidt, et al., 1989). The present experiment was able to repeat these findings, thus indicating that a simulation of a problem-based discussion can lead to similar learning gains as a real problem-based discussion.

The second hypothesis was that explanation to others would improve the recall of information studied after the discussion. Explanation did not increase the recall of information as compared to listening, neither on the immediate, nor on the delayed recall test. This is at odds with general findings from classroom research, which usually finds positive relations between elaborative explanation in small groups and achievement (Webb, 1989). It also contradicts the findings from several experimental studies that showed positive effects of explanation on achievement, as compared to listening (Ross \& Di Vesta, 1976; Spurlin, et al., 1984). Two possible explanations for these deviating results are discussed below.

First, elaboration during a problem-based discussion may indeed not have a high impact on recall. During a problem-based discussion, students create a tentative theory that explains the phenomena in the problem (Schmidt, et al., 2009). This initial theory does not necessarily correspond to information that students will encounter during the self-study phase that follows the problem-based discussion. The theory may be naive and contain misconceptions, which can be corrected during the reporting phase after self-study. The reporting phase focuses on relevant information encountered during self-study and allows students to elaborate on this information. Perhaps this focussed form of discussion yields more elaboration on relevant content than the problem-based discussion that precedes self-study.

Like the reporting phase in $\mathrm{PBL}$, most studies to small group learning focus on elaboration after the acquisition of new knowledge. These investigations usually presented new information to students first and then allowed them to discuss the new material in small groups. Many of these studies have found indications for a positive effect of elaboration during the group discussion on achievement (Dansereau, 1988; King, et al., 1998; Webb \& Farivar, 1999). It may therefore be possible that a discussion after the acquisition of new information is more conducive to 
learning than a problem-based discussion that precedes the acquisition of new knowledge.

A second possible reason for the lack of an 'elaboration by explanation effect' is that the listeners elaborated silently after hearing the explanations from the discussion leader. Recall that the time spent on the discussion was stretched out for the listening condition. This was done in order to equalise the relevant time-on-task between the explanation and the listening condition. A result of this manipulation was that the listeners received a short period of time after each explanation by the discussion leader. During these pauses, they may have elaborated silently on the explanations. It has been shown that students have many contentrelevant thoughts during a problem-based discussion that they do not speak out loud (De Grave, Boshuizen, \& Schmidt, 1996). Therefore, a 'silent elaboration' hypothesis (Dolmans \& Schmidt, 2006; Moust, Schmidt, De Volder, Belien, \& De Grave, 1987) may account for the lack of differences between the explainers and the listeners.

\section{Limitations and future research}

Some limitations of this study can be put forward. First, the time period of the intervention was relatively short. Real problem-based discussions can last more than one hour (Hmelo-Silver, 2004; Schmidt, et al., 2009) and in this experiment the time period for the discussion was around fifteen minutes. A future experiment could extend the time period of the discussion and allow more time for self-study. Secondly, the thoughts of the listeners were not captured after the experiment. It would have been possible to ask them after the experiment what they were thinking during the discussion. This has been practised before (De Grave, et al., 1996) and can lead to valuable new insights about silent elaboration. Alternatively, silent elaboration can be prevented by adjusting the experimental manipulation so that participants are discouraged to elaborate. This would create an opportunity to test elaboration with more precision.

\section{References}

Cohen, J. (1988). Statistical power analysis for the behavioral sciences (2nd ed.). Hillsdale, NJ: Erlbaum.

Cohen, J. (1992). A power primer. Psychological Bulletin, 112(1), 155-159.

Dansereau, D. F. (1988). Cooperative learning strategies. In C. E. Weinstein, E. T. Goetz \& P. A. Alexander (Eds.), Learning and study strategies: Issues in assessment, instruction, and evaluation (pp. 103-120). San Diego, CA: Academic Press.

De Grave, W. S., Boshuizen, H. P. A., \& Schmidt, H. G. (1996). Problem based learning: Cognitive and metacognitive processes during problem analysis. Instructional Science, 24(5), 321-341.

De Grave, W. S., Schmidt, H. G., \& Boshuizen, H. P. A. (2001). Effects of problembased discussion on studying a subsequent text: A randomized trial among first year medical students. Instructional Science, 29(1), 33-44. 
Dolmans, D. H. J. M., \& Schmidt, H. G. (2006). What do we know about cognitive and motivational effects of small group tutorials in problem-based learning? Advances in Health Sciences Education, 11(4), 321-336.

Durling, R., \& Schick, C. (1976). Concept attainment by pairs and individuals as a function of vocalization. Journal of Educational Psychology, 68(1), 83-91.

Hmelo-Silver, C. E. (2004). Problem-based learning: What and how do students learn? Educational Psychology Review, 16(3), 235-266.

King, A., Staffieri, A., \& Adelgais, A. (1998). Mutual peer tutoring: Effects of structuring tutorial interaction to scaffold peer learning. Journal of Educational Psychology, 90(1), 134-152.

Krol, K., Janssen, J., Veenman, S., \& Van der Linden, J. (2004). Effects of a cooperative learning program on the elaborations of students working in dyads. Educational Research and Evaluation, 10(3), 205-237.

Larson, C. O., Dansereau, D. F., O'Donnell, A. M., Hythecker, V. I., Lambiotte, J. G., \& Rocklin, T. R. (1985). Effects of metacognitive and elaborative activity on cooperative learning and transfer. Contemporary Educational Psychology, 10(4), 342-348.

Lloyd, J., Margetson, D., \& Bligh, J. G. (1998). Problem-based learning: A coat of many colours. Medical Education, 32(5), 492-494.

Machiels-Bongaerts, M., Schmidt, H. G., \& Boshuizen, H. P. A. (1995). The effect of prior knowledge activation on text recall: An investigation of two conflicting hypotheses. British Journal of Educational Psychology, 65(4), 409-423.

McDonald, B. A., Larson, C. O., Dansereau, D. F., \& Spurlin, J. E. (1985). Cooperative dyads: Impact on text learning and transfer. Contemporary Educational Psychology, 10(4), 369-377.

Moust, J. H. C., Schmidt, H. G., De Volder, M. L., Belien, J. J., \& De Grave, W. S. (1987). Effects of verbal participation in small group discussion. In J. T. E. Richardson, M. W. Eysenck \& D. W. Piper (Eds.), Student learning: Research in education and cognitive psychology (pp. 147-154). Guildford Maidenhead, BRK England: Society for Research into Higher Education, Open University Press.

O'Donnell, A. M. (2006). The role of peers and group learning. In P. H. Winne \& P. A. Alexander (Eds.), Handbook of educational psychology (pp. 781-802). Mahwah, NJ: Erlbaum.

O'Donnell, A. M., Dansereau, D. F., Rocklin, T. R., Hythecker, V. I., Lambiotte, J. G., Larson, C. O., et al. (1985). Effects of elaboration frequency on cooperative learning. Journal of Educational Psychology, 77(5), 572-580.

Reder, L. M. (1980). The role of elaboration in the comprehension and retention of prose: A critical review. Review of Educational Research, 50(1), 5-53.

Roseth, C. J., Johnson, D. W., \& Johnson, R. T. (2008). Promoting early adolescents' achievement and peer relationships: The effects of cooperative, competitive, and individualistic goal structures. Psychological Bulletin, 134(2), 223-246.

Ross, S. M., \& Di Vesta, F. J. (1976). Oral summary as a review strategy for enhancing recall of textual material. Journal of Educational Psychology, 68(6), 689-695.

Schmidt, H. G. (1993). Foundation of problem-based learning: Some explanatory notes. Medical Education, 27(5), 422-432.

Schmidt, H. G., De Volder, M. L., De Grave, W. S., Moust, J. H. C., \& Patel, V. L. (1989). Explanatory models in the processing of science text: The role of prior knowledge activation through small-group discussion. Journal of Educational Psychology, 81(4), 610-619.

Schmidt, H. G., Van der Molen, H. T., Te Winkel, W. W. R., \& Wijnen, W. H. F. W. (2009). Constructivist, problem-based learning does work: A meta-analysis of curricular comparisons involving a single medical school. Educational Psychologist, 44(4), 227-249.

Slavin, R. E., Hurley, E. A., \& Chamberlain, A. (2003). Cooperative learning and achievement: Theory and research. In G. E. Miller \& W. M. Reynolds (Eds.), 
Handbook of psychology: Educational psychology (Vol. 7, pp. 177-198). Hoboken, NJ: John Wiley \& Sons.

Springer, L., Stanne, M. E., \& Donovan, S. S. (1999). Effects of small-group learning on undergraduates in science, mathematics, engineering, and technology: A meta-analysis. Review of Educational Research, 69(1), 21-51.

Spurlin, J. E., Dansereau, D. F., Larson, C. O., \& Brooks, L. W. (1984). Cooperative learning strategies in processing descriptive text: Effects of role and activity level of the learner. Cognition and Instruction, 1(4), 451-463.

Teasley, S. D. (1995). The role of talk in children's peer collaborations. Developmental Psychology, 31(2), 207-220.

Webb, N. M. (1989). Peer interaction and learning in small groups. International Journal of Educational Research, 13(1), 21-39.

Webb, N. M., \& Farivar, S. (1999). Developing productive group interaction in middle school mathematics. In A. M. O'Donnell \& A. King (Eds.), Cognitive perspectives on peer learning (pp. 117-149). Mahwah, NJ: Erlbaum.

Wittrock, M. C. (1992). Generative learning processes of the brain. Educational Psychologist, 27(4), 531-541. 


\section{Chapter 4}

\section{Can a teacher who promotes elaboration during small group discussion improve academic achievement? ${ }^{3}$}

An experiment tested the effect of a teacher's elaborative questions during a small group discussion on students' recall of information. Sixtynine university students individually observed a small group that discussed a problem about thunder and lightning. A teacher who supervised the discussion directed eight questions at the observing student. In one experimental condition $(n=37)$, these questions were designed to provoke elaborative responses. In a second condition ( $n=$ $32)$, the questions were constructed to elicit superficial answers. After the small group discussion, all participants studied a text about thunder and lightning. Contrary to the expectations, the students did not recall significantly more from this text after responding to the elaborative questions during the discussion. In line with the expectations, the discussion with the elaborative questions improved long-term recall significantly for low ability students. The findings indicate that elaboration during small group discussion may be more useful for low than for high ability students.

\footnotetext{
${ }^{3}$ Van Blankenstein, F.M., Dolmans, D.H.J.M., Van der Vleuten, C.P.M., \& Schmidt, H.G. Can a teacher who promotes elaboration during small group discussion improve academic achievement? Under editorial review.
} 


\section{Introduction}

Collaborative learning may foster elaboration and subsequent academic achievement (O'Donnell, 2006; Slavin et al., 2003; Springer et al., 1999), but at the same time, it is difficult to determine whether elaboration is truly an effective 'working ingredient' or not. This difficulty arises from the myriad of other influences that can affect learning during the group process. The present study aimed to test the effect of elaboration on achievement while keeping the group process under experimental control. More specifically, it tested whether a teacher could improve students' academic achievement by asking elaborative questions during a small group, problem-based discussion.

\section{Elaboration in collaborative learning}

Several review studies have shown that small group, collaborative learning has a positive impact on learning outcomes, attitudes towards learning, and social relationships (Roseth, Johnson, \& Johnson, 2008; Slavin, 1983; Springer, Stanne, \& Donovan, 1999). However, there are many different approaches for collaborative learning, stemming from a variety of theories. One of the theoretical perspectives proposes that collaborative learning promotes cognitive elaboration (O'Donnell, 2006; Slavin et al., 2003; Springer et al., 1999). Elaboration can be defined as the generation of new and meaningful connections between new concepts, or between new concepts and prior knowledge (Wittrock, 1992). In theory, elaboration should lead to more interconnections inside the knowledge base, thereby 'enriching' the knowledge base and improving the recall of knowledge (Hamilton, 2004; Reder, 1980) Several findings suggest that students indeed recall more information when they are stimulated to generate new relations between concepts. For instance, students were better able to memorize words when they generated meaningful relations between these words (Bobrow \& Bower, 1969; Slamecka \& Graf, 1978). Also, various elaboration techniques have shown to improve the recall of information and the ability to apply that information to new situations (Johnsey et al., 1992; Mayer, 1980). These techniques seem to have a stronger positive effect on low ability students than on high ability students. This might be due to the fact that elaboration techniques adequately support low ability students, while they may be redundant for high ability students who already possess efficient learning strategies (Hamilton, 1989; Mayer, 1980).

Collaborative learning could stimulate elaboration because it results in deeper processing and a more active involvement with the subject-matter (O'Donnell, 2006). As a consequence, educational researchers have come up with several ways to evoke elaboration during student collaboration (Brown \& Palincsar, 1989; Dansereau, 1988; King, 2007; King et al., 1998; Krol et al., 2004; Mercer \& Sams, 2006; Schmidt, 1993; Webb \& Farivar, 1999). For instance, Dansereau et al. (1988) set up a program in which students reviewed textual materials in pairs. One of the students 
summarized the text verbally, while the other student detected omissions and errors in these summaries. This structured form of collaboration tended to improve achievement for both students, as compared to unstructured collaboration between two students or individual learning. In addition, various studies reported a positive correlation between providing explanations to others and achievement (Krol et al., 2004; Van Boxtel et al., 2000; Veenman et al., 2005; Webb, 1989). This also supports the elaboration hypothesis, because explanation to others may be a prerequisite for elaboration (Slavin et al., 2003). The rationale behind this is that students discover gaps in their own prior knowledge when they explain something to someone else. As a consequence, they need to generate new connections to fill these gaps (Nussbaum, 2008).

\section{Methodological issues with research to collaborative learning}

A problem with research to collaborative learning is that it is difficult to disentangle the effects of single, independent variables on achievement during the dynamic group process. Therefore, it may not always be clear whether it is elaboration or some other factor that promotes achievement. Moreover, the exchange of information will always vary between different groups. This leads to qualitative differences between group discussions which might affect individual learning outcomes. For example, it has been shown that groups with high achieving students produce more elaborate explanations than groups with a mixed composition of low and high achieving students (Fuchs, Fuchs, Hamlett, \& Karns, 1998; Webb et al., 1998). Therefore, the amount of elaboration can differ substantially across groups, randomly affecting individual learning outcomes. The present study acknowledged this and aimed at optimal experimental control over the group process. For this purpose, all research participants were exposed to the same, small group discussion.

\section{Promoting elaboration with elaborative questions}

As mentioned before, several studies have attempted to promote elaboration during student collaboration (Brown \& Palincsar, 1989; Dansereau, 1988; King, 2007; King et al., 1998; Krol et al., 2004; Mercer \& Sams, 2006; Schmidt, 1993; Webb \& Farivar, 1999). Some of these studies used interventions in which students learned to structure their discussion in order to elaborate more deeply (Dansereau, 1988; King, 2007). For example, King (2007) describes an intervention in which students revise textual materials while asking each other questions that elicit elaboration. The use of such questions, which can be called elaborative questions, has been described by other authors (Pressley et al., 1992; Rosenshine, Meister, \& Chapman, 1996) and proven to enhance academic achievement (Pressley et al., 1988; Pressley, Tanenbaum, McDaniel, \& Wood, 1990; Pressley et al., 1992).

Also in collaborative learning, there are signs that elaborative questions promote achievement. One recent study indicated that a 
teacher can improve students' mathematical reasoning by asking them repeatedly to explain their reasoning. The study compared three classroom teachers, one of whom asked students more often to explain and elaborate on their reasoning than the two other teachers. Students who were taught by the first teacher achieved better on various measures of mathematical reasoning than students in the two other classrooms (Webb et al., 2008). This indicates that students achieve better when they are asked more frequently to explain their thinking. Another recent, experimental study let students discuss the concepts of evolution in pairs (Asterhan \& Schwarz, 2007). One of the two students was actually a confederate to the experiment (i.e. an assistant, appointed by the investigators), who played the same role in front each other student who participated in the experiment. The other student, or actual participant in the study, never knew that the first student was a confederate. In an experimental condition, the confederate asked a set of elaborative questions, provided by the investigators, to the other student. In a control condition, both the confederate and the other student performed a neutral task. Conceptual understanding of evolutionary theory increased in the experimental condition and this positive effect sustained over one week. In contrast, the control condition did not show gains in conceptual understanding. Responding to the confederate's questions thus seemed to evoke a sustainable improvement in conceptual understanding.

\section{Using elaborative questions in problem-based learning}

Up till now, the impact of elaboration during collaborative learning has been discussed in general. Because of the great diversity in collaborative learning approaches, it might be valuable to illuminate the educational context of the present study, which is problem-based learning (PBL). Even PBL has been called 'a coat of many colors' (Lloyd et al., 1998), meaning that it comes in many forms. Nevertheless, Schmidt, Van der Molen, Te Winkel \& Wijnen (2009) defined six general principles for PBL. First of all, PBL uses a problem at the starting point of new learning. Second, it supports collaboration, namely through a small group discussion about the problem. Third, a teacher (also called a tutor) guides the small group discussion. Fourth, a PBL program contains fewer lectures because the problem is the predominant incentive for new learning. Fifth, students actively seek new, problem-relevant information after the small group discussion. And finally, they receive sufficient time for this self-study.

A problem usually describes a real-world situation as a collection of phenomena. These phenomena are interrelated, but these relations are not made explicit in the problem. For example, a problem can describe the creation of thunder and lightning in various observable phenomena (i.e. dark thunderclouds, hot and moist air, rain, a lightning bolt, thunder). During the small group discussion, students activate their prior knowledge about the problem and elaborate by searching for connections between the various phenomena. They will discover gaps in their knowledge and 
these gaps result in learning issues at the end of the group discussion. During the next days, students consult various sources for new information. This period of self-study is followed by a new group discussion, in which they report and elaborate on their findings (Schmidt et al., 2009).

There is no unequivocal evidence that students learn more from PBL than from conventional education (Albanese, 1993; Colliver, 2000; Vernon \& Blake, 1993), but there are indications that PBL students recall more knowledge over time than conventional students (Dochy et al., 2003). Given the great variety of practice in PBL, it may be difficult to derive from these findings which factors cause PBL to be effective. Most importantly, it seems that the effect of elaboration on achievement has never been studied in PBL. Some experimental studies showed that students recalled more information from individual self-study when a problem-based discussion preceded the self-study (De Grave et al., 2001; Schmidt, 1984; Schmidt et al., 1989). Still, none of these studies showed that elaboration was responsible for this positive effect. The present experiment was designed to fill this gap.

In PBL, teachers can play an important role in eliciting elaboration, because they guide and facilitate the learning of students during the group discussion (Neville, 1999). Therefore, PBL teachers do not only rely on their content expertise, but should also be good process facilitators who guide the group discussion in the right direction (Dolmans et al., 2002). Stimulating elaboration and the integration of knowledge is part of this process facilitation (De Grave et al., 1999). PBL teachers can accomplish this by connecting the topic of the discussion with prior knowledge from the literature (Lee et al., 2009), stimulating students to explore their own ideas, and encouraging them to appraise the material more critically (Wilkerson, 1994). There are also indications that the questions teachers ask during PBL group meetings influence final achievement in certain domains (Budé, Imbos, Van der Wiel, Broers, \& Berger, 2009). During a PBL course in statistics, some teachers used directive questions that stimulated students to elaborate on the relevant concepts they needed to understand. Other teachers did not use these questions. Students who were taught with the directive questions performed slightly better on a final examination at the end of the course than students who were not exposed to the directive questions. The authors acknowledged that more research was needed to examine if low ability students would profit more from the tutor prompts than high ability students. This hypothesis is in agreement with the earlier mentioned findings that elaboration is more effective for low than for high ability students (Hamilton, 1989; Mayer, 1980). Also, the authors mentioned that the experiment was a field study in which not all variables could be controlled. Again, this underscores the necessity for experimental research with an optimal control over potential confounding variables. 
Research hypotheses

The present study aimed at testing whether a teacher who asked elaborative questions to students would promote their achievement as compared to a teacher who asked superficial questions. This was examined in an experiment that simulated a problem-based, small group discussion. There were two hypotheses. First of all, responding to elaborative questions should lead to a higher amount of recall from information studied after the group discussion than responding to superficial questions. Second, this effect should be greater for low than for high ability students. In order to prevent noise from other, random influences on the recall of information, the experiment standardized the group discussion by presenting it as a simulation to the research participants. This method ensured that all participants were exposed to the same group discussion.

\section{Method}

Participants

Participants were 69 students from bachelor programs in Medicine (50), Health Sciences (15), Molecular Life Sciences (3) and Psychology (1). In order to reduce individual differences in prior knowledge, students were chosen according to the type of curriculum they had followed in secondary school. In the Netherlands, students can prepare for university by choosing between four different programs. Two of these are oriented towards the sciences, with courses e.g. in biology, physics and chemistry. The selection criterion was that students had completed one of these two programs. Participants' mean age was $20.52(S D=1.45)$. They were selected with advertisements and by active recruitment, and received a financial compensation of $€ 20$,- for their participation. The university were the experiment was conducted applies PBL throughout all of its' faculties, so all participants were familiar with this learning method.

\section{Materials}

Examples of the materials can be found in Appendix B. All materials were presented to research participants on a computer screen via a website that was devised especially for the experiment. The materials can be divided in two parts: (1) study materials and tests for these study materials, and (2) materials for the simulated small group discussion. Both will be described in detail below.

Study materials and tests. The study materials and tests were all organized according to eight topics about thunder and lightning. The eight topics explained (1) the creation of thunder clouds; (2) electrical charges inside a thundercloud; (3) electrical charges between a cloud and the surface of the earth; (4) the creation of lightning; (5) the creation of thunder; (6) where lightning strikes; (7) indirect strike by lightning; and (8) what to do during a thunder storm. Based on these eight topics, two texts were written: a prior knowledge text and a study text. The prior 
knowledge text was used to provide participants with some relevant prior knowledge for the discussion. This text briefly described the eight topics about thunder and lightning in 328 words. The study text (1615 words) elaborated on each of these topics. Two tests were constructed, one for the prior knowledge text and one for the study text. The test for the prior knowledge text contained 11 multiple choice questions (MCQs). This test was used as a pretest as well, in order to assess participants' prior knowledge about thunder and lightning. The test for the study text consisted of 8 open-ended questions, each referring to one of the eight topics. These open-ended questions were used to measure immediate and delayed recall of the study text.

Small group discussion. A video of a problem-based discussion was recorded with a Sony DCR VX2000e video camera in a room where PBL group meetings were normally held. The video showed four students and a teacher discussing a problem about thunder and lightning. The problem was adopted from a teacher training program in PBL and described a situation with thunder and lightning during a warm summer day in 102 words. The group discussion contained eight scenes, each representing one of the eight topics in the study materials. The students in the video discussed these topics briefly and they involved knowledge from the prior knowledge text in the discussion. Below is an example of a dialogue between students about the second topic, which dealt with electrical charges inside a thundercloud:

S: What I don't understand, is how this thundercloud-thing works.

$\mathrm{J}$ : I am not telling you I fully understand this, but... I think there is a difference in electrical charge inside a cloud... right? [Looks puzzled to the others.]

During the recording sessions, sixteen close-ups of a teacher were captured on video as well. In each close-up, the teacher faced the camera and asked a question to the observer of the video. Each of these questions followed logically the last discussion scene with the students. Eight of the questions were called elaborative and the other eight superficial. The elaborative questions aimed at the generation of new ideas based on the prior knowledge text. These questions were edited into the discussion after each relevant scene with the students, so that the discussion maintained a natural flow. One example of an elaborative question is:

In a cloud, there are many currents of air. The cloud also contains water drops, and hail stones. But what happens then? How can a difference in electrical charge come about within a cloud?

This question referred back to some concepts in the prior knowledge text (i.e. air currents, water drops and hail stones) and then asked the 
participant to explain how these elements could be combined to cause different electrical charges inside a cloud. The superficial questions asked for rehearsal of the prior knowledge text or clarification of a statement from a student in the video. These questions were edited into a second version of the video to replace the elaborative questions. Like in the video with the elaborative questions, each superficial question followed the natural flow of the discussion. One superficial question for instance asked: "Do you know what he means?" This question referred to a statement by one of the students (J.) in the video, who rephrased an idea from the prior knowledge text ("I think there is a difference in electrical charge inside a cloud."). So in this case, the participant was directed to information from the prior knowledge text and not stimulated explicitly to generate a new idea.

Figure 1: Overview of the experimental procedure

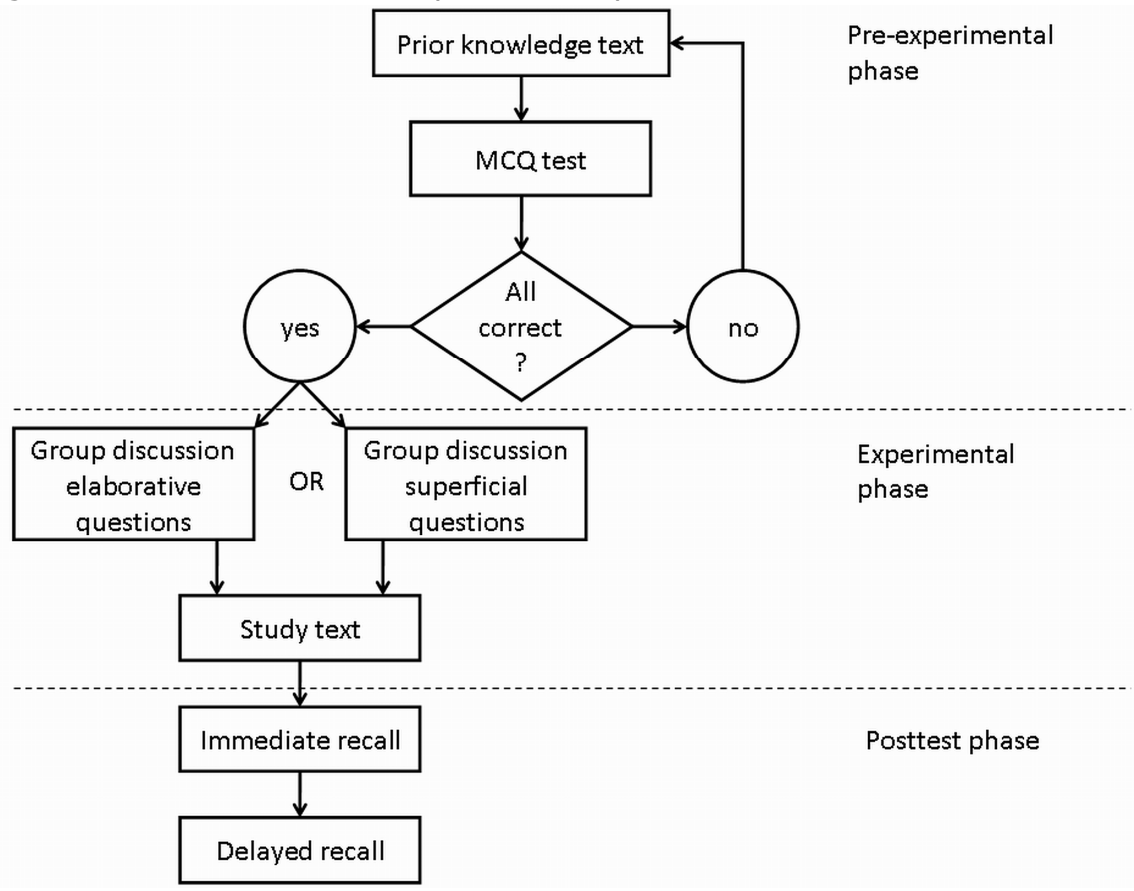

\section{Procedure}

The experiment was conducted in a psychological laboratory and can roughly be divided a pre-experimental phase, an experimental phase and a posttest phase. Figure 1 provides an overview of the procedure. The pre-experimental phase served to (1) provide participants with some relevant prior knowledge for the group discussion, (2) to reduce preexperimental, individual differences in prior knowledge, and (3) to assess their ability to acquire the prior knowledge. Therefore, all participants read the prior knowledge text and took a short test with multiple-choice 
questions (MCQs). The test was used to assess participants' ability to acquire the prior knowledge text. The experimental phase included the video of the small group discussion, with either the elaborative or the superficial questions. Students were randomly assigned to a condition in which they observed the video with the elaborative questions, or to a condition in which they observed the video with the superficial questions. Directly after the group discussion, all participants processed the study text. The posttest phase contained immediate and delayed recall measures for the study text.

Pre-experimental phase. All participants came to a research lab and were seated in a closed, one-person room, with a 19 inch flat screen set at a reading distance of approximately $70 \mathrm{~cm}$. First, they completed the 11 MCQs as a pretest for general knowledge about thunder and lightning. Then, they studied the prior knowledge text and filled in the MCQs again. All participants repeated this process of studying and testing until they answered all the MCQs correctly. If they still made errors after their third attempt, they automatically received only those text passages that corresponded with the errors they made on the MCQ test they completed. To prevent sequential recognition, both the MCQs and the multiple-choice response alternatives were reordered each time they were represented. Furthermore, the number of attempts to pass the test was monitored. $43.7 \%$ of the participants completed the test in one attempt, $32.4 \%$ in two, $19.7 \%$ in three and $2.8 \%$ in four.

Experimental phase. The experimental phase followed the preexperimental phase directly. First, all participants were instructed that they would participate in a problem-based discussion and that a teacher would ask them questions during this discussion. They were also told to answer these questions verbally. Upon proceeding to the next page, they observed a scene that introduced the students and the teacher by name. New instructions then followed, in which participants read that they would now practice the answering to the teacher's questions. A new scene appeared, showing the students discussing an irrelevant topic (i.e. why water comes out of a tap). The practice scene ended with a question by the teacher, which participants could respond to verbally. After the practice scene, they were told that they would progress to the actual problem-based discussion. At this time, they also received specific instructions for their experimental condition. The instructions for the elaborative questions condition $(n=37)$ were:

Answer the questions as extensively as possible, until you cannot think of any more ideas. Verbalize anything that comes to mind, even if you are not sure whether your answer is completely correct. Feel free to come up with new and original ideas. Again, it does not matter if you answer is completely right. What is more important is that you tell everything you can come up with. 
These instructions were given to stimulate the generation of new ideas. Participants in the superficial questions condition $(n=32)$ did not receive these instructions.

After these instructions, the problem-based discussion commenced. First, the group and the problem appeared on the screen for 1 minute, so participants could read the problem. Then, the discussion started. In the elaborative questions condition, participants responded to the elaborative questions by the teacher. There was no time restriction for answering these questions. The total time spent on the discussion was recorded $(M=$ 13 minutes, 9 seconds; $S D=2$ minutes, 49 seconds) and used to determine the time for discussion in the superficial questions condition. In this second experimental condition, participants observed the discussion as well, but this time they responded to the superficial teacher questions. The response time for each question was stretched till the average amount of time spent by the elaborative questions condition, minus the duration of the whole discussion, divided by the total number of scenes (eight). Thus, participants in the superficial questions condition received the same amount of response time as (on average) participants in the elaborative questions condition. After the discussion, all participants processed the study text for 15 minutes. A time bar at the top of the screen indicated how much time was left. Following this study phase, they completed the immediate recall measure. After 1 week, they returned to the research lab and completed the delayed recall measure. They were not told beforehand that they would be tested again after one week.

\section{Analyses}

The pretest score was defined as the number of MCQs answered correctly before studying the prior knowledge text. The minimum score was 1 and the maximum score 11 . The number of attempts participants needed to complete the MCQ test was taken as the measure to assess ability to acquire prior knowledge. More attempts signified greater difficulties. The immediate and delayed recall measures were segmented into idea units (Mayer, 1985) by the first author (coder 1) and an independent coder (coder 2). An idea unit was defined as a clause with at least one subject-verb or subject-verb group combination. The inter-rater reliability of the segmentation was determined from the perspective of each coder (Strijbos, Martens, Prins, \& Jochems, 2006). For this purpose, each coder segmented the answers of one immediate and one delayed recall protocol. The number of corresponding segments was divided by the total number of segments obtained by coder 1, resulting in a $94.97 \%$ agreement. The number of corresponding segments was also divided by the total number of segments obtained by coder 2, which yielded an agreement of $94.14 \%$. These values seemed to signify a sufficient reliability and coder 2 continued to segment the remainder of the posttest results. 
The same segmentation procedure was applied to the study text, resulting in an agreement of $94.38 \%$ from the perspective of coder 1 and $96.10 \%$ from the perspective of coder 2. Differences were discussed, resulting in a final, segmented text, which was used as an answer key to score the segmented results from the immediate and delayed recall measures. These segments were matched with the segments from the study text and each match was awarded 1 point. Double matches were not scored. Both coders performed this task in MEPA (Multiple Episode Protocol Analysis), which uses Cohen's Kappa's $(\kappa)$ to determine the interrater reliability. Values under .40 signify a poor, values between .40 and .75 an intermediate to good, and values above .75 an excellent reliability. $\kappa$ reached .73 on the immediate and .74 on the delayed recall measure, signifying good reliability. The rest of the segmented posttest results were split up and each part was scored by one coder.

The effect of the experimental treatment was evaluated with an independent t-test on immediate and delayed recall scores in SPSS 15.0. The pretest score was included as well in order to check if prior knowledge was randomly distributed across the two experimental conditions. In order to see if the treatment had a differential effect on participants high and low in ability to acquire the pre-experimental prior knowledge, a median split was performed on the number of attempts to pass the MCQ test. The median was 1 , with $47.3 \%$ of the participants passing the test in one attempt (high ability students). The remainder needed 2, 3 or 4 attempts (low ability students). One t-test on immediate and delayed recall tested the effect of the treatment for low ability students and a second t-test examined the effect for the high ability students. Finally, a t-test was performed in order to check if the high ability students recalled more on the immediate and delayed measure than the low ability students. This could signify that the high ability students were indeed better able to acquire the new knowledge than the low ability students. The pretest score was included in this analysis as well, to check for prior knowledge differences between high and low ability students. Cohen's $d$ denoted the effect sizes, with a value of 0.2 indicating a small effect, 0.5 a medium effect and 0.8 a large effect (Cohen, 1992).

\section{Results}

Table 1 shows the results of the pretest, the immediate recall measure, and the delayed recall measure for each experimental condition. There was no significant difference on the pretest between the two conditions, $t(1,67)=.23, p=.82, d=.06$ (two-tailed). The treatment had a small to medium, non-significant effect on immediate recall, $t(1,67)=1.61, p$ $=.11, d=.39$, although the elaborative questions condition recalled slightly more idea units than the superficial questions condition. Delayed recall showed the same trend towards higher recall after elaborative questions, but again the effect was small to medium and not significant, $t(1,67)=1.65, p=.10, d=.40$. 
Table 1. Pretest, immediate recall, and delayed recall scores as a function of condition

\begin{tabular}{lccccccc}
\hline Condition & $n$ & \multicolumn{2}{c}{ Pretest } & \multicolumn{2}{c}{ Immediate recall } & \multicolumn{2}{c}{ Delayed recall } \\
\cline { 2 - 8 } & & $M$ & $S D$ & $M$ & $S D$ & $M$ & $S D$ \\
\hline $\begin{array}{l}\text { Superficial } \\
\text { questions }\end{array}$ & 32 & 7.06 & 1.29 & 29.91 & 10.72 & 26.28 & 9.31 \\
$\begin{array}{l}\text { Elaborative } \\
\text { questions }\end{array}$ & 37 & 7.14 & 1.38 & 33.62 & 8.39 & 29.86 & 8.68 \\
\begin{tabular}{l} 
Contrast \\
\hline
\end{tabular} & $p=.82, d=.06$ & $p=.11, d=.39$ & $p=.10, d=.40$ \\
\hline
\end{tabular}

Table 2 shows the results of the pretest, the immediate recall measure and the delayed recall measure for the high and low ability students. The treatment had no significant effect for the high ability students, neither on immediate, $t(1,27)=.84, p=.41, d=.31$, nor on delayed recall, $t(1$, $27)=.51, p=.61, d=.19$. For the low ability students, the treatment did not produce a significant effect on immediate recall, $t(1,38)=1.62, p$ $=.14, d=.52$. In contrast, there was a significant, medium to large effect on delayed recall, $t(1,38)=2.11, p=.04, d=.67$. This effect was in the predicted direction, so the low ability students who responded to elaborative questions recalled more on the longer term than the low ability students who responded to the superficial questions.

Table 2. Pretest, immediate recall, and delayed recall scores as a function of condition and student ability

\begin{tabular}{|c|c|c|c|c|c|c|c|c|}
\hline \multirow[t]{2}{*}{ Ability } & \multirow[t]{2}{*}{ Condition } & \multirow[t]{2}{*}{$n$} & \multicolumn{2}{|c|}{ Pretest } & \multicolumn{2}{|c|}{$\begin{array}{c}\text { Immediate } \\
\text { recall }\end{array}$} & \multicolumn{2}{|c|}{ Delayed recall } \\
\hline & & & $M$ & $S D$ & $M$ & $S D$ & $M$ & $S D$ \\
\hline \multirow[t]{4}{*}{ High } & $\begin{array}{l}\text { Superficial } \\
\text { questions }\end{array}$ & 14 & 7.14 & 1.23 & 33.14 & 10.19 & 30.50 & 8.73 \\
\hline & $\begin{array}{l}\text { Elaborative } \\
\text { questions }\end{array}$ & 15 & 7.27 & 1.34 & 36.40 & 10.67 & 32.33 & 10.47 \\
\hline & $\begin{array}{l}\text { Superficial } \\
\text { questions }\end{array}$ & 18 & 7.00 & 1.37 & 27.39 & 10.72 & $23.00 *$ & 8.58 \\
\hline & $\begin{array}{l}\text { Elaborative } \\
\text { questions }\end{array}$ & 22 & 7.05 & 1.43 & 31.73 & 5.96 & $28.18 *$ & 6.99 \\
\hline
\end{tabular}

* Superficial vs. elaborative questions: $t(1,38)=2.11, p=.04, d=.67$

Exploring the results of the high and low ability students revealed that the former did not outperform the latter on the pretest, $t(1,67)=.56, p$ $=58, d=.14$. This indicates that both groups had no different entry levels of prior knowledge. High ability students had an average of 7.21 correct answers $(S D=1.26)$ and low ability participants an average of 7.03 correct answers $(S D=1.38)$. In contrast, the high ability students 
recalled significantly more from the study text $(M=34.83, S D=10.39)$ than the low ability students $(M=29.78, S D=8.60)$ on the immediate measure, $t(1,67)=2.21, p=.03, d=.54$. The former students also recalled more on the delayed measure $(M=31.45, S D=9.54)$ than the latter $(M=25.85, S D=8.08), t(1,67)=2.63, p=.01, d=.64$. Therefore, it seemed that the high ability students indeed had better capacities to learn the new information.

\section{Discussion}

Interpretation of findings

The present study aimed to study the effect of responding to a teacher's elaborative questions during a problem-based discussion on recall of subsequently studied information. The group process was controlled experimentally by simulating the discussion. A first hypothesis was that elaborative questioning would improve the recall of information that students processed after engaging in problem-based discussion, as compared to superficial questioning. A second hypothesis was that this effect would be larger for low than for high ability students. The results did not provide strong support for the first hypothesis, as the teacher's elaborative questions did not cause a significant improvement in recall. However, there was a trend in the predicted direction. The second hypothesis received more support, because the treatment seemed to have a larger effect for participants who needed multiple attempts to pass a pre-experimental MCQ test than for participants who needed only one attempt to pass this test. Moreover, this positive effect for the low ability students was significant on delayed recall.

Earlier studies have found that elaboration techniques are more effective for low than for high ability students (Hamilton, 1989; Mayer, 1980). These findings receive support by the present results, because the high ability students recalled more information from the text than the low ability students. At the same time, the pretest scores did not differ significantly between these two groups, suggesting that the entry level of prior knowledge was roughly equal across the two groups. This supports the assumption that participants with one attempt were better able to remember and recall the learning materials than those who needed multiple attempts. Moreover, the results may build on the limitations of an earlier PBL study (Budé et al., 2009). That study indicated that directive teacher questions during problem-based group discussion had a slightly positive impact on final achievement. However, the investigators acknowledged that their study was unable to detect achievement differences between high and low ability students. The present findings indicate that low ability students retain more knowledge over time when they are helped with elaborative questions during small group discussion than high ability students.

The fact that the treatment only affected the long-term recall of low ability students can be interpreted from the cognitive elaboration 
perspective on collaborative learning (O'Donnell, 2006; Slavin et al., 2003; Springer et al., 1999). Reder (1980) and Hamilton (2004) proposed that elaboration enriches the knowledge base because it encourages students to create additional connections between different concepts. This results in a 'redundant' knowledge base in which knowledge is retained over a longer period of time. From this point of view, the long-term effect for the low ability students may not be surprising. Dochy et al. (2003) reported that PBL students retained more knowledge over time than students from conventional curricula. Improved retention of knowledge in $\mathrm{PBL}$ might be in part explained by elaboration that occurs during a problem-based discussion (Schmidt, 1993). Moreover, long-term achievement effects have been found in other studies to collaborative learning as well. Asterhan and Schwarz (2007) found that improvements in conceptual understanding sustained over one week when students responded to elaborative questions by a fellow student. Responding to elaborative questions can cause elaboration because students will generate new relations and discover gaps in their own knowledge base (Nussbaum, 2008). The present results suggest that this might extend the retention period of knowledge.

\section{Limitations and future research}

A possible drawback of this experiment is that the experimental treatment was too short in order to be effective for all participants. The elaborative questions condition spent an average of 13 minutes and 9 seconds on the discussion. This may not have been long enough to yield a strong effect on recall. Classroom interventions often last for considerably longer periods of time, ranging from various weeks to several months (see e.g. King et al., 1998; Veenman en al., 2005). The longevity of these intervention programs may render them more effective (Nussbaum, 2008). The experimental approach used in this study cannot live up to these prolonged periods, but it may be worth extending the treatment in a future study.

A second potential flaw comes with the new methodology to study collaborative learning. Holding the quality of the group discussion equal across all research participants required a simulated discussion, which may have harmed the ecological validity of the study. One particular missing element was the interaction between research participants and other students. Interaction may be the most conducive element of collaboration, because it entails a process of co-construction, or a mutual understanding by building on each others' contributions in the discussion (Chi, 2009). The lack of co-construction raises the question if the present findings would apply in a real-world situation. On the one hand, it can be argued that co-construction is such an important factor that it cannot be left out when studying collaborative learning. On the other hand, it may be assumed that the mere act of explaining something to another student is also part of a natural group discussion. This is exactly what the present 
experiment aimed at. That is, it opted to test one of the many potential variables that affect learning during student collaboration. This variable was elaboration, as operationalized by providing explanations in response to elaborative questions. If researchers want to map the working ingredients of collaborative learning, they might want to use a microscopic approach in which independent variables are tested one by one. This is what the present experiment aimed at doing.

A third possible limitation is that the experimental treatment produced an unfair advantage for the participants who responded to the elaborative questions. The elaborative questions may have provided more directive guidance, aimed at relevant information in the study text, than the superficial questions. Although the asking of directive questions may be common practice in real-life, problem-based discussions, it might indeed lead to an unfair advantage from a researcher's perspective. Striking a good balance between a realistic learning environment and experimental control is one of the issues the new research method has to deal with. Future research could tilt more towards experimental control, e.g. by disassociating completely the relation between elaborative questions and self-study after the group discussion.

A future study could also take a closer look at the role of relevant prior knowledge before the group discussion. The present results suggest that the effectiveness of the elaboration treatment depended on students' ability level. Indeed, another factor that can have a substantial influence on final learning achievement is prior knowledge. Some research suggests that elaboration is more effective when students possess more background knowledge before entering an experiment (Willoughby et al., 1993; Woloshyn et al., 1992). Participation in a problem-based discussion may also be more effective when students have a basic level of relevant prior knowledge before the discussion. They can use this knowledge to discover new relations between concepts during the discussion. Prior knowledge could therefore be manipulated experimentally in a future experiment, in order to examine whether it moderates the effect of elaboration on recall or not.

\section{Implications for practice}

PBL teachers can help low ability students to recall more from their self-study by asking them elaborative questions during a problem-based discussion that precedes the phase of self-study. This means that the teacher should challenge especially poorer students to generate new connections with their prior knowledge. This may enable the students to construct a solid knowledge base with more interconnections. When the students encounter new ideas that align with their enriched knowledge base, they can remember these ideas for an extended period of time. It might also be an option to let the better students construct elaborative questions for the poorer students during the small group discussion. This way, the better students can learn how to identify the most essential 
connections within the learning materials. They can refer to these connections in their questions, which might for them be a good exercise to attain a deeper understanding of the materials. At the same time, they will aid the poorer students' learning process by letting the latter respond to their self-generated questions.

\section{References}

Albanese, M. A. (1993). Problem-based learning: A review of literature on its outcomes and implementation issues. Academic Medicine, 68(1), 52-81.

Asterhan, C. S. C., \& Schwarz, B. B. (2007). The effects of monological and dialogical argumentation on concept learning in evolutionary theory. Journal of Educational Psychology, 99(3), 626-639.

Bobrow, S. A., \& Bower, G. H. (1969). Comprehension and recall of sentences. Journal of Experimental Psychology, 80(3), 455-461.

Brown, A. L., \& Palincsar, A. S. (1989). Guided, cooperative learning and individual knowledge acquisition. In L. B. Resnick (Ed.), Knowing, learning, and instruction: Essays in honor of Robert Glaser (pp. 393-451). Hillsdale, NJ: Erlbaum.

Budé, L., Imbos, T., Van der Wiel, M., Broers, N., \& Berger, M. (2009). The effect of directive tutor guidance in problem-based learning of statistics on students' perceptions and achievement. Higher Education, 57(1), 23-36.

Chi, M. T. H. (2009). Active-constructive-interactive: A conceptual framework for differentiating learning activities. Topics in Cognitive Science, 1(1), 73-105.

Cohen, J. (1992). A power primer. Psychological Bulletin, 112(1), 155-159.

Colliver, J. A. (2000). Effectiveness of problem-based learning curricula: Research and theory. Academic Medicine, 75(3), 259-266.

Dansereau, D. F. (1988). Cooperative learning strategies. In C. E. Weinstein, E. T. Goetz \& P. A. Alexander (Eds.), Learning and study strategies: Issues in assessment, instruction, and evaluation (pp. 103-120). San Diego, CA: Academic Press.

De Grave, W. S., Dolmans, D. H. J. M., \& Van der Vleuten, C. P. M. (1999). Profiles of effective tutors in problem-based learning: Scaffolding student learning. Medical Education, 33(12), 901-906.

De Grave, W. S., Schmidt, H. G., \& Boshuizen, H. P. A. (2001). Effects of problembased discussion on studying a subsequent text: $A$ randomized trial among first year medical students. Instructional Science, 29(1), 33-44.

Dochy, F., Segers, M., Van den Bossche, P., \& Gijbels, D. (2003). Effects of problem-based learning: A meta-analysis. Learning and Instruction, 13(5), 533-568.

Dolmans, D. H. J. M., Gijselaers, W. H., Moust, J. H. C., De Grave, W. S., Wolfhagen, I. H. A. P., \& Van der Vleuten, C. P. M. (2002). Trends in research on the tutor in problem-based learning: Conclusions and implications for educational practice and research. Medical Teacher, 24(2), 173-180.

Fuchs, L. S., Fuchs, D., Hamlett, C. L., \& Karns, K. (1998). High-achieving students' interactions and achievement on complex mathematical tasks as a function of homogeneous and heterogeneous pairings. American Educational Research Journal, 35(2), 227-267.

Hamilton, R. J. (1989). The effects of learner-generated elaborations on concept learning from prose. The Journal of Experimental Education, 57(3), 205-217.

Hamilton, R. J. (2004). Material appropriate processing and elaboration: The impact of balanced and complementary types of processing on learning concepts from text. British Journal of Educational Psychology, 74(2), 221-237.

Johnsey, A., Morrison, G. R., \& Ross, S. M. (1992). Using elaboration strategies training in computer-based instruction to promote generative learning. Contemporary Educational Psychology, 17(2), 125-135. 
King, A. (2007). Beyond literal comprehension: A strategy to promote deep understanding of text. In D. S. McNamara (Ed.), Reading comprehension strategies: Theories, interventions, and technologies (pp. 267-290). Mahwah, NJ: Erlbaum.

King, A., Staffieri, A., \& Adelgais, A. (1998). Mutual peer tutoring: Effects of structuring tutorial interaction to scaffold peer learning. Journal of Educational Psychology, 90(1), 134-152.

Krol, K., Janssen, J., Veenman, S., \& Van der Linden, J. (2004). Effects of a cooperative learning program on the elaborations of students working in dyads. Educational Research and Evaluation, 10(3), 205-237.

Lee, G.-H., Lin, Y.-H., Tsou, K.-I., Shiau, S.-J., \& Lin, C.-S. (2009). When a problem-based learning tutor decides to intervene. Academic Medicine, 84(10), 1406-1410.

Lloyd, J., Margetson, D., \& Bligh, J. G. (1998). Problem-based learning: A coat of many colours. Medical Education, 32(5), 492-494.

Mayer, R. E. (1980). Elaboration techniques that increase the meaningfulness of technical text: An experimental test of the learning strategy hypothesis. Journal of Educational Psychology, 72(6), 770-784.

Mayer, R. E. (1985). Structural analysis of science prose: Can we increase problemsolving achievement? In B. K. Britton \& J. B. Black (Eds.), Understanding expository text: A theoretical and practical handbook for analyzing explanatory text. Hillsdale, NJ: Erlbaum.

Mercer, N., \& Sams, C. (2006). Teaching children how to use language to solve maths problems. Language and Education, 20(6), 507-528.

Neville, A. J. (1999). The problem-based learning tutor: Teacher? Facilitator? Evaluator? Medical Teacher, 21(4), 393-401.

Nussbaum, E. M. (2008). Collaborative discourse, argumentation, and learning: Preface and literature review. Contemporary Educational Psychology, 33, 345359.

O'Donnell, A. M. (2006). The role of peers and group learning. In P. H. Winne \& P. A. Alexander (Eds.), Handbook of educational psychology (pp. 781-802). Mahwah, NJ: Erlbaum.

Pressley, M., Symons, S., McDaniel, M. A., Snyder, B. L., \& Turnure, J. E. (1988). Elaborative interrogation facilitates acquisition of confusing facts. Journal of Educational Psychology, 80(3), 268-278.

Pressley, M., Tanenbaum, R., McDaniel, M. A., \& Wood, E. (1990). What happens when university students try to answer prequestions that accompany textbook material? Contemporary Educational Psychology, 15(1), 27-35.

Pressley, M., Wood, E., Woloshyn, V. E., Martin, V., King, A., \& Menke, D. (1992). Encouraging mindful use of prior knowledge: Attempting to construct explanatory answers facilitates learning. Educational Psychologist, 27(1), 91109.

Reder, L. M. (1980). The role of elaboration in the comprehension and retention of prose: A critical review. Review of Educational Research, 50(1), 5-53.

Rosenshine, B., Meister, C., \& Chapman, S. (1996). Teaching students to generate questions: A review of the intervention studies. Review of Educational Research, 66(2), 181-221.

Schmidt, H. G. (1984). Activatie van voorkennis en tekstverwerking / Activation of prior knowledge and text processing. Nederlands Tijdschrift voor de Psychologie en haar Grensgebieden, 39(6), 335-347.

Schmidt, H. G. (1993). Foundation of problem-based learning: Some explanatory notes. Medical Education, 27(5), 422-432.

Schmidt, H. G., De Volder, M. L., De Grave, W. S., Moust, J. H. C., \& Patel, V. L. (1989). Explanatory models in the processing of science text: The role of prior knowledge activation through small group discussion. Journal of Educational Psychology, 81(4), 610-619.

Schmidt, H. G., Van der Molen, H. T., Te Winkel, W. W. R., \& Wijnen, W. H. F. W. (2009). Constructivist, problem-based learning does work: A meta-analysis of 
curricular comparisons involving a single medical school. Educational Psychologist, 44(4), 227-249.

Slamecka, N. J., \& Graf, P. (1978). The generation effect: Delineation of a phenomenon. Journal of Experimental Psychology: Human Learning and Memory, 4(6), 592-604.

Slavin, R. E., Hurley, E. A., \& Chamberlain, A. (2003). Cooperative learning and achievement: Theory and research. In G. E. Miller \& W. M. Reynolds (Eds.), Handbook of psychology: Educational psychology (Vol. 7, pp. 177-198). Hoboken, NJ: John Wiley \& Sons.

Springer, L., Stanne, M. E., \& Donovan, S. S. (1999). Effects of small group learning on undergraduates in science, mathematics, engineering, and technology: A meta-analysis. Review of Educational Research, 69(1), 21-51.

Strijbos, J.-W., Martens, R. L., Prins, F. J., \& Jochems, W. M. G. (2006). Content analysis: What are they talking about? Computers \& Education, 46(1), 29-48.

Van Boxtel, C., Van der Linden, J., \& Kanselaar, G. (2000). Collaborative learning tasks and the elaboration of conceptual knowledge. Learning and Instruction, $10,311-330$.

Veenman, S., Denessen, E., Van den Akker, A., \& Van der Rijt, J. (2005). Effects of a cooperative learning program on the elaborations of students during help seeking and help giving. American Educational Research Journal, 42(1), 115151.

Vernon, D. T., \& Blake, R. L. (1993). Does problem-based learning work? A metaanalysis of evaluative research. Academic Medicine, 68(7), 550-563.

Webb, N. M. (1989). Peer interaction and learning in small groups. International Journal of Educational Research, 13(1), 21-39.

Webb, N. M., \& Farivar, S. (1999). Developing productive group interaction in middle school mathematics. In A. M. O'Donnell \& A. King (Eds.), Cognitive perspectives on peer learning (pp. 117-149). Mahwah, NJ: Erlbaum.

Webb, N. M., Franke, M. L., Ing, M., Chan, A., De, T., Freund, D., et al. (2008). The role of teacher instructional practices in student collaboration. Contemporary Educational Psychology, 33(3), 360-381.

Webb, N. M., Nemer, K. M., Chizhik, A. W., \& Sugrue, B. (1998). Equity issues in collaborative group assessment: Group composition and achievement. American Educational Research Journal, 35(4), 607-651.

Wilkerson, L. (1994). Identification of skills for the problem-based tutor: Student and faculty perspectives. Instructional Science, 22(4), 303-315.

Willoughby, T., Waller, T. G., Wood, E., \& MacKinnon, G. E. (1993). The effect of prior knowledge on an immediate and delayed associative learning task following elaborative interrogation. Contemporary Educational Psychology, 18(1), 36-46.

Wittrock, M. C. (1992). Generative learning processes of the brain. Educational Psychologist, 27(4), 531-541.

Woloshyn, V. E., Pressley, M., \& Schneider, W. (1992). Elaborative-interrogation and prior-knowledge effects on learning of facts. Journal of Educational Psychology, 84(1), 115-124. 


\section{Chapter 5}

\section{Relevant prior knowledge moderates the effect of elaboration during small group discussion on academic achievement ${ }^{4}$}

This study set out to test whether relevant prior knowledge would moderate a positive effect of elaboration during small discussion on academic achievement. In a $2 \times 2$ experimental design, 66 undergraduate students observed a video showing a small group, problem-based discussion about thunder and lightning. In the video, a teacher asked questions to the observing participant. Participants either elaborated by responding to these questions, or did not elaborate, but completed a distraction task after each question. They received either relevant or irrelevant prior knowledge before the discussion. After the discussion, all participants studied a text about thunder and lighting and completed immediate and delayed recall tests for this text. Elaboration had no main effect on recall, but there was a significant interaction effect between relevant prior knowledge and elaboration. The results suggest that elaboration is helpful for students with more prior knowledge, but harmful for students with less prior knowledge.

\footnotetext{
${ }^{4}$ Van Blankenstein, F.M., Dolmans, D.H.J.M., Van der Vleuten, C.P.M., \& Schmidt, H.G. Relevant prior knowledge moderates the effect of elaboration during small group discussion on academic achievement. Under editorial review.
} 


\section{Introduction}

Collaborative learning is widely applied in education, but still little is known about the cognitive processes that make collaborative learning successful. This is caused by the complexity of collaborative settings, in which many factors can influence learning. This study focused on a specific instructional format, problem-based learning (PBL), and used a controlled, experimental design in order to reduce the number of confounders to final learning outcomes. The first aim was to examine the effect of elaboration during small group discussion on the recall of information studied after the discussion. The second aim was to evaluate relevant prior knowledge as a moderator for the effect of elaboration on recall.

\section{Cognitive elaboration in collaborative learning}

Cognitive theories for collaborative learning stress the importance of cognitive elaboration (O'Donnell, 2006; Slavin et al., 2003). Collaboration can stimulate elaboration because students process information more deeply when they interact with each other. Elaboration can be defined as the generation of meaningful new relations between prior knowledge, or between prior knowledge and new information (Wittrock, 1992). A theoretical expectation is that it leads to an enriched knowledge base with more interconnections. Inside this enriched knowledge base, information should be retained better (Hamilton, 2004; Reder, 1980).

Research has indeed shown that students remember more information from textual materials when they use elaboration techniques during selfstudy (Dansereau et al., 1979; Mayer, 1980; Pressley, McDaniel, Turnure, Wood, \& Ahmad, 1987; Pressley et al., 1988). For example, they have been instructed to verbally summarize a text and detect errors and omissions in each other's summary (Larson et al., 1985; McDonald et al., 1985; O'Donnell, 1996; O'Donnell et al., 1985; Rewey et al., 1989; Spurlin et al., 1984). This usually promoted recall of the studied information, especially for those who summarized the text (Spurlin et al., 1984). Students can thus elaborate during collaboration by explaining some learning materials to other students (Slavin et al., 2003). Research has shown that the frequency of elaborative explanation during small group discussion correlates positively with learning achievement (Van Boxtel et al., 2000; Webb, 1989; Webb et al., 2008). According to some, explanation to others challenges the explainer to generate new relations and form new perspectives (Bargh \& Schul, 1980). The explainer may detect gaps in his own knowledge and use explanation to fill in these gaps (Webb et al., 1995). In other words, explanation to others can provoke elaboration.

\section{Cognitive elaboration in problem-based learning}

PBL is a collaborative learning format that comes in many forms (Lloyd et al., 1998). The present experiment adopted the definitions of PBL by 
Schmidt, Van der Molen, Te Winkel \& Wijnen (2009). These authors describe PBL as a process in which students try to explain several phenomena that belong to a real-world scenario (i.e. the problem). The group discussion forms the basis of subsequent self-study. After this selfstudy, students gather again to report their findings. In other words, a learning cycle starts with a problem-based discussion and ends with a reporting phase after self-study (also see Hmelo-Silver, 2004).

During the problem-based discussion, students can activate their prior knowledge, reason together, build theories and experience cognitive conflict (Dolmans \& Schmidt, 2006). Research has shown that a problembased discussion can improve the recall of a text studied after the discussion (De Grave et al., 2001; Schmidt, 1984; Schmidt et al., 1989). Schmidt et al. (1989) let students discuss a problem that described why a blood cell swells in pure water and shrinks in salt. After the discussion, they individually studied a text about osmosis and diffusion, which explained the underlying mechanisms for the phenomena in the blood cell problem. In a control group, students discussed a problem about a different topic and then read the osmosis and diffusion text. Students who discussed the blood cell problem recalled more information from the text than students who discussed the problem about the different topic.

Although a problem-based discussion seems to be able to improve recall, it is not clear which cognitive activities are responsible for this effect. Considering the already mentioned findings from collaborative learning, one would expect that elaboration (by explanation to others) is an important activity that fosters learning during the discussion. Some studies signify that PBL students retain more knowledge over time than students in lecture-based programs (Capon \& Kuhn, 2004; Dochy et al., 2003; Eisenstaedt, Barry, \& Glanz, 1990; Tans, Schmidt, SchadeHoogeveen, \& Gijselaers, 1986). This might point out that PBL indeed promotes elaboration, because elaboration should lead to an increase in deep processing and therefore improve the retention of knowledge (Reder, 1980). However, one study reported that there was no positive correlation between the number of explanations students generated during a problem-based discussion and their recall from subsequent self-study (Moust et al., 1987). More empirical data is thus needed to support the hypothesis that elaboration during problem-based discussion promotes achievement. The present experiment set out to do this, by testing the effect of elaboration during the problem-based discussion on recall of information studied after the discussion.

\section{The interaction between prior knowledge and elaboration}

Prior knowledge seems to guide what students recall from new information. This can be illustrated by experiments in which students activated relevant prior knowledge before self-study (Machiels-Bongaerts et al., 1995; Peeck, 1982; Pressley et al., 1990; Wetzels et al., 2011). Machiels Bongaerts et al. let students activate prior knowledge about a 
fishery policy of the European Union and then presented them with a text about this policy. The text also contained information that was related to the policy (i.e. increased unemployment due to the policy and alternative income sources) and information that was unrelated to the policy. A control group activated information about an irrelevant topic. Students who activated prior knowledge about the policy recalled more information from the text than the control group. More specifically, they did not only recall more about the policy, but also about the related information. Prior knowledge activation thus seemed to improve the recall of information from the text. In addition, it especially improved the recall of information that either corresponded with, or was related to, the activated prior knowledge.

Likewise, Wetzels et al. (2011) found that prior knowledge activation improved achievement on learning tasks that were related to the activated prior knowledge. The investigators proposed that prior knowledge activation served a 'stage-setting function'. The activated prior knowledge 'set the stage' for new learning and therefore improved the learning of new information that was related to the activated knowledge. A problembased discussion might serve a similar stage setting function. Schmidt et al. (1989) proposed that problem-based discussion leads to a shared mental model of the problem, which will facilitate the study of new information that relates to the problem.

Prior knowledge has also shown to moderate the positive effect of elaboration on the learning of facts (Willoughby et al., 1993; Woloshyn et al., 1992). That is, students who elaborated on facts, by generating a reason why they were true, recalled more of these facts when they had more prior knowledge.

Since problem-based discussions allow students to activate and elaborate on their prior knowledge (Schmidt, 1993), it may be worth to study elaboration in combination with higher or lower amounts of prior knowledge. In some versions of $\mathrm{PBL}$, students receive a limited amount of knowledge at the start of the group meeting, just before the problembased discussion commences (Hmelo-Silver \& Barrows, 2008). The present experiment followed this example, by providing research participants with a limited amount of information before they entered a small group discussion.

\section{Problems with research to collaborative learning}

Research to small group learning has to deal with the problem that group processes are highly dynamic and therefore create many variables that potentially affect learning outcomes. Since experimental interventions often take place at the group level, it is difficult to determine which specific cognitive processes promote achievement. For example, the amount of elaboration during a group discussion may depend on the cognitive ability level of individual group members (Webb et al., 1998). From a research perspective, it might be valuable to rule out these 
random influences from the group on learning. This will allow investigators to study independent variables more precisely, without confounding variables that create experimental noise. It seems that the group process must be standardized in order to accomplish this. The present experiment aimed at doing this by creating a video recording of a problem-based discussion, which was supervised by a teacher. This video was shown to individual research participants in a psychological laboratory. This new method facilitated the testing of independent variables, while omitting other influences from the group's process. More about this will follow in the method section.

\section{Summary and hypotheses}

In sum, collaborative learning needs more empirical evidence for the hypothesis that elaboration is responsible for improved academic achievement. Elaboration may be moderated by the amount of prior knowledge students have before they enter a small group discussion. A problem is that complex group processes produce many potential influences on final learning outcomes. This makes it difficult to study the interaction between elaboration and prior knowledge independent from other factors. Therefore, the current experiment ensured that all research participants were exposed to the same small group discussion. For this purpose, a video recording of the discussion was made and presented to the participants. There were two hypotheses. First of all, elaboration during the group discussion was expected to improve the recall of information that participants studied after the discussion. The second hypothesis was that elaboration would lead to higher recall when participants received relevant prior knowledge before the group discussion. In other words, the second hypothesis was an interaction effect between prior knowledge and elaboration.

\section{Method}

Participants

Participants were 66 undergraduate students who had chosen a secondary school learning trajectory that focused on the social sciences. In the Netherlands, students progress through secondary school from age 12 up till 18. Part of them completes a curriculum that prepares them for university education. Within this curriculum, they can choose between four tracks. Two of these are science-oriented and the other two focus on the social sciences. Only participants with backgrounds in the social sciences were selected, because they presumably had less prior knowledge about the study topic, which was science-oriented. They came from study programs in law (46), economics and business administration (7), psychology (5), health sciences (2), art (1) and art and social sciences (1). Their mean age was $20.93(S D=2.22)$. They were selected with advertisements and by active recruitment. All participants were familiar with PBL and received a financial compensation for their participation. 


\section{Materials}

Study materials and tests. Twenty-one sentences were written about thunder and lightning and 21 sentences about seismographic activity. The sentences about thunder and lightning were presented to half of the participants as relevant prior knowledge for a problem-based group discussion. The sentences about seismographic activity were not relevant for the discussion and presented to the other half of the participants. Two sentence-completion tests were devised, one for the thunder and lightning sentences and one for the seismographic activity sentences. These tests presented the sentences in random order, each sentence lacking one or several key words. Participants had to fill in these missing words. The sentences about thunder and lightning are presented at the end of Appendix B. Words that participants had to fill in during the sentence completion test are underlined.

A problem from a PBL teacher training program was adopted for the small group discussion. The problem described a thunder and lightning storm during a warm summer day in 102 words. It contained several phenomena that were related to thunder and lightning, such as warm temperatures, thunderclouds and rain drops.

A study text about thunder and lightning was written, which provided relevant new information about the problem. This text was offered after the small group discussion and explained in 1104 words how lightning is created and what a person should do during a thunder storm. For example, one paragraph elaborated on the first, second and third thunder and lightning sentence, which stated that (1) thunderclouds are very high; (2) warm air from the south of France enters the Netherlands during the summer; and (3) the atmosphere contains warm and cold air currents. Below is an excerpt from this paragraph, which elaborates on the three sentences by describing one situation in which air currents lead to thunder storms.

Ten open-ended questions were devised to test how much information participants recalled from the study text. These questions were used for an immediate and a delayed posttest. Below is an example of one of the posttest questions:

Describe the two situations in which air currents cause thunder and lightning during the summer.

Small group discussion. A video of a small group discussion was recorded with a Sony DCR VX2000e video camera in a room where PBL group meetings were usually held. In the video, four students discussed the problem about thunder and lightning. The students tackled various issues related to thunder and lightning, as exemplified in one dialogue between two of the four students:

S: What I don't understand, is how this thundercloud-thing works. 
J: I am not telling you I fully understand this, but... I think there is

a difference in electrical charge inside a cloud... Right? [Looks puzzled to the others.]

During the recording session, eight scenes with a teacher were shot as well. The teacher asked questions into the camera, so to the observer of the video. These questions encouraged the observer to explain the complex process of thunder and lightning, using the phenomena in the problem. They were specifically designed to relate concepts from the thunder and lightning sentences with each other and the problem. Furthermore, they always followed a part of the discussion that led up to the question. So for example, the abovementioned part of the discussion was followed by this question by the teacher:

In a cloud, there are many currents of air. The cloud also contains water drops and hail stones. But what happens then? How can a difference in electrical charge come about within a cloud?

In this example, the teacher first referred back to the third and sixth sentence about thunder and lightning, which stated that (1) warm and cold air currents take place in the atmosphere; and (2) a thundercloud contains water drops and hail stones. She then asked to relate these two principles with electrical charges inside a cloud, which relates to sentences 4 ("a difference in electrical charge within a thundercloud causes lightning") and 5 ("the thundercloud is charged positively at the top and negatively at the bottom"). In other words, the question stimulated the generation of new relations between prior knowledge from the sentences.

\section{Procedure}

Figure 1 shows a flowchart of the procedure. The experiment used a 2 $x 2$ design with elaboration (yes/no) and relevant prior knowledge (yes/no) as independent variables. Participants were randomly assigned to cubicles inside a research lab. Each cubicle contained a 19 inch flat screen, at a reading distance of approximately $70 \mathrm{~cm}$, showing one of the four experimental treatments. Headphones were provided for each participant. Before they entered the research lab, we explained to participants that this was a study to PBL in which they would be exposed to a PBL simulation. All further instructions were given on the screen.

Participants in the elaboration with prior knowledge condition $(n=19)$ studied the thunder and lightning sentences and answered the teacher's elaborative questions during the discussion. Their instructions were that they would participate in a problem-based discussion. During the discussion, a teacher would ask them some questions. They could use information from the sentences and their own ideas to answer these questions. Specifically, the instructions for answering the questions were: (1) write the first thing that comes to mind; (2) write as much as you can 
come up with; (3) write as many new ideas as possible; (4) keep writing until you can think of no more ideas; (5) write whole sentences; (6) do not revise your writings.

Figure 1. Flowchart of the experimental procedure

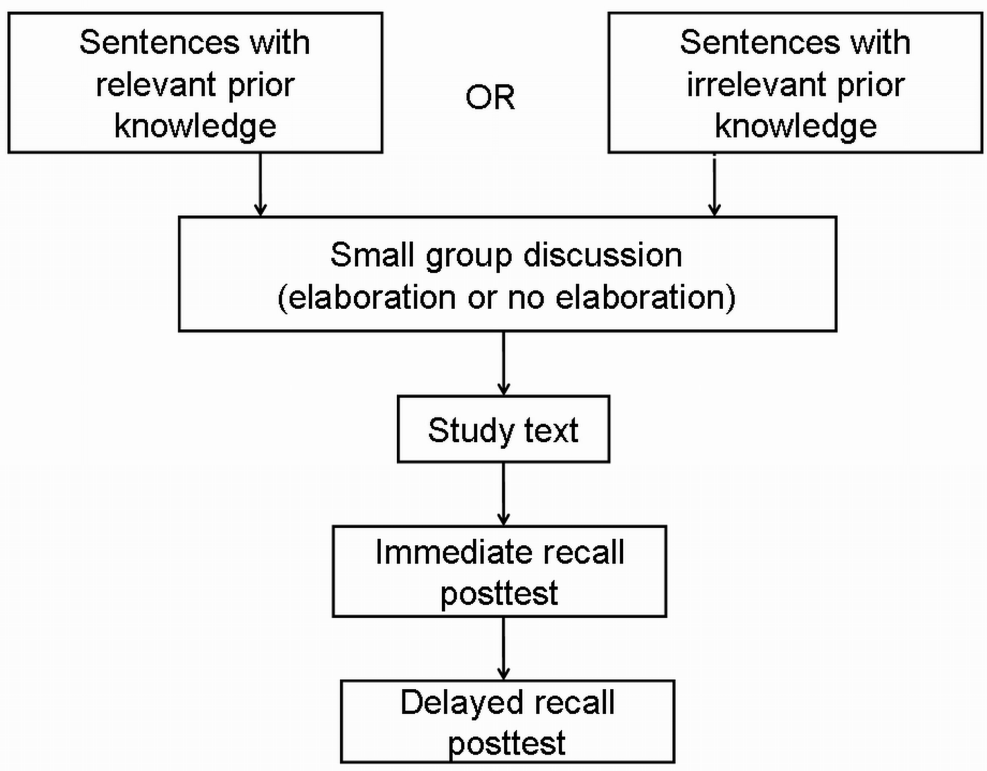

Participants in the elaboration with prior knowledge condition were also told that they would be introduced to the group first and practice the answering of questions. Upon receiving the instructions, they read each sentence at their own pace. They could continue to a next sentence by hitting the spacebar button. After the last sentence, they completed the sentence-completion test. They then observed the introductory scene, which introduced the students and the teacher by name. Following this, they practiced the procedure by watching a short discussion about an irrelevant subject (i.e. why water comes out of a tap) and answering a question by the teacher about this topic.

Subsequently, the problem appeared on the screen for one minute and the discussion started. After each question, a blank screen with a text field appeared. Participants could type their answer in this text field and continue with the discussion by clicking a button on the screen. They spent an average of 1311.63 seconds $(S D=438.35)$, or 21 minutes and 51.63 seconds on this task. After the discussion, the study text appeared on the screen for 15 minutes. Participants studied this text and were told beforehand that a test would follow after 15 minutes. A time bar at the top of the screen indicated how much time was left. After this period, the ten open-ended questions appeared on the screen and participants completed these as the immediate posttest. Three weeks later, they 
returned to the research lab and completed these questions again as the delayed posttest.

In the elaboration without prior knowledge condition $(n=18)$, participants followed the same procedure as in the elaboration with prior knowledge condition, but this time they read the 21 sentences and completed the sentence-completion test about seismographic activity. Contrary to the procedure in the elaboration with prior knowledge condition, they were not told that information from the sentences was needed to answer questions by a teacher. Thus, participants who elaborated without prior knowledge did not receive the relevant prior knowledge, but did elaborate by answering the teacher's questions. They spent an average of 1225.61 seconds $(S D=674.31)$, or 20 minutes and 25.61 seconds on the discussion.

In the no elaboration with prior knowledge condition $(n=14)$, participants followed the same procedure as in the elaboration with prior knowledge condition, but this time they received a distraction task after each question by the teacher. These tasks were games of tetris. So while the elaboration with prior knowledge condition elaborated by answering the teacher's questions, the no elaboration with prior knowledge condition played tetris during these intervals. Distraction tasks were use because there are indications that students elaborate considerably without voicing their thoughts during problem-based discussions (De Grave et al., 1996). The distraction tasks were thus included to prevent silent elaboration. The time spent on the discussion was based on the average time spent by the elaboration with prior knowledge condition (21 minutes and 51.63 seconds).

Since both conditions received the relevant prior knowledge about thunder and lightning, it was checked whether both groups had the same level of prior knowledge. A t-test did not show a significant difference in number of errors on the sentence-completion test, $t(1,33)=.71, p=$ .48 .

In the no elaboration without prior knowledge condition ( $n=15)$, participants performed the same tasks as in the elaboration without prior knowledge condition, but they also received the distraction tasks instead of answering the teacher's questions. Therefore, they neither received relevant prior knowledge, nor did they elaborate during the discussion. Their time spent on the discussion was based on the average time spent by the elaboration without prior knowledge condition (20 minutes and 25.61 seconds).

\section{Analyses}

The posttest results were segmented into idea units (Mayer, 1985). Two coders, unaware of each participant's experimental treatment, performed this activity. An idea unit typically describes one action or event and was defined as a unit that contained one subject-verb clause. Both coders initially segmented the results of two randomly selected 
participants. The inter-rater reliability was calculated from the perspective of coder 1 , who segmented the smallest total number of idea units. The number of agreements between coder 1 and 2 was divided by this total number, resulting in an agreement percentage of $86.82 \%$. Differences were discussed until consensus was reached. Thereafter, both coders independently segmented the remaining posttest results.

In order to determine how much was remembered from the text, the idea units from the posttest results were matched with idea units from the study text. Therefore, coder 1 segmented the study text in idea units and numbered each unit. Then, coder 1 discussed the applicability of the resulting segmented text with coder 2 . This resulted in some changes in the segmented text, which was subsequently used as an answer key for scoring the test results. The segmented results were coded with MEPA (Multiple Episode Protocol Analysis) by looking for matches between idea units from the posttests and the study text. Each match was assigned the number of the idea unit from the study text and awarded one point. Points were added up to create a total score for each participant. The inter-coder reliability was calculated in MEPA with Cohen's Kappa $(\kappa)$. Values under .40 signify a poor, values between .40 and .75 an intermediate to good, and values above .75 an excellent reliability. For this purpose, each coder matched the idea units from two randomly selected results (one immediate and one delayed posttest result) with the idea units from the study text. On a first try, $\kappa$ was .54 , whereupon the two coders discussed their differences. On a next try, with two new randomly selected test results (one immediate and one delayed posttest result), $\kappa$ reached .75 , a value that balanced between good and excellent reliability. This reliability was regarded sufficient and therefore coder 1 and 2 independently scored the remaining results.

The final results of the immediate and delayed posttest were analyzed in SPSS 15.0 with analysis of variance (ANOVA), including elaboration (yes/no) and relevant prior knowledge (yes/no) as independent variables. The measure for the effect size was $\eta^{2}$. For $\eta^{2}$, the indication for a small effect is .01, for a medium effect .06, and for a large effect .14 (Cohen, 1988). The ANOVA included pairwise comparisons with Bonferroni correction in order to identify specific between-group differences.

\section{Results}

Figure 2 depicts the scores on the immediate and delayed posttests. The means and standard deviations of the immediate posttest are reported in Table 1 . On the immediate posttest, neither elaboration, $F(1$, 62 ) $=2.36, p=.13, \eta^{2}=.04$ (small effect), nor prior knowledge, $F(1,62$ ) $=1.81, p=.18, \eta^{2}=.03$ (small effect), had a significant effect on recall. However, the interaction between elaboration and prior knowledge approached significance, $F(1,62)=3.79, p=.06, \eta^{2}=.06$ (medium effect). The pairwise comparisons demonstrated that participants who elaborated with prior knowledge recalled significantly more from the study 
text $(M=37.79, S D=10.44)$ than participants who elaborated without prior knowledge $(M=27.39, S D=15.92), p=.02$. Pairwise comparisons also revealed that no elaboration without prior knowledge actually led to higher recall $(M=38.40, S D=11.48)$ than elaboration without prior knowledge $(M=27.39, S D=15.92), p=.02$. Elaboration with prior knowledge $(M=37.79, S D=10.44)$ did not improve recall compared to no elaboration with prior knowledge $(M=36.50, S D=12.19), p=.78$.

Figure 2. Mean number of recalled idea units on the immediate and delayed posttest

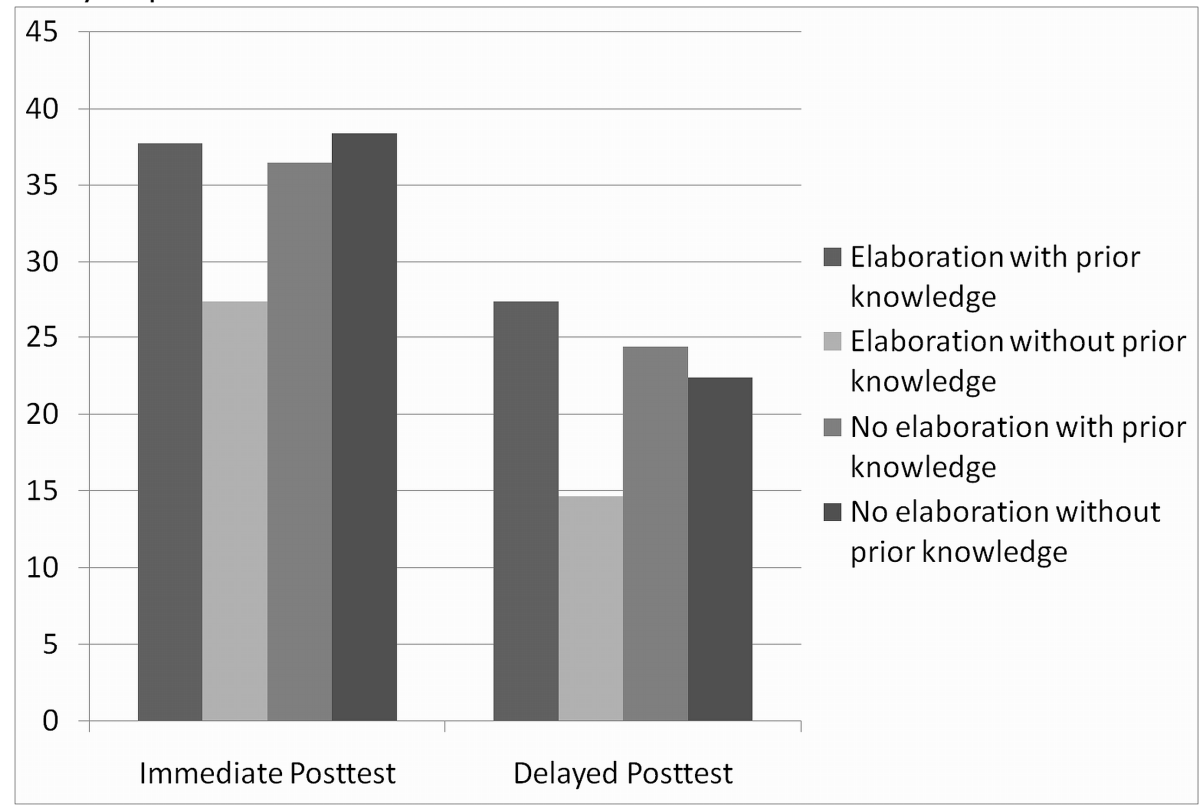

The results of the delayed posttest can be found in Table 2 . These results again did not reveal an effect by elaboration, $F(1,62)=.69, p=$ $.41, \eta^{2}=.01$ (small effect). In contrast, prior knowledge did have an effect on the delayed results, $F(1,62)=7.07, p=.01, \eta^{2}=.10$ (medium effect). Furthermore, the interaction between elaboration and prior knowledge was significant, $F(1,62)=4.00, p=.05, \eta^{2}=.06$ (medium effect). Again, the elaboration with prior knowledge condition recalled significantly more $(M=27.42, S D=9.23)$ than the elaboration without prior knowledge condition $(M=14.61 S D=11.91), p=.01$. Also, no elaboration without prior knowledge once more led to higher recall scores $(M=22.40, S D=11.30)$ than elaboration without prior knowledge $(M=$ $14.61, S D=11.91), p=.04$. And finally, elaboration with prior knowledge $(M=27.42, S D=9.23)$ was not more effective than no elaboration with prior knowledge $(M=24.40, S D=11.30), p=42$. 
Table 1. Mean number of recalled idea units on immediate posttest

\begin{tabular}{|c|c|c|c|c|c|c|c|c|c|}
\hline \multirow{2}{*}{$\begin{array}{l}\text { Relevant } \\
\text { prior } \\
\text { knowledge }\end{array}$} & \multicolumn{9}{|c|}{ Elaboration } \\
\hline & \multicolumn{3}{|c|}{ Yes } & \multicolumn{3}{|c|}{ No } & \multicolumn{3}{|c|}{ Total } \\
\hline & $M$ & $S D$ & $n$ & $M$ & $S D$ & $n$ & $M$ & $S D$ & $n$ \\
\hline Yes & 37.79 & 10.44 & 19 & 36.50 & 12.19 & 14 & 37.24 & 11.05 & 33 \\
\hline No & 27.39 & 15.92 & 18 & 38.40 & 11.48 & 15 & 32.39 & 14.94 & 33 \\
\hline Total & 32.73 & 14.21 & 37 & 37.48 & 11.65 & 29 & 34.82 & 13.26 & 66 \\
\hline
\end{tabular}

Elaboration vs. no elaboration: $F(1,62)=2.36, p=.13, \eta^{2}=.04$

Prior Knowledge $*$ elaboration: $F(1,62)=3.79, p=.06, \eta^{2}=.06$

Table 2. Mean number of recalled idea units on delayed posttest

\begin{tabular}{|c|c|c|c|c|c|c|c|c|c|}
\hline \multirow{2}{*}{$\begin{array}{l}\text { Relevant } \\
\text { prior } \\
\text { knowledge }\end{array}$} & \multicolumn{9}{|c|}{ Elaboration } \\
\hline & \multicolumn{3}{|c|}{ Yes } & \multicolumn{3}{|c|}{ No } & \multicolumn{3}{|c|}{ Total } \\
\hline & $M$ & $S D$ & $n$ & $M$ & $S D$ & $n$ & $M$ & $S D$ & $n$ \\
\hline Yes & 27.42 & 9.23 & 19 & 24.40 & 11.30 & 14 & 26.06 & 10.46 & 33 \\
\hline No & 14.61 & 11.91 & 18 & 22.40 & 11.30 & 15 & 18.15 & 12.11 & 33 \\
\hline Total & 21.19 & 12.32 & 37 & 23.28 & 11.49 & 29 & 22.11 & 11.91 & 66 \\
\hline
\end{tabular}

Elaboration vs. no elaboration: $F(1,62)=.69, p=.41, \eta^{2}=.01$

Prior knowledge $*$ elaboration: $F(1,62)=4.00, p=.05, \eta^{2}=.06$

\section{Discussion}

Interpretation of the findings

This experiment looked whether elaboration during a problem-based discussion would improve recall from self-study after the discussion. In addition, the moderating influence of prior knowledge on elaboration was examined. There were two hypotheses. First of all, elaboration was expected to increase recall. The second hypothesis was that prior knowledge would moderate the effect of elaboration on recall, leading to higher recall scores when relevant prior knowledge was present.

The first hypothesis did not receive support by the data. This seems to be in line with scant evidence from PBL studies. Moust and colleagues (1987) found no positive correlation between the amount of elaborative explanation during a problem-based discussion and recall from subsequent self-study. Unfortunately, this study did not test a causal relationship between explanation and recall. This also accounts for other reported correlations, which do however tend to show a positive relation between elaborative explanation and achievement (Van Boxtel et al., 2000; Webb, 1989; Webb et al., 2008). Some more evidence for a causal relationship between explanation and recall comes from an experiment that showed a positive effect of explaining over listening on recall of textual information (Spurlin et al., 1984). That is, students who verbally summarized a text recalled more from this text than students who 
listened to the verbal summaries. This suggests that the act of explaining during collaborative discussion fosters achievement. Why then did it not improve recall in the current experiment?

It is possible that a problem-based discussion creates fewer opportunities for content relevant explanations than other forms of collaboration. What many forms of collaboration have in common, is that the discussion follows or coincides with the acquisition of relevant new information (Dansereau, 1988; King et al., 1998; Webb \& Farivar, 1999). Problem-based discussion seems to diverge from this path, as it precedes the acquisition of most relevant prior knowledge. As explained by Schmidt et al. (2009) and Hmelo-Silver (2004), the discussion of the problem forms the basis of new learning. This learning can take place through individual self-study that students perform after the discussion. Hence, they will find most of the new information after they have been discussing the problem. The question is whether a problem-based discussion is focused on relevant knowledge to the same degree as a discussion that succeeds the acquisition of relevant new information. The reporting phase in PBL is such a discussion. During the reporting phase, students report their findings from self-study to each other. This may be a more adequate moment to stimulate elaboration, because students then have already obtained more relevant knowledge about the problem. Therefore, their explanations could be more focused on relevant information, which might help them to remember it better.

The second hypothesis received support by the findings, because elaboration had a larger effect on recall when participants had relevant prior knowledge before the discussion than when they had no relevant prior knowledge. This is in line with findings from earlier experiments (Willoughby et al., 1993; Woloshyn et al., 1992), which showed elaboration to be more effective when students possessed more relevant prior knowledge about the subject. However, participants without relevant prior knowledge also attained higher recall scores when they did not elaborate than when they elaborated. In addition, elaboration with prior knowledge was not more effective than no elaboration with prior knowledge. This suggests that elaboration with relevant prior knowledge did not improve recall as much as elaboration without prior knowledge impeded it.

What could be an explanation for this? It is possible that the prior knowledge provided before the experiment guided participant's answers to the teacher's questions and thereby 'set the stage' for new learning (Wetzels et al., 2011). It has been shown that students recall more information that relates to their own activated prior knowledge (MachielsBongaerts et al., 1995; Peeck, 1982; Pressley et al., 1990). In the present experiment, participants who elaborated with relevant prior knowledge may have created a knowledge base that was closely related to the study text they encountered after the discussion. They built this knowledge base through their explanations, as a response to the teacher's questions. In 
other words, elaboration on the relevant prior knowledge provided good guidance for further self-study. Elaboration with irrelevant prior knowledge may have provided ill guidance, confusing participants when they tried to come up with adequate responses to the teacher's questions and impeding their intake of knowledge from the study text.

Elaboration with irrelevant prior knowledge may also have created more misconceptions than elaboration with relevant prior knowledge. Participants who elaborated without prior knowledge possibly relied more on their own, personal prior knowledge to answer the teacher's questions. Since they lacked a science-oriented background, perhaps this personal knowledge contained misconceptions. As a consequence, they generated more misconceptions during the discussion than their counterparts who received relevant prior knowledge. Misconceptions tend to be persistent, even when students are confronted with contradictory information (Chinn \& Brewer, 1993). So if the study text contained information that contradicted the framework, the misconceptions may have persisted.

For example, some participants reported a misconception that thunder and lightning was created by friction between clouds during the small group discussion. One of the relevant prior knowledge sentences was: "A difference in electrical charge within a thundercloud causes lightning". This sentence could have repaired the misconception before entering the discussion. Moreover, participants could have used the sentence to generate answers to the teacher's questions, thereby creating a knowledge base that was coherent with the study text. The sentences about seismographic activity could probably not repair the misconception, because they dealt with a different topic. Therefore, it seems likely that these sentences did not aid participants in creating a relevant knowledge base for further self-study.

\section{Limitations and future research}

There are some limitations in this study that need to be considered. First, the experiment used a video recording of a small group discussion, which may not have represented a real life situation. However, this drawback came with the benefit of gaining experimental control over the group process. And although not the same degree of interaction and coconstruction (Van Boxtel et al., 2000) could be reached as in a real-life situation, the activities that were performed during the experiment seemed to resemble those of a natural discussion. That is, the participants in the elaboration conditions provided explanations to other students, as a response to questions by a teacher. They were stimulated to activate prior knowledge and construct new theories, which are common activities in PBL (Dolmans \& Schmidt, 2006). And after the discussion, they performed self-study, which is also part of the PBL process (Hmelo-Silver, 2004; Schmidt et al., 2009). With the current research approach, some steps could be made in detecting which elaboration during problem-based discussion has a positive effect on recall. 
A second limitation might be that the experimental treatment was too short to cause an effect. A problem-based discussion can normally take more than an hour (Schmidt et al., 2009) and students can discuss one problem even up until two hours, distributed over two meetings (HmeloSilver \& Barrows, 2008). In the present experiment, the discussion only took approximately 20 minutes. Considering findings that collaborative learning is more effective when the collaboration contains more elaboration episodes (O'Donnell et al., 1985), there is a possibility that the main effect of elaboration was attenuated by the brief period for discussion. Nonetheless, it can also be argued that participation was more active than in a normal discussion, where students would not be addressed by a teacher as frequently as in the present experiment. Participants in the two elaboration conditions were activated eight times by the teacher. The question remains whether more elaboration episodes during the discussion will improve subsequent learning.

Future research could thus check whether adding elaboration episodes yields a larger effect. Furthermore, it could be investigated whether the ideas generated during the discussion lead students to construct a contextual framework that influences what and how much they recall from their subsequent self-study. If the discussion creates a framework that is relevant for self-study, perhaps more is remembered from it. As such, problem-based discussion may be a better preparation for future studying when the ideas emerging during the discussion are more related to subsequent self-study. It might also be interesting to test the effect of misconceptions on recall. Misconceptions may have a negative impact on the learning and recall of subsequently studied information. In contrast, correct or plausible conceptions could have a positive influence on learning. If this is true, problem-based discussion might be a better preparation for new learning when students produce fewer misconceptions during the discussion.

\section{Implications for practice}

The present findings may have some implications for educators in collaborative learning. It is important that a problem-based discussion fits well with the students' prior knowledge. Therefore, it may be important to provide students with some relevant prior knowledge before they enter the discussion. In some versions of $\mathrm{PBL}$, students receive a limited amount of information at the beginning of the group session, just before they start a problem-based discussion (Hmelo-Silver \& Barrows, 2008). This information should only contain loose concepts, since students need to generate new connections between these concepts themselves, by means of the discussion. Lacking some basic level of relevant prior knowledge may actually be detrimental for future learning, as the present results indicate.

The PBL teacher can also help students to use their prior knowledge in the right way. For example, the teacher can ask directive questions which 
point more directly to the relevant concepts students need to recall from their self-study after the discussion (Budé et al., 2009). By doing this, the teacher may retrieve relevant prior knowledge from the students. So in sum, teachers might improve students' recall from self-study by offering them some relevant prior knowledge before the discussion and asking questions during the discussion to retrieve this knowledge.

\section{References}

Bargh, J. A., \& Schul, Y. (1980). On the cognitive benefits of teaching. Journal of Educational Psychology, 72(5), 593-604.

Budé, L., Imbos, T., Van der Wiel, M., Broers, N., \& Berger, M. (2009). The effect of directive tutor guidance in problem-based learning of statistics on students' perceptions and achievement. Higher Education, 57(1), 23-36.

Capon, N., \& Kuhn, D. (2004). What's so good about problem-based learning? Cognition and Instruction, 22(1), 61-79.

Chinn, C. A., \& Brewer, W. F. (1993). The role of anomalous data in knowledge acquisition: A theoretical framework and implications for science instruction. Review of Educational Research, 63(1), 1-49.

Cohen, J. (1988). Statistical power analysis for the behavioral sciences (2nd ed.). Hillsdale, NJ: Erlbaum.

Dansereau, D. F. (1988). Cooperative learning strategies. In C. E. Weinstein, E. T. Goetz \& P. A. Alexander (Eds.), Learning and study strategies: Issues in assessment, instruction, and evaluation (pp. 103-120). San Diego, CA: Academic Press.

Dansereau, D. F., Collins, K. W., McDonald, B. A., Holley, C. D., Garland, J., Diekhoff, G., et al. (1979). Development and evaluation of a learning strategy training program. Journal of Educational Psychology, 71(1), 64-73.

De Grave, W. S., Boshuizen, H. P. A., \& Schmidt, H. G. (1996). Problem based learning: Cognitive and metacognitive processes during problem analysis. Instructional Science, 24(5), 321-341.

De Grave, W. S., Schmidt, H. G., \& Boshuizen, H. P. A. (2001). Effects of problembased discussion on studying a subsequent text: $A$ randomized trial among first year medical students. Instructional Science, 29(1), 33-44.

Dochy, F., Segers, M., Van den Bossche, P., \& Gijbels, D. (2003). Effects of problem-based learning: A meta-analysis. Learning and Instruction, 13(5), 533-568.

Dolmans, D. H. J. M., \& Schmidt, H. G. (2006). What do we know about cognitive and motivational effects of small group tutorials in problem-based learning? Advances in Health Sciences Education, 11(4), 321-336.

Eisenstaedt, R. S., Barry, W. E., \& Glanz, K. (1990). Problem-based learning: Cognitive retention and cohort traits of randomly selected participants and decliners. Academic Medicine, 65(9, Suppl.), 11-12.

Hamilton, R. J. (2004). Material appropriate processing and elaboration: The impact of balanced and complementary types of processing on learning concepts from text. British Journal of Educational Psychology, 74(2), 221-237.

Hmelo-Silver, C. E. (2004). Problem-based learning: What and how do students learn? Educational Psychology Review, 16(3), 235-266.

Hmelo-Silver, C. E., \& Barrows, H. S. (2008). Facilitating collaborative knowledge building. Cognition and Instruction, 26, 48-94.

King, A., Staffieri, A., \& Adelgais, A. (1998). Mutual peer tutoring: Effects of structuring tutorial interaction to scaffold peer learning. Journal of Educational Psychology, 90(1), 134-152.

Larson, C. O., Dansereau, D. F., O'Donnell, A. M., Hythecker, V. I., Lambiotte, J. G., \& Rocklin, T. R. (1985). Effects of metacognitive and elaborative activity on cooperative learning and transfer. Contemporary Educational Psychology, $10(4), 342-348$. 
Lloyd, J., Margetson, D., \& Bligh, J. G. (1998). Problem-based learning: A coat of many colours. Medical Education, 32(5), 492-494.

Machiels-Bongaerts, M., Schmidt, H. G., \& Boshuizen, H. P. A. (1995). The effect of prior knowledge activation on text recall: An investigation of two conflicting hypotheses. British Journal of Educational Psychology, 65(4), 409-423.

Mayer, R. E. (1980). Elaboration techniques that increase the meaningfulness of technical text: An experimental test of the learning strategy hypothesis. Journal of Educational Psychology, 72(6), 770-784.

Mayer, R. E. (1985). Structural analysis of science prose: Can we increase problemsolving performance? In B. K. Britton \& J. B. Black (Eds.), Understanding expository text: A theoretical and practical handbook for analyzing explanatory text. Hillsdale, NJ: Erlbaum.

McDonald, B. A., Larson, C. O., Dansereau, D. F., \& Spurlin, J. E. (1985). Cooperative dyads: Impact on text learning and transfer. Contemporary Educational Psychology, 10(4), 369-377.

Moust, J. H. C., Schmidt, H. G., De Volder, M. L., Belien, J. J., \& De Grave, W. S. (1987). Effects of verbal participation in small group discussion. In J. T. E. Richardson, M. W. Eysenck \& D. W. Piper (Eds.), Student learning: Research in education and cognitive psychology (pp. 147-154). Guildford Maidenhead, BRK England: Society for Research into Higher Education, Open University Press.

O'Donnell, A. M. (1996). Effects of explicit incentives on scripted and unscripted cooperation. Journal of Educational Psychology, 88(1), 74-86.

O'Donnell, A. M. (2006). The role of peers and group learning. In P. H. Winne \& P. A. Alexander (Eds.), Handbook of educational psychology (pp. 781-802). Mahwah, NJ: Erlbaum.

O'Donnell, A. M., Dansereau, D. F., Rocklin, T. R., Hythecker, V. I., Lambiotte, J. G., Larson, C. O., et al. (1985). Effects of elaboration frequency on cooperative learning. Journal of Educational Psychology, 77(5), 572-580.

Peeck, J. (1982). Effects of mobilization of prior knowledge on free recall. Journal of Experimental Psychology: Learning, Memory, and Cognition, 8(6), 608-612.

Pressley, M., McDaniel, M. A., Turnure, J. E., Wood, E., \& Ahmad, M. (1987). Generation and precision of elaboration: Effects on intentional and incidental learning. Journal of Experimental Psychology: Learning, Memory, and Cognition, 13(2), 291-300.

Pressley, M., Symons, S., McDaniel, M. A., Snyder, B. L., \& Turnure, J. E. (1988). Elaborative interrogation facilitates acquisition of confusing facts. Journal of Educational Psychology, 80(3), 268-278.

Pressley, M., Tanenbaum, R., McDaniel, M. A., \& Wood, E. (1990). What happens when university students try to answer prequestions that accompany textbook material? Contemporary Educational Psychology, 15(1), 27-35.

Reder, L. M. (1980). The role of elaboration in the comprehension and retention of prose: A critical review. Review of Educational Research, 50(1), 5-53.

Rewey, K. L., Dansereau, D. F., Skaggs, L. P., Hall, R. H., \& Pitre, U. (1989). Effects of scripted cooperation and knowledge maps on the processing of technical material. Journal of Educational Psychology, 81(4), 604-609.

Schmidt, H. G. (1984). Activatie van voorkennis en tekstverwerking / Activation of prior knowledge and text processing. Nederlands Tijdschrift voor de Psychologie en haar Grensgebieden, 39(6), 335-347.

Schmidt, H. G. (1993). Foundation of problem-based learning: Some explanatory notes. Medical Education, 27(5), 422-432.

Schmidt, H. G., De Volder, M. L., De Grave, W. S., Moust, J. H. C., \& Patel, V. L. (1989). Explanatory models in the processing of science text: The role of prior knowledge activation through small-group discussion. Journal of Educational Psychology, 81(4), 610-619.

Schmidt, H. G., Van der Molen, H. T., Te Winkel, W. W. R., \& Wijnen, W. H. F. W. (2009). Constructivist, problem-based learning does work: A meta-analysis of 
curricular comparisons involving a single medical school. Educational Psychologist, 44(4), 227-249.

Slavin, R. E., Hurley, E. A., \& Chamberlain, A. (2003). Cooperative learning and achievement: Theory and research. In G. E. Miller \& W. M. Reynolds (Eds.), Handbook of psychology: Educational psychology (Vol. 7, pp. 177-198). Hoboken, NJ: John Wiley \& Sons.

Spurlin, J. E., Dansereau, D. F., Larson, C. O., \& Brooks, L. W. (1984). Cooperative learning strategies in processing descriptive text: Effects of role and activity level of the learner. Cognition and Instruction, 1(4), 451-463.

Tans, R. W., Schmidt, H. G., Schade-Hoogeveen, B. E., \& Gijselaers, W. H. (1986). Sturing van het onderwijsleerproces door middel van problemen: een veldexperiment / Problem-based learning: A field experiment. Tijdschrift voor Onderwijsresearch, 11(1), 35-46.

Van Boxtel, C., Van der Linden, J., \& Kanselaar, G. (2000). Collaborative learning tasks and the elaboration of conceptual knowledge. Learning and Instruction, 10, 311-330.

Webb, N. M. (1989). Peer interaction and learning in small groups. International Journal of Educational Research, 13(1), 21-39.

Webb, N. M., \& Farivar, S. (1999). Developing productive group interaction in middle school mathematics. In A. M. O'Donnell \& A. King (Eds.), Cognitive perspectives on peer learning (pp. 117-149). Mahwah, NJ: Erlbaum.

Webb, N. M., Franke, M. L., Ing, M., Chan, A., De, T., Freund, D., et al. (2008). The role of teacher instructional practices in student collaboration. Contemporary Educational Psychology, 33(3), 360-381.

Webb, N. M., Nemer, K. M., Chizhik, A. W., \& Sugrue, B. (1998). Equity issues in collaborative group assessment: Group composition and performance. American Educational Research Journal, 35(4), 607-651.

Webb, N. M., Troper, J. D., \& Fall, R. (1995). Constructive activity and learning in collaborative small groups. Journal of Educational Psychology, 87(3), 406-423.

Wetzels, S. A. J., Kester, L., \& van Merriënboer, J. J. G. (2011). Adapting prior knowledge activation: Mobilisation, perspective taking, and learners' prior knowledge. Computers in Human Behavior, 27(1), 16-21.

Willoughby, T., Waller, T. G., Wood, E., \& MacKinnon, G. E. (1993). The effect of prior knowledge on an immediate and delayed associative learning task following elaborative interrogation. Contemporary Educational Psychology, 18(1), 36-46.

Wittrock, M. C. (1992). Generative learning processes of the brain. Educational Psychologist, 27(4), 531-541.

Woloshyn, V. E., Pressley, M., \& Schneider, W. (1992). Elaborative-interrogation and prior-knowledge effects on learning of facts. Journal of Educational Psychology, 84(1), 115-124. 


\section{Chapter 6}

\section{General discussion}

\section{Introduction and research questions}

The aims of this thesis were to (1) test the effect of elaboration during small group discussion on the recall of information; and (2) examine the role of elaborative questions and relevant prior knowledge as facilitators for elaboration and recall.

Collaborative learning is often studied in classrooms and over extended periods of time (King et al., 1998; Krol et al., 2004; Mercer \& Sams, 2006; Veenman et al., 2005; Webb \& Farivar, 1999). These long-term studies may have the advantage of allowing students to elaborate on their knowledge more often (Nussbaum, 2008). Still, not all classroom studies found unequivocal evidence for the positive impact of elaborative discussion on achievement (Krol et al, 2004; Veenman et al., 2005). This may not come as a surprise, since a dynamic classroom environment can produce many confounders to final learning outcomes. These confounders can be external or internal. External confounders can be defined as influences from outside the group (i.e. factors that are not part of the collaboration but nevertheless influence learning outcomes, such as changes in a curriculum, important tests, etc.). Internal confounders are defined as influences from within the group (i.e. factors that are part of the collaboration and influence learning outcomes, like a higher quality of information exchange in one group than in another, etc.). The studies conducted for this thesis attempted to investigate collaborative learning in a more controlled environment. External confounders were controlled by performing small-scale experiments. Internal confounders were controlled by ensuring that all research participants were exposed to exactly the same group process. Therefore, the experiments used simulations of a collaborative setting.

In this thesis, the context for collaborative learning was problem-based learning $(\mathrm{PBL})$. $\mathrm{PBL}$ possesses a unique feature, because it puts collaboration at the beginning of new learning. Students start out with discussing a problem that describes a real-world situation. During this discussion, they try to explain the problem, which leads to the discovery of gaps in the knowledge base. In order to fill these gaps, they formulate learning issues and start their self-study. This step is usually followed by a reporting phase in which they share their findings with each other (HmeloSilver, 2004; Schmidt et al., 2009). The first step, the problem-based discussion, is unique because it requires students to collaborate before they study new information. In other forms of collaborative learning, the discussion tends to follow the acquisition of new information (Dansereau, 
1988; King, 2007). Problem-based discussion therefore acts as a preparation for self-study, during which students activate prior knowledge, elaborate on that prior knowledge and organize the knowledge around the problem (Schmidt, 1993). This form of discussion has proven to facilitate the self-study after the discussion (De Grave et al., 2001; Schmidt et al., 1989). The purpose of this thesis was to analyze in more detail which group-related cognitive activities were responsible for this effect.

A new method to study collaborative learning was developed, in which the group discussion was simulated. For this purpose, problem-based discussions were recorded on video and shown to research participants. This new method produced several advantages. Firstly, it ensured that all participants were exposed to exactly the same exchange of information in the group. Secondly, the video could easily be edited and therefore adjusted to include experimental manipulations. These manipulations tested the following overall research questions:

- Does elaboration during a problem-based discussion increase recall from self-study after the discussion (experiment 1 and 2)?

- Do certain variables, i.e. a teacher's elaborative questions and relevant prior knowledge, promote elaboration and recall (experiment 3 and 4$)$ ?

This chapter will start with reporting the main findings and theoretical conclusions. Some limitations of the experiments will be described next, followed by suggestions for future research. The chapter concludes with a tentative translation of the experimental findings to educational practice.

\section{Main findings and conclusions}

Does elaboration during small group discussion enhance recall?

Experiments 1 en 2 addressed the first research question dealing with the effectiveness of elaboration in a controlled, experimental situation. Elaboration was evoked by letting students explain their thoughts to other students during the simulated group discussion. The main hypothesis of the first experiment (Chapter 2) was therefore that providing explanations during the group discussion would lead to better recall scores than listening during the same discussion. A second hypothesis was that providing explanations and listening would both improve recall compared to listening to an off-topic discussion. This second hypothesis was included to see if earlier findings (Schmidt et al., 1989; De Grave et al., 2001) could be replicated with the new methodology. Before the experiments, all participants $(N=70)$ received some relevant prior knowledge to elaborate on during the discussion. They then observed a video of a group discussing a problem about airplane radar. In the explanation condition, participants elaborated by providing explanations to other students. In the listening condition, they listened to explanations from other students. In a control condition, they observed a video with a group discussion about alcohol. After the video, all participants studied a text about airplane radar. 
The explanation condition indeed recalled significantly more from the text than the listening condition, but only on a delayed and not on an immediate recall test. This mirrors the findings from earlier studies that compared explaining to listening during collaborative learning (Ross \& Di Vesta, 1976; Spurlin et al., 1984). It is also in line with the cognitive elaboration perspective for collaborative learning, which states that students elaborate effectively by explaining their knowledge to others in the group (Krol et al., 2004; Slavin et al., 2003). The long-term effect seems to provide support for the richness hypothesis (Hamilton, 2004), which states that elaboration enriches the knowledge base and therefore leads to a longer retention of knowledge (Reder, 1980). The long-term effect also follows a general tendency towards a better long-term retention of knowledge among PBL students (Dochy et al., 2003). The secondary hypothesis could also be confirmed, because students in the explanation and listening condition recalled more information directly after the group discussion than students in the control condition. The new methodology thus appeared to yield results similar to earlier PBL experiments with real-life, problem-based discussions (Schmidt et al., 1989; De Grave et al., 2001).

The second experiment (Chapter 3, $N=71$ ) adjusted the procedure in order to optimize experimental control. The purpose was to exclude relevant 'time on task' as a confounder for the final results, because this variable could have a positive impact on learning achievement (Wang et al., 1990). The experiment therefore equalized the time spent on explaining and listening. The period that the listening condition spent on the discussion was stretched out until it reached the average time spent on the discussion by the explanation condition. With this small procedural adjustment, the hypotheses of experiment 1 were tested again. Experiment 2 thus examined if providing explanations would improve recall compared to listening, and if explanation and listening would enhance recall compared to the control treatment.

Surprisingly, the explanation condition did not recall more from the text than the listening condition this time, neither immediately after the group discussion, nor on the delayed recall test. This suggested that the results of the first experiment were confounded by additional time on task for the explainers. However, an alternative reason should also be considered. Extending the discussion of the listening condition created pauses in the video, during which the listeners could reflect on explanations from the group. There is evidence that students reflect silently during a problem-based discussion, meaning that they have many non-verbalized, content relevant thoughts during the discussion (De Grave et al., 1996). Perhaps the pauses created more opportunities for the listeners to reflect silently on explanations from other students, rendering delayed recall scores that were almost equal to the scores of the explainers. Considering the secondary hypothesis, both the explanation and the listening condition recalled more from the text than the control 
condition. So in contrast to the main hypothesis, the secondary hypothesis received support in both experiment 1 and 2 .

Combined, the first two experiments not only indicated that elaboration was beneficial for long-term recall, but also that time on task could confound this effect. Furthermore, the results put forward the possibility that silent reflection on explanations from others encouraged recall. In order to rule out this possibility, the procedure was adjusted in experiment 3 and 4 in order to prevent silent reflection. Experiment 3 did this by letting all participants explain their thoughts (i.e. there was no listening condition). Experiment 4 discouraged silent reflection by presenting distraction tasks to participants who did not elaborate during the group discussion. In both experiments, time on task was controlled the same way as in experiment 2, so by equalizing the time spent on the group discussion across experimental conditions.

Teacher's elaborative questions and relevant prior knowledge.

Experiments 3 and 4 continued to investigate the role of elaboration in more detail. Experiment 3 (Chapter 4) tested whether a teacher could improve recall by asking elaborative questions during the discussion. Promoting elaboration in the group is one of the core tasks of a PBL teacher (De Grave et al., 1999) and a teacher can do this by letting students explain their reasoning (Hmelo-Silver, 2004) and asking them to relate the discussion to their prior knowledge (Lee et al., 2009). There were indications that a teacher could improve learning achievement by asking directive, elaborative questions during PBL group sessions (Budé et al., 2009). The hypothesis was therefore that a teacher could improve recall by asking elaborative questions that challenged students to generate new relations between concepts from their prior knowledge. In order to test this hypothesis, the video of the group discussion included a teacher who asked questions to the observer. The topic of the group discussion was thunder and lightning. Like in experiment 1 and 2, all participants $(N=69)$ received some relevant prior knowledge before the group discussion. A multiple-choice test checked whether they had remembered the prior knowledge correctly or not. In one experimental condition (elaborative questions condition), the teacher's questions were manipulated so that participants could generate new relations with the provided prior knowledge in order to explain how thunder and lightning worked. In a second condition (superficial questions condition), the questions were designed to elicit superficial answers that repeated the provided prior knowledge or remarks by other group members.

There were no differences between the two conditions on the outcomes of the multiple-choice test before the group discussion. Furthermore, the elaborative questions only seemed to benefit students who needed more than one attempt to pass the multiple-choice test. Like in the first experiment, this effect was only significant on the delayed recall test, which provided additional evidence for the richness hypothesis (Hamilton, 
2004; Reder, 1980). The results were also consistent with earlier found interaction effects between ability level and learning achievement, where elaboration was more effective for low- than for high-ability students (Hamilton, 1989; Mayer, 1980). The findings of experiment 3 therefore seem consistent with theory and previous research and suggest that students who have more trouble with the subject-matter profit more from a teacher who stimulates elaboration during the group discussion.

The results of experiment 3 also indicated that prior knowledge could be an important determinant for the effectiveness of elaboration during the group discussion. The effectiveness of elaboration seemed to depend on the ability to acquire relevant prior knowledge before the experiment. This led to the conclusion that the role of prior knowledge should be studied in more detail. Therefore, experiment 4 (Chapter 5) examined whether relevant prior knowledge could moderate the effect of elaboration during the discussion. Relevant prior knowledge has shown to promote the effect of elaboration on recall in previous research (Willoughby et al., 1993; Woloshyn et al., 1992) and therefore an interaction effect between prior knowledge and elaboration was expected. This hypothesis was tested in a $2 \times 2$ experimental design (elaboration: yes/no; prior knowledge: yes/no). Half of the participants $(N=66)$ elaborated during the group discussion and the other half completed a distraction task to prevent silent reflection. Also, half of the participants obtained relevant prior knowledge before the experiment and half of them received irrelevant prior knowledge. For reliable testing of the second independent variable (prior knowledge), only students with little prior knowledge about the study topic were selected.

Elaboration and prior knowledge did not produce main effects, neither on short-term, not on long-term recall. The lack of a main effect by elaboration was at odds with the results of experiment 1 , which found a significant effect of elaboration on delayed recall. However, it followed the results of experiment 2, which showed no significant effects of elaboration on short- and long-term recall. Like in experiment 2, time on group discussion was held equal across experimental conditions. Therefore, it seemed that elaboration again did not improve recall when time on task was put under experimental control. With regard to the experiment's hypothesis, the expected interaction between prior knowledge and elaboration was found. Participants who elaborated with relevant prior knowledge recalled significantly more from the text than participants who elaborated without relevant prior knowledge. Contrary to experiment 1 and 3, there was an effect on both immediate and delayed recall, suggesting that relevant prior knowledge is pivotal for the effectiveness of elaboration during the group discussion. A possible reason for the interaction effect is that elaboration in combination with relevant prior knowledge supported the construction of a contextual framework, which in turn facilitated self-study. A similar explanation can be discerned in research to prior knowledge activation. Prior knowledge activation is 
believed to 'set the stage' for new learning (Wetzels et al., 2011). Indeed, the activated prior knowledge seems to determine which information is recalled best later on (Machiels-Bongaerts et al., 1995; Peeck, 1982). Something similar might happen when students elaborate during a group discussion. Their elaborations can create a contextual framework that determines which information will be recalled best. Relevant prior knowledge might foster the construction of a framework that provides more leads for further self-study. As a consequence, more from this selfstudy can be recalled at a later stage.

\section{General conclusions}

Overall, the four experiments provided new insights in the role of elaboration during collaborative group discussion. Elaboration improved recall from self-study after the group discussion, but only when time on task was an uncontrolled confounding variable. In addition, low-ability students seemed to benefit more from elaborative questions than highability students. And finally, relevant prior knowledge turned out to be a crucial element for the effectiveness of elaboration. This thesis was probably the first to exert full experimental control over the quality of a group discussion. It was also the first to test the effect of elaboration during the discussion on learning after a group discussion. Including delayed recall measures provided the additional benefit of analyzing both short- and long-term effects. Furthermore, the studies yielded useful suggestions for improvement of the experimental method, such as controlling for silent reflection and the time spent on the discussion. An advantage for the future is that investigators can study collaborative learning more easily, since they only need to record one group discussion, which they can use subsequently to test many experimental manipulations. Moreover, the method can be applied to all kinds of collaborative learning environments. The new approach thus proved its' value and may be promising for the future.

The experiments were conducted in a PBL-context, so an interpretation of the results from the perspective of this educational format may be worthwhile. PBL has a unique feature, which is the problem-based discussion. This group discussion requires students to discuss a topic before they discover more about it. Hmelo-Silver (2004) suggests that PBL therefore creates a good 'time for telling' (Schwartz \& Bransford, 1998), as it encourages students to become actively involved with the learning materials before 'the time is ripe' for them to acquire more information about it. It is important that students express their misconceptions during the problem-based discussion, because they need to correct these errors when they study new information after the discussion. As a consequence, the explanations during the group discussion can be inaccurate or false (Schmidt et al., 2009). For example, students can collaboratively discuss a problem about thunder and lightning. One student, who knows little about electrical currents and 
charges, may propose that it is friction that causes lightning. This would be a false explanation, because lightning is actually caused by electrically charged particles in the atmosphere. Such false explanations might have contributed to the results of this thesis, for example the lack of an elaboration effect in experiments 2 and 4. One PBL-study has shown that the amount of elaboration during a problem-based discussion did not correlate with the amount of recall from self-study after the discussion (Moust et al., 1987). Perhaps false explanations during the discussion contributed to these findings as well.

\section{Limitations}

Some limitations of this study can be given. Firstly, the most important methodological improvement also had a downside. Controlling the quality of the group discussion with a video simulation made it impossible to study interaction between students. During collaboration, students can engage in three types of activities: active learning, constructive learning and interactive learning (Chi, 2009). It can be argued that this thesis tested constructive learning in the group, because students actively constructed explanations, which they directed at other students. However, they did not receive feedback from these others and could therefore not build on replies from fellow students. In other words, the process of coconstruction, extending the line of thought by supplementing each others' remarks (Chi, 2009; Van Boxtel et al., 2000), was missing. Adding coconstruction could benefit understanding because it allows students not only to construct explanations, but to build on each others' contributions as well.

The lack of co-construction raises questions about the applicability of the present findings to real-world situations. One argument could be that co-construction is an essential factor to study in collaborative learning. Without it, collaboration cannot be studied realistically. However, smaller scale activities, like providing an explanation and responding to a teacher's question, are part of a natural group discussion. Although these activities do not encompass a group-level process like co-construction, they can be studied individually in order to learn their relative contributions to learning achievement. The question therefore might not be whether collaboration should be studied in a real environment, but which activities during collaboration are truly conducive to learning. This requires a microscopic approach in which separate independent variables are to be concerned, and need to be selected and tested one by one. Moreover, the tested variables should be based on the theoretical assumptions that underlie collaborative learning.

A second limitation might be the time length of the experimental treatment. Problem-based discussions tend to last one hour (Schmidt et al., 2009) and sometimes students can discuss one problem for up to five hours, spread over two sessions (Hmelo-Silver \& Barrows, 2008). In the current experiments, discussions only lasted for periods of 15 to 20 
minutes. Perhaps this period was too short to yield a strong effect. Still, it can also be argued that participants elaborated more actively than they would normally do during a group discussion, because the treatment explicitly invited them to do so.

A third limitation could be that the quality of the explanations was not examined. Previous research has for instance coded the level of elaboration in students' explanations to others (Webb \& Farivar, 1999). This degree of elaboration in explanations can be related to learning achievement and provides more insights in the effective components of problem-based discussion. A qualitative analysis of verbal protocols was not the prime purpose of this thesis, because the studies aimed at measuring the effect of elaboration on immediate and delayed recall.

A fourth point is that the explanations may have been too broad and tentative for a meaningful connection with information encountered after the discussion. It was already mentioned that a problem-based discussion allows students to come up with false or inaccurate explanations. This can lead to a wide variety of explanations, part of which will not be logically related to the contents of subsequent self-study. For instance, some students may falsely believe that friction causes lightning, while others know correctly that it is caused by electrically charges particles. This example illustrates that students can generate a wide variety of ideas during the discussion, which are either true or false. The validity and accuracy of these explanations probably depend on individual differences in prior knowledge and may influence how much students recall from selfstudy after the discussion.

\section{Suggestions for future research}

Next, some suggestions will follow to solve the problems mentioned above. The first limitation, a lack of co-construction, can be circumvented by including collaborative reasoning in the experimental procedure. Coconstruction can be established either between a teacher and students or between students. The first type of co-construction occurs when the teacher scaffolds the students' learning. By asking questions and lecturing at the appropriate level of the students, the teacher can scaffold their learning process. During this process, the teacher will discover how he can help the students most efficiently. The students in turn can indicate where help is needed and show the teacher if the help was useful and understood. As such, scaffolding can be seen as a joint construction of knowledge between a teacher and students. Recent work has shown that a virtual tutor can successfully scaffold the learning of one student by constructing feedback based on written input by the student (Gholson et al., 2009). Therefore, it is possible to simulate scaffolding between a student and a tutor, yet it remains unknown whether virtual tutors can also be used in small groups.

The second type of co-construction is that between students. This probably differs from scaffolding by a teacher. While scaffolding entails 
there is an expert-novice relationship, co-construction between students suggests there is an interaction between two or more persons who know more or less the same. For this type of co-construction, it may be possible to use collaboration scripts. Such scripts were developed in face-to-face collaborative settings in order to create a division of labor during the group discussion (Dansereau, 1988). In practice, this meant that one student summarized a previously studied text, while another student tried to detect errors and omissions in these summaries. More recently, scripts have been used in computer supported collaborative learning (CSCL) to enhance the quality of interactions in the group (Dillenbourg \& Tchounikine, 2007). CSCL has been implemented in PBL-programs as well (Hmelo-Silver, Chernobilsky, \& Jordan, 2008) and it could be used to study the effect of co-construction on learning achievement. Concretely, some students in the group could adopt the role of 'co-constructor' and generate explanations together with another student, while other students could play the role of 'active follower' who follows the explanations produced by the two co-constructors. So in this example, co-construction would be compared to active following of the group discussion.

A second suggestion for future research is to increase the length of the experimental treatment. The discussion could last longer and the number of elaboration episodes may be increased. Since multiple elaboration episodes have shown to boost learning achievement (O'Donnell et al., $1985)$, this change might lead to a larger effect on recall.

The third and fourth limitations can both be solved by examining the nature of the explanations during the problem-based discussion. The quality of the explanations can be coded according to different levels of elaboration (Webb \& Farivar, 1999) and correlated with recall. Qualitative analyses can also reveal which degree of the explanations is false or inaccurate. False and inaccurate explanations may cause a large variety of explanations during the discussion, which can affect the recall scores. On the one hand, false and inaccurate explanations may be an ill preparation for further self-study and therefore reduce its' recall. On the other hand, these explanations may lead to the discovery of misconceptions, which can be corrected successfully during the self-study. Discovering inconsistencies between misconceptions and new information might lead to additional elaboration and improve recall. Thus, the effect of false and inaccurate explanations on recall is still an open question and needs further studying.

A final suggestion for future research is to compare the problem-based discussion with the subsequent reporting phase after self-study. PBL covers a cycle in which students discuss a problem, perform self-study and discuss again to report their findings (Hmelo-Silver, 2004; Schmidt et al., 2009). During the problem-based discussion, they may provide a relatively high number of false and inaccurate explanations because they do not have the correct answers yet. During the reporting phase, there may be more correct and accurate explanations. Therefore, a future study 
could evaluate if the problem-based discussion has a different effect on recall than the reporting phase. If the reporting phase indeed includes more correct explanations, it may foster recall to a higher degree than the problem-based discussion.

\section{Implications for practice}

Teachers need to be aware that a problem-based discussion is an effective means to prepare students for future self-study. During the discussion, students can activate and elaborate on prior knowledge, and thereby construct a contextual framework that is relevant for new learning. Of particular importance is that elaboration during the group discussion can promote long-term recall. Teachers may take this into account when they supervise the group discussion, by prompting them to generate explanations that are not simply paraphrases of prior knowledge, but challenge them to generate new relations between prior knowledge and apply these to the problem. However, elaboration may not always be effective and some criteria need to be considered. First, active elaboration is probably more effective for students who have more difficulties with the subject-matter in general, whereas it may be redundant for students who learn the materials more easily. Second, relevant prior knowledge plays a pivotal role in the effectiveness of elaboration. If teachers want students to elaborate efficiently and recall more after the discussion, they should make sure that students possess at least some relevant prior knowledge before the group discussion. In a PBL context, it may be profitable to provide students with some relevant prior knowledge before they enter the problem-based discussion. Without this prior knowledge, they may not be able to build a strong foundation for further self-study.

\section{References}

Budé, L., Imbos, T., Van der Wiel, M., Broers, N., \& Berger, M. (2009). The effect of directive tutor guidance in problem-based learning of statistics on students' perceptions and achievement. Higher Education, 57(1), 23-36.

Chi, M. T. H. (2009). Active-constructive-interactive: A conceptual framework for differentiating learning activities. Topics in Cognitive Science, 1(1), 73-105.

Dansereau, D. F. (1988). Cooperative learning strategies. In C. E. Weinstein, E. T. Goetz \& P. A. Alexander (Eds.), Learning and study strategies: Issues in assessment, instruction, and evaluation (pp. 103-120). San Diego, CA: Academic Press.

De Grave, W. S., Boshuizen, H. P. A., \& Schmidt, H. G. (1996). Problem based learning: Cognitive and metacognitive processes during problem analysis. Instructional Science, 24(5), 321-341.

De Grave, W. S., Dolmans, D. H. J. M., \& Van der Vleuten, C. P. M. (1999). Profiles of effective tutors in problem-based learning: Scaffolding student learning. Medical Education, 33(12), 901-906.

De Grave, W. S., Schmidt, H. G., \& Boshuizen, H. P. A. (2001). Effects of problembased discussion on studying a subsequent text: A randomized trial among first year medical students. Instructional Science, 29(1), 33-44.

Dillenbourg, P., \& Tchounikine, P. (2007). Flexibility in macro-scripts for computersupported collaborative learning. Journal of Computer Assisted Learning, 23(1), 1-13. 
Dochy, F., Segers, M., Van den Bossche, P., \& Gijbels, D. (2003). Effects of problem-based learning: A meta-analysis. Learning and Instruction, 13(5), 533-568.

Gholson, B., Witherspoon, A., Morgan, B., Brittingham, J. K., Coles, R., Graesser, A. C., et al. (2009). Exploring the deep-level reasoning questions effect during vicarious learning among eighth to eleventh graders in the domains of computer literacy and Newtonian physics. Instructional Science, 37(5), 487493.

Hamilton, R. J. (1989). The effects of learner-generated elaborations on concept learning from prose. The Journal of Experimental Education, 57(3), 205-217.

Hmelo-Silver, C. E. (2004). Problem-based learning: What and how do students learn? Educational Psychology Review, 16(3), 235-266.

Hmelo-Silver, C. E., \& Barrows, H. S. (2008). Facilitating collaborative knowledge building. Cognition and Instruction, 26, 48-94.

Hmelo-Silver, C. E., Chernobilsky, E., \& Jordan, R. (2008). Understanding collaborative learning processes in new learning environments. Instructional Science, 36(5-6), 409-430.

King, A. (2007). Beyond literal comprehension: A strategy to promote deep understanding of text. In D. S. McNamara (Ed.), Reading comprehension strategies: Theories, interventions, and technologies (pp. 267-290). Mahwah, NJ: Erlbaum.

King, A., Staffieri, A., \& Adelgais, A. (1998). Mutual peer tutoring: Effects of structuring tutorial interaction to scaffold peer learning. Journal of Educational Psychology, 90(1), 134-152.

Krol, K., Janssen, J., Veenman, S., \& Van der Linden, J. (2004). Effects of a cooperative learning program on the elaborations of students working in dyads. Educational Research and Evaluation, 10(3), 205-237.

Lee, G.-H., Lin, Y.-H., Tsou, K.-I., Shiau, S.-J., \& Lin, C.-S. (2009). When a problem-based learning tutor decides to intervene. Academic Medicine, 84(10), 1406-1410.

Machiels-Bongaerts, M., Schmidt, H. G., \& Boshuizen, H. P. A. (1995). The effect of prior knowledge activation on text recall: An investigation of two conflicting hypotheses. British Journal of Educational Psychology, 65(4), 409-423.

Mayer, R. E. (1980). Elaboration techniques that increase the meaningfulness of technical text: An experimental test of the learning strategy hypothesis. Journal of Educational Psychology, 72(6), 770-784.

Mercer, N., \& Sams, C. (2006). Teaching children how to use language to solve maths problems. Language and Education, 20(6), 507-528.

Moust, J. H. C., Schmidt, H. G., De Volder, M. L., Belien, J. J., \& De Grave, W. S. (1987). Effects of verbal participation in small group discussion. In J. T. E. Richardson, M. W. Eysenck \& D. W. Piper (Eds.), Student learning: Research in education and cognitive psychology (pp. 147-154). Guildford Maidenhead, BRK England: Society for Research into Higher Education, Open University Press.

Nussbaum, E. M. (2008). Collaborative discourse, argumentation, and learning: Preface and literature review. Contemporary Educational Psychology, 33, 345359.

O'Donnell, A. M., Dansereau, D. F., Rocklin, T. R., Hythecker, V. I., Lambiotte, J. G., Larson, C. O., et al. (1985). Effects of elaboration frequency on cooperative learning. Journal of Educational Psychology, 77(5), 572-580.

Peeck, J. (1982). Effects of mobilization of prior knowledge on free recall. Journal of Experimental Psychology: Learning, Memory, and Cognition, 8(6), 608-612.

Reder, L. M. (1980). The role of elaboration in the comprehension and retention of prose: A critical review. Review of Educational Research, 50(1), 5-53.

Ross, S. M., \& Di Vesta, F. J. (1976). Oral summary as a review strategy for enhancing recall of textual material. Journal of Educational Psychology, 68(6), 689-695. 
Schmidt, H. G. (1993). Foundation of problem-based learning: Some explanatory notes. Medical Education, 27(5), 422-432.

Schmidt, H. G., De Volder, M. L., De Grave, W. S., Moust, J. H. C., \& Patel, V. L. (1989). Explanatory models in the processing of science text: The role of prior knowledge activation through small-group discussion. Journal of Educational Psychology, 81(4), 610-619.

Schmidt, H. G., Van der Molen, H. T., Te Winkel, W. W. R., \& Wijnen, W. H. F. W. (2009). Constructivist, problem-based learning does work: A meta-analysis of curricular comparisons involving a single medical school. Educational Psychologist, 44(4), 227-249.

Schwartz, D. L., \& Bransford, J. D. (1998). A time for telling. Cognition and Instruction, 16(4), 475-522.

Slavin, R. E., Hurley, E. A., \& Chamberlain, A. (2003). Cooperative learning and achievement: Theory and research. In G. E. Miller \& W. M. Reynolds (Eds.), Handbook of psychology: Educational psychology (Vol. 7, pp. 177-198). Hoboken, NJ: John Wiley \& Sons.

Spurlin, J. E., Dansereau, D. F., Larson, C. O., \& Brooks, L. W. (1984). Cooperative learning strategies in processing descriptive text: Effects of role and activity level of the learner. Cognition and Instruction, 1(4), 451-463.

Van Boxtel, C., Van der Linden, J., \& Kanselaar, G. (2000). Collaborative learning tasks and the elaboration of conceptual knowledge. Learning and Instruction, $10,311-330$.

Veenman, S., Denessen, E., Van den Akker, A., \& Van der Rijt, J. (2005). Effects of a cooperative learning program on the elaborations of students during help seeking and help giving. American Educational Research Journal, 42(1), 115151.

Wang, M. C., Haertel, G. D., \& Walberg, H. J. (1990). What influences learning? A content analysis of review literature. Journal of Educational Research, 84(1), 30-43.

Webb, N. M., \& Farivar, S. (1999). Developing productive group interaction in middle school mathematics. In A. M. O'Donnell \& A. King (Eds.), Cognitive perspectives on peer learning (pp. 117-149). Mahwah, NJ: Erlbaum.

Wetzels, S. A. J., Kester, L., \& van Merriënboer, J. J. G. (2011). Adapting prior knowledge activation: Mobilisation, perspective taking, and learners' prior knowledge. Computers in Human Behavior, 27(1), 16-21.

Willoughby, T., Waller, T. G., Wood, E., \& MacKinnon, G. E. (1993). The effect of prior knowledge on an immediate and delayed associative learning task following elaborative interrogation. Contemporary Educational Psychology, 18(1), 36-46.

Woloshyn, V. E., Pressley, M., \& Schneider, W. (1992). Elaborative-interrogation and prior-knowledge effects on learning of facts. Journal of Educational Psychology, 84(1), 115-124. 


\section{Appendices}

\section{Appendix A: Materials used in experiments 1 and 2}

\section{Text before the small group discussion}

A common phenomenon in nature is that vibrations are passed to particles in the surrounding area. When this happens, we speak of waves. Waves pass on a vibration to particles in a medium. This medium can consist of all kinds of substances: water, air, but also a rope. Passing on a vibration is also called the propagation of a wave [...].

Waves can reflect when they hit a surface. For example, a bat sends out sound waves, which propagate in all directions, and receives the echoes of these sound waves. This way, it can determine the distance between itself and its surroundings (for instance the wall or the bottom of a cave). This is because the echo returns within a certain amount of time. Furthermore, sound travels back and forth between the bat and for example the bottom of the cave at a fixed speed. Within this travel time, the sound covers a distance that depends on the speed of sound. Thus, the distance is the speed of sound multiplied by the travel time. This way, a bat travelling through a dark cave can determine the distance to the walls and bottom, thus preventing it from colliding with walls or other objects.

\section{Problem discussed in the video}

The air traffic control tower at Amsterdam airport has a radar system on the top of its roof. This radar sends electromagnetic waves into the sky in order to measure the distance to airplanes. The waves are sent in pulses. Each pulse contains a series of successive waves. However, the waves can quickly lose energy, which decreases the range of the pulses. In order to prevent this, the radar can increase the amplitude of the waves. Unfortunately, this only helps a little bit. The length of the pulses can also be increased, but this also has little effect. Nevertheless, there is a way to maintain an optimal range.

\section{Questions from group members in the video}

1. Female student 1: How does a bat know that a wall is nearby?

2. Female student 1: But how does he know the distance to the wall?

3. Female student 2: And this signal, does it travel in a straight direction?

4. Male student: Maybe that's related to the quick attenuation of waves. Waves spread out, don't they? Wasn't that also related to their energy?

5. Male student: Wasn't there an example with water?

6. Female student 2: Does this energy have something to do with amplitude? 
7. Female student 1: But wait, we were talking about sound waves, right? These spread out in a different way than waves in water, right?

8. Female student 1: But what happens with the energy then?

9. Female student 2: But wasn't there another way in which waves could become smaller, let's say attenuate?

10. Male student: There was an example with a rope, wasn't there?

11. Female student 1: But that does not happen with sound waves, does it?

12. Male student: But why do the waves attenuate in this problem?

13. Female student 2: These particles, weren't they related to the speed of waves?

14. Female student 2: So if you don't have a medium, would a wave still be able to propagate?

15. Male student: Wait, I don't understand. Why not?

16. Female student 1: But the problem says: 'electromagnetic waves'. How do we know these have anything to do with sound waves?

17. Male student: There is more that we don't know. In the line below that one a 'pulse' is mentioned. What is a pulse?

18. Male student: Yeah, okay, but what do they mean by that?

19. Female student 2: And why does it only help a little bit to increase the amplitude?

20. Female student 1: And extending these pulses doesn't help a lot either. How's that possible?

21. And there is also a good solution to the problem. What could that be?

\section{Excerpt from study text after the video}

Electromagnetic waves are waves of a special kind. They consist of two waves that are perpendicular to each other. One wave is generated by an electrical field and the other by a magnetic field. Their mutual interaction (when one wave peaks the other bottoms out) creates a joint circular movement. Propagation of the wave extends this into a corkscrew comparable to a vertical loop of a roller coaster.

There are two reasons why radar uses this type of waves. First, electromagnetic waves do not need a medium to propagate and second they are extremely fast. Because no medium is needed, there is no friction and no resulting attenuation. This is a good thing for radar, because unattenuated waves retain their energy and as a result are able to travel over long distances. We will return to this later.

The second reason why radar uses electromagnetic waves is their high velocity. In a vacuum electromagnetic waves propagate at the speed of light $(300,000 \mathrm{~km} / \mathrm{hr})$. For the sake of convenience we will assume that this speed is the same in air.

Posttest questions about the study text

1. Radar uses pulses to measure distance. Explain what a pulse is, while using the terms electromagnetic waves and electromagnetic energy. 
2. Radar sends out pulses instead of a continuous stream of waves. Explain why.

3. Pulses can show overlap.

a. Explain what overlap means and how it affects the measurement of distance.

b. How does radar prevent overlap from occurring?

4. Explain how radar measures distance. Use the following terms: antenna, clock, energy source, pulses, echo's.

5. What is noise and how can it be caused?

6. Radar uses electromagnetic waves because these do not need a medium in order to propagate. Explain why this is a reason.

7. Radar uses electromagnetic waves because these travel very fast. Why is this advantageous? Name all the reasons you can come up with.

8. Electromagnetic waves normally spread in all directions.

a. What influence does this have on the energy that they contain?

b. What happens to the energy when the waves hit something and reflect?

9. Why does the range of the radar decrease when electromagnetic waves spread out?

10. Radar can extend its' range by increasing the amplitude.

a. What is the amplitude and what causes it?

b. Why does increasing the amplitude extend the range?

c. Explain why this method is ineffective.

11. A more effective way to increase the range is converging the waves.

a. Explain why.

b. How does a radar converge its' waves?

c. What cannot be prevented when the radar converges its' waves?

d. How is this problem solved?

12. How does radar determine the position of airplanes?

13. How does radar determine the bearing of airplanes? 


\section{Appendix B: Materials used in experiments 3 and 4}

Problem discussed in the video

You are staying with your family in a vacation home in a hilly area. This morning, you and your smaller brother got up early and went into the hills with your bicycles. It turned out to become a hot, humid summer day. In the afternoon, dark thunderclouds appeared in the sky. Suddenly, you see lightning bolt dashing towards the earth. A few seconds later, it is followed by a rattling thunderclap. Soon afterwards, it starts pouring out of the sky. When your brother tries to seek shelter under a group of trees, you immediately pull him away from underneath these trees, into the open field. There, you tell him to squat.

Questions from teacher in the video

\section{S = Superficial \\ $E=$ Elaborative}

S: What are thunder clouds?

E: Do you know why a cumulonimbus cloud becomes so tall?

S: Do you know what J. means? (J. rephrased the prior knowledge that a cloud contains an electrical charge.)

$E$ : In a cloud, there are many currents of air. The cloud also contains water drops and hail stones. But what happens then? How can a difference in electrical charge come about within a cloud?

S: What R. just said, I do not understand entirely. Could you tell more about this? ( $R$. rephrased the prior knowledge that an electrical charge comes about within a cloud and erroneously states that cloud transfers this charge to the ground.)

$\mathrm{E}$ : If I understand $\mathrm{R}$. correctly, there is also a difference in electrical charge between the cloud and the earth. Could you explain how this difference in electrical charge comes about?

S: What is a lightning bolt, actually?

E: When you watch the sky carefully during a summer evening with thunder and lightning, you first see small flashes of light, followed by a lightning bolt. Can you explain this?

S: Do you know this perhaps? (After a remark by $\mathrm{R}$. that he does not know what thunder is.)

$\mathrm{E}$ : What does the loud noise have to do with the lightning bolt?

S: Where does lightning strike usually? 
$\mathrm{E}$ : The problem scenario stated that you pull your little brother from under the tree, into the open field. But is that not unsafe? Do you know why he does this?

S: What happens when you are hit by lightning?

E: Imagine a lightning bolt striking twenty meters away from you. I have read somewhere this is very dangerous too. But why? You are far enough from where it strikes.

S: Do you know what you can do best when lightning hits you?

$\mathrm{E}$ : Why is it your brother should squat and not lie down?

Note: Experiment 4 only used the elaborative questions.

Excerpt from study text after the video

In one situation, the air rises in the atmosphere during a warm period in the south of France. This causes a low pressure area. Warm air is lighter than cold air and therefore it rises. The rising air contains vaporized water, which forms clouds. Because the air rises quickly, these clouds stretch and become very high thunder clouds. The thunderclouds drift in our direction [i.e. the Netherlands] on a wind from the south.

\section{Relevant prior knowledge sentences in experiment 4}

1. Thunderclouds are very high clouds that reach till the upper levels of the atmosphere.

2. During the summer, warm air comes in our direction from the south of France.

3. All kinds of warm and cold air currents take place in the atmosphere.

4. A difference in electrical charge within a thundercloud causes lightning.

5. The thundercloud is charged positively at the top and negatively at the bottom.

6. The thundercloud contains water drops and hail stones.

7. During thunder and lightning, the electrical charges of the cloud and the earth differ.

8. The earth is charged positively compared to the cloud.

9. Lightning is an electrical current.

10. Just before the lightning bolt, there is a stepped leader.

11. Sometimes, you can see a small flash just before the lightning bolt.

12. Thunder is a loud bang you hear after the lightning bolt.

13. A lightning bolt is incredibly hot.

14. Lightning prefers to strike on points that stick out from their surroundings.

15. Lightning prefers to strike on points that conduct electricity well. 16. When you are struck by lightning, an electrical current runs through your body. 
17. Even at a reasonable distance from the point where lightning strikes, you can be in danger.

18. During thunder and lightning, you should go inside and close all windows and doors.

19. When you are outside during lightning, you should find shelter.

20. During lightning, you are safe inside a car.

21. When you are in an open field during lightning and cannot find any shelter, you should squat with your feet against each other.

Note: participants had to fill in the underscored words.

Irrelevant prior knowledge sentences in experiment 4

1. An earthquake is a vibration of the earth's crust.

2. Sometimes, the earth's mantle underneath the crust shakes as well.

3. The vibration is usually caused by fault lines.

4. A well-known fault line is the San Andreas Fault in California.

5. The earth exists of different layers.

6. The outer layer of the earth is called the crust.

7. The crust is made up of tectonic plates.

8. Tectonic plates are large pieces of earth that 'float' on the mantle underneath.

9. Two plates rubbing against each other cause a series of vibrations.

10. The crust consists of magma.

11. Magma is a red hot, syrupy mass.

12. Magma rises to the surface during an earth quake.

13. Underneath the mantle lies the earth's core.

14. The core is the center of the earth.

15. The core is an extremely hot sphere.

16. The place where plates drift against each other is called the hypocenter.

17. The hypocenter's depth can range from 60 to several hundreds of kilometers.

18. The place above the hypocenter on the earth's surface is called the epicenter.

19. The epicenter of an earthquake can also lie at the bottom of the sea.

20. An earthquake under the sea causes a tsunami.

21. A seismograph is a sling that registers movements in the crust.

Note: participants had to fill in the underscored words. 


\section{Summary}

Students can learn a lot from collaborating with each other, but at the same time the group process is highly complex. As a consequence, the impact of collaboration on learning achievement is a difficult study. One of the central aims of this thesis was to develop a new research method that would simplify the study of collaborative learning. Where educational researchers often investigate group learning in dynamic classrooms settings (King et al., 1998; Krol et al., 2004; Mercer \& Sams, 2006; Veenman et al., 2005; Webb \& Farivar, 1999), this thesis took a different approach. It explored the possibility to study collaboration in a more controlled, experimental environment.

The most important methodological adjustment this thesis made was to add experimental control over the quality of the group process. During collaboration, students can learn a lot from their mutual exchange of knowledge. However, the quality of this knowledge exchange can vary from group to group. In some groups, the discussion may therefore be more conducive to learning than in other groups. Previous research has never taken this notion into account and therefore, the present thesis aimed at increased control over the group process. It accomplished this be creating a simulation of a collaborative group discussion. A group discussion was recorded on video and presented to research participants in a controlled, experimental environment. By doing this, the exchange of knowledge in the group discussion was the same for all participants. Moreover, independent variables could be tested meticulously by making small adjustments to the video. These tested variables were grounded in the cognitive elaboration perspective of collaborative learning (O'Donnell, 2006; Slavin et al., 2003; Springer et al., 1999), which states that collaboration promotes cognitive elaboration and therefore fosters learning. Cognitive elaboration can be defined as the generation of new and meaningful relations between concepts (Levin, 1988; Wittrock, 1992). It leads to additional connections between the concepts, which are stored in memory. The additional connections lead to a richer and more redundant memory structure that contains more cues for retrieval. Therefore, it should be easier to retrieve information from memory at a later moment (Hamilton, 2004; Reder, 1980). It can be assumed that several activities promote elaboration in the group, but one that seems to stand out is explaining the learning materials to other students (Slavin et al., 2003). Several studies have shown that students who explain learning materials to each other learn more than individual learners (Dansereau, 1988). Also, students who do the explaining tend to recall more from the learning materials than students who listen to the explanations (Ross \& Di Vesta, 1976; Spurlin et al., 1984). This mirrors the findings from research to self-explanation, an individual activity that has improved achievement on a variety of learning tasks (Chi et al., 1994; De Bruin et al., 2007; 
Renkl et al., 1998). Explanation to others can lead to elaboration because it "may encourage explainers to clarify or reorganize materials in new ways, recognize and fill gaps in understanding, recognize and resolve inconsistencies, develop new perspectives, and construct more elaborate conceptualizations (Webb et al., 1995)." Therefore, the present thesis took explanation as a means to evoke elaboration during collaboration and tested the impact of this activity on subsequent learning achievement.

It was acknowledged that other variables could influence elaboration during the group process. Therefore, another central aim of this thesis was to test the effect of two additional variables on learning achievement. These variables were elaborative questions by a teacher and relevant prior knowledge. Several experiments have shown that students recall more information after generating explanations as a response to elaborative questions (Pressley et al., 1988; Pressley et al., 1992; Woloshyn et al., 1992). There are also indications that elaborative questions improve achievement during collaboration (King, 1990). Furthermore, there is evidence that a teacher can enhance students' achievement by prompting them to explain their reasoning (Webb et al., 2008). Therefore, it was expected that a teacher could promote learning achievement by asking elaborative questions.

In addition, it was hypothesized that the acquisition of relevant prior knowledge before the collaboration would facilitate elaboration and therefore improve learning achievement. Earlier experiments showed that relevant prior knowledge moderates the effect of elaboration on recalling facts (Willoughby et al., 1993; Woloshyn et al., 1992). That is, having relevant prior knowledge significantly improved the effect of elaboration on recalling new information. The expectation was that this would happen as well in a collaborative setting.

The educational context chosen to study collaborative learning was problem-based learning ( $P B L)$. We selected this specific form of group learning not only for practical reasons (i.e. the studies were performed at a university where PBL is the default method for education), but also because $\mathrm{PBL}$ builds on the cognitive elaboration perspective for collaborative learning. More specifically, PBL aims at the activation of and elaboration on prior knowledge during collaborative group discussions (Schmidt, 1993). It encompasses a cycle in which students first discuss a real-life situation in a small group. This situation is usually called the 'scenario' or the 'problem'. During the discussion, they will discover that they need more knowledge to explain the problem. So after the group discussion, they perform self-study in order to find more information that relates to the problem. When they have collected and studied enough materials, they gather again and report their findings. This final stage is called the reporting phase. (Hmelo-Silver, 2004; Schmidt et al., 2009).

The first part of the cycle is called the problem-based discussion, because the discussion is based on a real-life situation called the problem. This phase makes PBL quite unique. The problem-based discussion entails 
that students try to explain the problem before they actually gather more information about it. In other forms of collaborative learning, collaborative discussion tends to follow the acquisition of new information (Dansereau, 1988; King, 2007). Collaboration thus often serves to review previously learned information, whereas problem-based discussion intends to prepare students for new learning.

A first experiment tested the main independent variable: elaboration during the group discussion (Chapter 2). Research participants $(N=70)$ came to a psychological laboratory and observed a video of a problembased group discussion in one of three experimental conditions. In the first condition, they participated constructively in the group discussion by providing explanations to other group members. In a second condition, they participated passively, i.e. only listened to explanations from another group member. In a control condition, they participated passively in a discussion about an irrelevant topic. In agreement with the PBL cycle, all participants performed self-study after the group discussion. The results of this first experiment demonstrated that those who explained or listened during the discussion recalled more from this self-study than those in the control condition on the short term. This mirrored earlier findings of studies in which students performed real-life PBL discussions (De Grave et al., 2001; Schmidt et al., 1989), so these findings were replicated in the new, experimentally controlled situation.

After a delay of four weeks, the explainers recalled more than the listeners. It thus seemed that providing explanations facilitated long-term recall, which follows the notion that elaboration enriches the memory structure and therefore facilitates recall (Hamilton, 2004; Reder, 1980). The data also fit the cognitive elaboration perspective for collaborative learning (O'Donnell, 2006; Slavin et al., 2003; Springer et al., 1999) and the theoretical expectations of cognitive learning in PBL (Schmidt, 1993). Furthermore, the results corresponded with the general finding that PBL students retain more knowledge over time than students in conventional curricula (Dochy et al., 2003). It can therefore be concluded that elaboration during problem-based discussion improves long-term recall.

A possible drawback of the first experiment was that the explainers spent more time on providing explanations during the group discussion than the listeners spent on listening to explanations. Since relevant 'time on task' generally contributes to enhanced learning achievement (Wang et al., 1990), it was decided to replicate the experiment while providing more time for the listeners to listen and process the explanations from other students. Under these slightly adapted circumstances, we tested again if explanation would improve long-term recall (Chapter 3). The number of participants was approximately the same as in the first experiment $(N=71)$. The long-term effect of providing explanations on recall could not be replicated. This suggests that the results of experiment 1 were indeed confounded by the extra time it took to provide explanations. A second possibility is that the added time for the listeners 
in experiment 2 allowed them to reflect silently on the explanations they listened to. Silent reflection during problem-based discussions occurs (De Grave et al., 1996) and perhaps a similar reflection caused the listeners to recall more knowledge on the long term. Therefore, a tentative conclusion was that additional time to process explanations from other students improved long-term recall about as much as explaining to other students.

Experiment 3 tested the effect of a teacher who asked elaborative questions during the group discussion on students' recall of knowledge (Chapter 4). In PBL, teachers do not only convey knowledge to students, but also try to facilitate their learning process (Dolmans et al., 2002; Hmelo-Silver, 2004; Neville, 1999). An important task of the PBL teacher is to promote elaboration during the group discussion (De Grave et al., 1999) and to probe students to explain their reasoning (Wilkerson, 1994). Teachers can also ask students to relate contributions in the group discussion to their own prior knowledge (Lee et al., 2009). There is some evidence that teachers can promote learning achievement by asking directive, elaborative questions during PBL group meetings (Budé et al., 2009). The third experiment tried to extend these findings by studying elaborative teacher questions in a highly controlled, experimental environment.

Sixty-nine participants observed a video of a group discussion with a teacher. In the first experimental condition, the teacher asked elaborative questions. In the second condition, she asked superficial questions. All participants received some relevant prior knowledge before the group discussion and the 'elaborative questions' asked them to combine elements from this knowledge in order to generate new ideas. In contrast, the 'superficial questions' asked participants to reproduce the given prior knowledge or remarks by other group members. It was expected that participants would recall more from their self-study when they had answered the elaborative questions during the group discussion. However, this effect was not found. Reasons for this were sought and it seemed that mastering the provided prior knowledge played a role. Not all participants mastered this prior knowledge after studying it one time. Some needed two, three or four attempts to master the prior knowledge. The elaborative questions hardly affected participants who mastered the prior knowledge in one attempt, but they significantly improved long-term recall among participants who needed two, three or four attempts. They recalled more knowledge on the long term after responding to the elaborative questions than after responding to the superficial questions. It thus seemed that the elaborative questions were only beneficial for participants with more difficulties to master the prior knowledge. This corresponds to findings that elaboration is more effective for low- than for high-ability students (Hamilton, 1989; Mayer, 1980). Furthermore, the improved long-term recall mirrored the findings of experiment 1 and the theoretical expectation that elaboration facilitates the retrieval of knowledge (Hamilton, 2004; Reder, 1980). However, the results also 
made clear that the role of prior knowledge obtained before the group discussion should not be underestimated.

The role of prior knowledge was further explored in experiment 4, which tested if relevant prior knowledge could moderate the effect of elaboration on recall (Chapter 5). This expectation was based on studies with individual learners (Willoughby et al., 1993; Woloshyn et al., 1992) which showed that elaboration was especially effective when students possessed relevant prior knowledge about the subject. In a $2 \times 2$ experimental design, participants $(N=66)$ watched the same video as in experiment 3 , with the teacher who asked the elaborative questions. Half of the participants elaborated by answering the questions, whereas the other half completed distraction tasks. Also, half of the participants obtained relevant prior knowledge before the discussion, whereas the other half received irrelevant prior knowledge. The expected interaction effect was found. Participants who elaborated with relevant prior knowledge recalled significantly more than participants who elaborated without this prior knowledge. This accounted for both short- and longterm recall. The results indicated that relevant prior knowledge was pivotal for the effectiveness of elaboration during the group discussion. Perhaps the relevant prior knowledge provided more leads for the generation of new connections that were relevant for the group discussion and subsequent self-study. It is therefore possible that elaboration on the relevant prior knowledge 'set the stage' for new learning (Wetzels et al., 2011). Students tend to recall more information that fits the context of their activated prior knowledge (Machiels-Bongaerts et al., 1995; Peeck, 1982). Apparently, the activation of prior knowledge sets the stage for new learning, creating a contextual framework that determines which subsequently studied information is recalled best. Something similar can happen when students elaborate (Levin, 1988). That is, students will recall especially those parts of knowledge on which they elaborated beforehand. So when they elaborate on certain prior knowledge, they may create a contextual framework that determines which information will be recalled best later on. Future research could examine this by looking for overlap between the explanations from the group discussion and the information students recall after the group discussion.

Combined, the results suggest that elaboration during the group discussion facilitates long-term recall, but there are certain conditions for this effect. Elaborative teacher questions seem to be especially beneficial for students who master relevant prior knowledge less quickly. In addition, relevant prior knowledge appears to be a crucial factor for a positive effect of elaboration on short- and long-term recall. The new research method for collaborative learning proved to be useful, because it enabled the testing of elaboration while ignoring random effects by the group process. Furthermore, there were indications that the new method yielded similar results as real-life, collaborative settings. Moreover, the new method facilitates the study of collaborative learning, because the 
experiments can be conducted easily once appropriate materials have been developed. Another advantage is that researchers can apply the method to various forms of collaborative learning.

However, some caveats need to be considered. The new study method came with a downside, namely the inability to study interaction between students. Interaction may be even more promising for cognitive growth than constructive activities like providing self-explanations or explanations to others (Chi, 2009). The experiments particularly lacked the process of co-construction, which means that students extend a line of thought by supplementing each others' explanations (Chi, 2009; Van Boxtel et al., 2000). Adding co-construction could improve the experimental procedure.

A second limitation might be that collaboration was studied in a very specific context, namely a problem-based discussion. The effect of elaboration in other collaborative learning contexts may be different. A unique feature of a problem-based discussion is that collaboration precedes a phase of self-study. The problem forms the basis for selfstudy, hence the name problem-based learning. Other forms of collaborative learning often allow students to discuss something after they have learned it (Dansereau, 1988; King, 2007). Compared to these other forms, problem-based discussion may lead to a relatively broad discussion, because students still have little knowledge about the problem. It is possible that the explanations in such a discussion are relatively diverse and tentative. Tentative explanations can be defined as explanations that do not match the information that students encounter after the group discussion. For example, an (incorrect) explanation that friction causes lightning would be tentative when students subsequently learn that lightning is created by electrically charged particles in the atmosphere. Students can correct such tentative explanations during the PBL reporting phase after self-study. During this reporting phase, they can elaborate on their findings by explaining these to each other. This activity resembles the extensively studied act of explaining previously learned materials to others (Dansereau, 1988; King et al., 1998) or to oneself (Chi et al., 1994; De Bruin et al., 2007; Renkl et al., 1998). Explanations during the reporting phase are closely related to the self-study and are therefore probably less tentative. Therefore, the reporting phase may lead to a better recall of knowledge than the problem-based discussion. Future research could examine this, as well as the nature of the explanations during the problem-based discussion and the reporting phase. The problem-based discussion may contain more tentative explanations than the reporting phase, and this might be related to the amount of eventually recalled knowledge.

This thesis provided some new insights in collaborative learning. Not only did it show that student collaboration can be studied without random influences from the group discussion, it also provided empirical data for the cognitive elaboration perspective of collaborative learning (O'Donnell, 2006; Slavin et al., 2003; Springer et al., 1999). The results suggest that 
there are certain conditions under which elaboration facilitates self-study after problem-based discussion. Elaboration by means of providing explanations to others fosters long-term recall, but listening to explanations from others may be as conducive when students have additional time to process these explanations. A teacher can promote recall of information among low-achieving students by asking elaborative questions during the group discussion. And finally, elaboration during the group discussion needs to be supported by a basic level of prior knowledge. Students can use concepts from this prior knowledge to construct new and meaningful connections during the group discussion. 


\section{Samenvatting}

Studenten kunnen veel leren van samenwerken, maar tegelijkertijd is het groepsproces waar zij deel van uitkamen erg complex. Daardoor is het moeilijk om de invloed van samenwerking op leerprestaties te bestuderen. Het belangrijkste doel van dit proefschrift was om een nieuwe onderzoeksmethode te ontwikkelen die de studie van samenwerkend leren zou vergemakkelijken. Onderwijskundigen onderzoeken groepsleren vaak in een dynamische omgeving zoals een klaslokaal (King et al., 1998; Krol et al., 2004; Mercer \& Sams, 2006; Veenman et al., 2005; Webb \& Farivar, 1999). Dit proefschrift gebruikte een nieuwe benadering door samenwerkend leren in een gecontroleerde, experimentele omgeving te bestuderen.

De belangrijkste methodologische aanpassing was het toevoegen van experimentele controle over de kwaliteit van de groepsdiscussie. Tijdens samenwerking kunnen studenten veel leren van hun wederzijdse uitwisseling van kennis. De kwaliteit van deze kennis varieert echter van groep tot groep. Het is daarom mogelijk dat de discussie in sommige groepen meer bevorderlijk is voor het leren dan in andere groepen. Eerder onderzoek heeft dit nooit in ogenschouw genomen en daarom beoogde dit proefschrift de experimentele controle over het groepsproces te verhogen. Dit werd bereikt door een simulatie van een groepsdiscussie te creëren. Hiertoe werd een groepsdiscussie op video opgenomen en gepresenteerd aan onderzoeksdeelnemers in een gecontroleerde, experimentele setting. Zo werd elke individuele deelnemer blootgesteld aan exact dezelfde kennisuitwisseling in de groepsdiscussie. Bovendien kon de video gemakkelijk worden gemanipuleerd voor het testen van verschillende onafhankelijke variabelen. Deze getoetste variabelen vonden hun oorsprong in het cognitieve elaboratieperspectief van samenwerkend leren (O'Donnell, 2006; Slavin et al., 2003; Springer et al., 1999), dat aanvoert dat samenwerking cognitieve elaboratie en daardoor leerprestaties bevordert. Cognitieve elaboratie wordt gedefinieerd als de constructie van nieuwe en betekenisvolle relaties tussen bestaande concepten in het geheugen (Levin, 1988; Wittrock, 1992). Elaboratie leidt tot extra verbindingen tussen deze concepten, dus tot een verrijking van de kennisstructuur. Vervolgens biedt deze structuur meer aanknopingspunten (retrieval cues) voor het ophalen van kennis uit het geheugen. Het zou daarom gemakkelijker moeten zijn om informatie na een tijdje uit het geheugen op te diepen (Hamilton, 2004; Reder, 1980).

Het kan worden aangenomen dat verschillende activiteiten elaboratie tijdens het groepsproces bevorderen. Eén daarvan is het verklaren van leerstof aan anderen (Slavin et al., 2003). Verschillende studies hebben aangetoond dat studenten die elkaar verklaringen geven meer leren dan studenten die individueel leren (Dansereau, 1988). Er zijn ook aanwijzingen dat studenten die verklaringen geven meer leerstof 
onthouden dan studenten die luisteren naar deze verklaringen (Ross \& Di Vesta, 1976; Spurlin et al., 1984). Ook het verklaren van leerstof aan jezelf (met zogenaamde 'zelfverklaringen') heeft in diverse studies tot betere leerprestaties geleid (Chi et al., 1994; De Bruin et al., 2007; Renkl et al., 1998). Verklaringen geven aan anderen kan tot elaboratie leiden omdat het "de gevers van verklaringen kan aansporen tot het verhelderen of reorganiseren van materialen, het herkennen en opvullen van leemtes in het begrip, het herkennen en oplossen van inconsistenties, het ontwikkelen van nieuwe perspectieven en het construeren van uitgebreidere concepten (Webb et al., 1995)." Om die reden gebruikte de studies in dit proefschrift het geven van verklaringen als activiteit voor het opwekken van elaboratie tijdens samenwerkend leren, met als doel het testen van de invloed van deze activiteit op latere leerprestaties.

Nog een doel van dit proefschrift was om twee extra variabelen te bestuderen die de elaboratie tijdens het groepsproces konden beïnvloeden. Deze variabelen waren verdiepende vragen door een docent en relevante voorkennis. Verschillende experimenten hebben aangetoond dat studenten meer informatie onthouden nadat zij verklaringen genereren als reactie op verdiepende vragen (Pressley et al., 1988; Pressley et al., 1992; Woloshyn et al., 1992). Er zijn ook aanwijzingen dat elaboratieve vragen leerprestaties bevorderen als studenten ze aan elkaar stellen tijdens samenwerking (King, 1990). Verder is er bewijs dat docenten de leerprestaties van hun studenten kunnen bevorderen door hen te blijven herinneren aan het geven van verklaringen voor datgene wat ze aan het leren zijn (Webb et al., 2008). De verwachting was daarom dat een docent prestaties kon bevorderen door verdiepende vragen te stellen.

Verder werd voorspeld dat het vergaren van relevante voorkennis voorafgaand aan de samenwerking elaboratie kon faciliteren, omdat de voorkennis meer aanknopingspunten zou bieden voor het genereren van nieuwe verbanden. Eerdere experimenten toonden aan dat relevante voorkennis het effect van elaboratie op het herinneren van feiten modereert (Willoughby et al., 1993; Woloshyn et al., 1992). Met andere woorden versterkte de voorkennis het positieve effect dat elaboratie had op het onthouden van nieuwe informatie. De verwachting was dat dit ook zou gebeuren in een omgeving voor samenwerkend leren.

De vorm van samenwerking die werd gebruikt in de experimenten was probleemgestuurd onderwijs (PGO). Hier lagen niet alleen praktische redenen aan ten grondslag (de experimenten werden uitgevoerd aan een universiteit waar PGO de standaard onderwijsmethode is). Een andere belangrijke redden was dat PGO bouwt op het cognitieve elaboratieprincipe dat eerder werd genoemd. PGO richt zich op het gezamenlijk activeren van voorkennis tijdens de samenwerking en het elaboreren op die voorkennis door middel van discussie (Schmidt, 1993). Het omvat een cyclus waarin studenten eerst een scenario (ook wel het 'probleem' genoemd) bespreken in een groepje. Het scenario beschrijft 
een situatie uit de werkelijkheid. Tijdens het bespreken ervan ontdekken studenten dat zij onvoldoende kennis hebben om het scenario te kunnen verklaren. Daarom voeren zij zelfstudie uit na de groepsdiscussie, zodat zij meer informatie vinden die relateert aan het scenario. Wanneer ze genoeg materialen hebben verzameld en bestudeerd komen ze weer samen om hun bevindingen aan elkaar te rapporteren. Deze laatste fase heet de rapportagefase (Hmelo-Silver, 2004; Schmidt et al., 2009).

Het eerste deel van de cyclus, de bespreking van het scenario, kan de probleemgestuurde discussie worden genoemd, omdat de discussie is gebaseerd op het probleem (het scenario). Deze fase maakt PGO uniek. De probleemgestuurde discussie houdt in dat studenten het probleem proberen te verklaren voordat zij nieuwe informatie erover hebben vergaard. In andere vormen van samenwerkend leren komt de discussie meestal na het vergaren van nieuwe informatie (Dansereau, 1988; King, 2007). Een discussie tussen samenwerkende studenten heeft dus vaak het herzien van eerder geleerde kennis als doel, terwijl een probleemgestuurde discussie studenten juist voorbereidt op het leren van nieuwe informatie.

Een eerste experiment toetste de belangrijkste onafhankelijke variabele: elaboratie tijdens een probleemgestuurde groepsdiscussie (Hoofdstuk 2). De onderzoeksdeelnemers $(N=70)$ kwamen naar een psychologisch laboratorium en observeerden een video van een probleemgestuurde discussie in één van drie experimentele condities. In de eerste conditie droegen zij constructief bij aan de discussie door verklaringen te geven aan andere groepsleden. In een tweede conditie participeerden zij passief door alleen te luisteren naar verklaringen van een ander groepslid. In een controleconditie namen zij ook passief deel, maar dit keer in een discussie over een irrelevant onderwerp. In overeenkomst met de PGO-cyclus voerden alle deelnemers zelfstudie uit na de groepsdiscussie. De resultaten van dit eerste experiment toonden aan dat deelnemers die uitleg gaven of luisterden tijdens de discussie op de korte termijn meer informatie onthielden dan deelnemers in de controleconditie. Dit weerspiegelde de bevindingen van eerdere PGOexperimenten waarin studenten PGO discussies in het echt hielden (De Grave et al., 2001; Schmidt et al., 1989). De bevindingen van deze eerdere studies werden dus gerepliceerd in de nieuwe, experimenteel beter gecontroleerde situatie.

Tijdens een herhaalde kennismeting na vier weken herinnerden de deelnemers die verklaringen hadden gegeven meer dan de deelnemers die hadden geluisterd naar verklaringen. Het leek er dus op dat het geven van verklaringen een positief effect had op het lange termijngeheugen. Dit ligt in lijn met de theoretische verwachting dat elaboratie de kennisstructuur verrijkt en daardoor meer aanknopingspunten (retrieval cues) biedt voor het ophalen van kennis (Hamilton, 2004; Reder, 1980). De resultaten ondersteunden het cognitieve elaboratieperspectief voor samenwerkend leren (O'Donnell, 2006; Slavin et al., 2003; Springer et al., 1999) en de 
theoretische verwachtingen van cognitief leren in PGO (Schmidt, 1993). Ook correspondeerden de resultaten met de algemene bevinding dat PGOstudenten meer kennis onthouden op de lange termijn dan studenten die onderwijs krijgen via conventionele curricula (Dochy et al., 2003). Het kan daarom geconcludeerd worden dat elaboratie tijdens probleemgestuurde discussie het lange termijngeheugen bevordert.

Een nadeel van het eerste experiment was dat de gevers van verklaringen meer tijd besteedden aan het geven van verklaringen dan de luisteraars aan het luisteren naar verklaringen. Omdat de tijd die wordt besteed aan relevante studie bijdraagt aan verhoogde leerprestaties (Wang et al., 1990), werd besloten om het experiment te herhalen en de luisteraars meer tijd te geven tijdens de discussie (Hoofdstuk 3). Het aantal deelnemers was ongeveer hetzelfde als in het eerste experiment $(N$ $=71$ ). Het lange termijneffect van verklaringen geven op het onthouden van kennis werd niet opnieuw gevonden. Dit suggereert dat dit effect in experiment 1 inderdaad beïnvloed werd door de extra tijd die het geven van verklaringen kostte. Een tweede mogelijkheid is dat de extra tijd die de luisteraars kregen hen meer gelegenheid bood om stil te reflecteren op de verklaringen van andere studenten. Stille reflectie komt voor tijdens probleemgestuurde discussies (De Grave et al., 1996) en misschien zorgde een dergelijke reflectie ervoor dat de luisteraars meer onthielden op de lange termijn. Een voorzichtige conclusie was daarom dat extra tijd voor het verwerken van verklaringen van anderen het lange termijngeheugen ongeveer net zo veel bevorderde als het geven van verklaringen aan andere studenten.

Experiment 3 toetste het effect van een docent die verdiepende vragen stelde tijdens de groepsdiscussie op het onthouden van kennis (Hoofdstuk 4). In PGO dragen docenten niet alleen kennis over naar studenten, zij faciliteren ook het leerproces van de studenten (Dolmans et al., 2002; Hmelo-Silver, 2004; Neville, 1999). Een belangrijke taak van de PGO-docent is het aansporen tot elaboratie tijdens de groepsdiscussie (De Grave et al., 1999), bijvoorbeeld door studenten hun redeneringen uit te laten leggen (Wilkerson, 1994). Docenten kunnen studenten ook vragen om de verschillende bijdragen aan de groepsdiscussie te relateren aan hun eigen, persoonlijke voorkennis (Lee et al., 2009). Er is enig bewijs dat docenten leerprestaties kunnen bevorderen door sturende, verdiepende vragen te stellen tijdens PGO-groepsdiscussies (Budé et al., 2009). Het derde experiment bouwde op deze gegevens door verdiepende vragen door een docent op te wekken in een gecontroleerde, experimentele studie.

Zesennegentig deelnemers observeerden een video van een groepsdiscussie met een docent. In de eerste experimentele conditie stelde de docent verdiepende vragen en in de tweede conditie oppervlakkige vragen. Alle deelnemers kregen vóór de groepsdiscussie enige relevante voorkennis. De verdiepende vragen lieten hen elementen uit deze voorkennis combineren tot nieuwe ideeën. De oppervlakkige 
vragen lieten hen de gegeven voorkennis (of opmerkingen van groepsleden) reproduceren. De verwachting was dat deelnemers meer van hun zelfstudie na de groepsdiscussie zouden onthouden als zij de verdiepende vragen hadden beantwoord. Deze voorspelling kwam echter niet uit. Hiervoor werden redenen gezocht en het leek erop dat het beheersen van de voorkennis een rol had kunnen spelen. Niet alle deelnemers beheersten deze voorkennis na haar één keer bestudeerd te hebben. Sommigen hadden twee, drie of vier pogingen nodig. De verdiepende docentvragen hadden nauwelijks invloed op deelnemers die de voorkennis in één poging beheersten, maar wel een significant en positief lange termijneffect op deelnemers die twee, drie of vier pogingen nodig hadden. Zij onthielden op de lange duur meer informatie als ze verdiepende vragen hadden beantwoord dan als ze oppervlakkige vragen hadden beantwoord. Het leek er dus op dat de verdiepende vragen alleen effectief waren voor deelnemers die meer moeite hadden de voorkennis te beheersen. Dit ligt op één lijn met bevindingen dat elaboratie effectiever is voor laag- dan voor hoogpresterende studenten (Hamilton, 1989; Mayer, 1980). Verder spoort het feit dat er alleen een effect op de lange termijn was met de resultaten van experiment 1 en de theoretische verwachting dat elaboratie het ophalen van kennis vergemakkelijkt (Hamilton, 2004; Reder, 1980). De resultaten toonden ook aan dat de rol van de voorkennis waarmee studenten een groepsdiscussie beginnen niet onderschat kan worden.

De rol van voorkennis werd verder verkend in experiment 4, dat toetste of relevante voorkennis het effect van elaboratie op onthouden informatie kon modereren (Hoofdstuk 5). Deze hypothese was gebaseerd op studies met individuele studenten (Willoughby et al., 1993; Woloshyn et al., 1992) die aantoonden dat elaboratie vooral bevorderend werkte als studenten vooraf relevante voorkennis over het onderwerp hadden. In een $2 \times 2$ experimenteel ontwerp observeerden deelnemers ( $N$ $=66$ ) dezelfde video als in experiment 3 . Ze observeerden de versie van de video waarin de docent de verdiepende vragen stelde. De helft van de deelnemers elaboreerde door de vragen te beantwoorden en de andere helft maakte in plaats hiervan afleidingstaken. Verder kreeg de helft van de deelnemers relevante voorkennis voor de groepsdiscussie en de andere helft irrelevante voorkennis. Het verwachte interactie-effect tussen elaboratie en voorkennis werd gevonden. Deelnemers die elaboreerden met relevante voorkennis onthielden significant meer dan deelnemers die elaboreerden zonder deze voorkennis. Dit effect gold voor zowel de korte als de lange termijn. De bevindingen impliceerden dat relevante voorkennis cruciaal is voor de effectiviteit van elaboratie tijdens groepsdiscussie. Waarschijnlijk bood de relevante voorkennis meer mogelijkheden voor het genereren van nieuwe verbanden die relevant waren voor de groepsdiscussie en de daaropvolgende zelfstudie. Het is daarom mogelijk dat elaboreren op relevante voorkennis een opstapje vormde voor de latere zelfstudie (Wetzels et al., 2011). Er zijn 
aanwijzingen dat studenten meer informatie onthouden die past binnen de context van door henzelf geactiveerde voorkennis (Machiels-Bongaerts et al., 1995; Peeck, 1982). De activering van voorkennis vormt blijkbaar een opstapje voor nieuw leren door een contextueel kader te scheppen dat bepaalt welke informatie het beste wordt onthouden. Iets dergelijks kan ook gebeuren als studenten elaboreren (Levin, 1988). Met andere woorden zullen studenten vooral die kennisonderdelen onthouden waarop zij op voorhand elaboreerden. Dus als zij elaboreren op bepaalde voorkennis scheppen ze wellicht een contextueel kader, waardoor ze informatie die strookt met de geactiveerde voorkennis beter onthouden. Verder onderzoek zou dit uit kunnen zoeken door de overlap tussen verklaringen tijdens de groepsdiscussie en onthouden informatie in kaart te brengen.

De gezamenlijke resultaten wijzen erop dat elaboratie tijdens probleemgestuurde groepsdiscussie het onthouden van kennis op de lange termijn bevordert. Er zijn echter enkele voorwaarden voor dit effect. Verdiepende docentvragen lijken vooral effectief te zijn voor studenten die aangeboden voorkennis minder snel beheersen. Verder lijkt relevante voorkennis van cruciaal belang voor een positief effect van elaboratie op het onthouden van kennis op de korte en lange termijn. De nieuwe onderzoeksmethode voor samenwerkend leren bewees zijn waarde omdat deze de toetsing van elaboratie tijdens een complex groepsproces vergemakkelijkte. Ook waren er indicaties dat de nieuwe methode dezelfde resultaten opleverde als experimenten met echte PGO-groepen. Experimenten kunnen gemakkelijk gerepliceerd worden met de nieuwe methode, wat de studie van samenwerkend leren simpeler maakt. Nog een voordeel is dat onderzoekers de methode kunnen toepassen op verschillende vormen van samenwerkend leren.

Er moeten echter enkele kanttekeningen worden gemaakt. De nieuwe onderzoeksmethode had als nadeel dat het moeilijk werd om de interactie tussen studenten te onderzoeken. Voor cognitieve ontwikkeling is interactie wellicht nog belangrijker dan constructieve activiteiten als verklaringen aan anderen of zelfverklaringen geven (Chi, 2009). In het bijzonder laakten de experimenten een proces dat co-constructie wordt genoemd. Co-constructie houdt in dat studenten een gedachtelijn voortzetten door elkaars verklaringen aan te vullen (Chi, 2009; Van Boxtel et al., 2000). Het toevoegen van co-constructie zou de experimentele methode kunnen verbeteren.

Een mogelijke tweede beperking is dat samenwerking werd onderzocht in een specifieke context, namelijk een probleemgestuurde discussie. Het effect van elaboratie kan verschillen in andere omgevingen voor samenwerkend leren. Een unieke eigenschap van een probleemgestuurde discussie is dat de samenwerking voorafgaat aan de zelfstudie. Het probleem vormt de basis voor zelfstudie, vandaar de naam probleemgestuurd onderwijs. Andere vormen van samenwerkend leren laten studenten vaak iets bediscussiëren nadat zij het geleerd hebben 
(Dansereau, 1988; King, 2007). In vergelijking met deze andere vormen leidt een probleemgestuurde discussie misschien tot een relatief brede discussie omdat studenten nog steeds weinig voorkennis over het probleem hebben. Het is mogelijk dat de verklaringen in zo'n discussie vrij uiteenlopend en tentatief zijn. Tentatieve verklaringen kunnen worden gedefinieerd als verklaringen die niet overeenkomen met de informatie die studenten tegenkomen tijdens de zelfstudie na de groepsdiscussie. Een (incorrecte) verklaring dat wrijving een bliksemflits veroorzaakt is bijvoorbeeld tentatief als de student vervolgens leert dat een bliksemflits tot stand komt door elektrisch geladen deeltjes in de atmosfeer. Studenten kunnen dergelijke tentatieve verklaringen rechtzetten tijdens de rapportagefase na de zelfstudie. Tijdens deze fase kunnen ze elaboreren op hun bevindingen door deze aan elkaar uit te leggen. Deze activiteit weerspiegelt het geven van verklaringen na zelfstudie en is vaak onderzocht, ofwel als verklaringen geven aan anderen (Dansereau, 1988; King et al., 1998), ofwel als zelfverklaringen (Chi et al., 1994; De Bruin et al., 2007; Renkl et al., 1998). Verklaringen tijdens de rapportagefase houden direct verband met de zelfstudie en zijn daarom waarschijnlijk minder tentatief. Het zou daarom kunnen dat de rapportagefase het onthouden van kennis meer bevordert dan de voorafgaande probleemgestuurde discussie. Dit kan onderzocht worden met vervolgonderzoek. Ook kan gekeken worden naar de aard van de gegeven verklaringen. Studenten produceren misschien meer tentatieve verklaringen tijdens de probleemgestuurde discussie dan tijdens de rapportagefase. Dit kan weer gerelateerd zijn aan de hoeveelheid uiteindelijk onthouden kennis.

Dit proefschrift verschafte nieuwe inzichten in het proces van samenwerkend leren. Het toonde aan dat elaboratie tijdens samenwerkend leren bestudeerd kan worden zonder de invloed van andere, willekeurige groepsprocessen. Het leverde ook empirisch bewijs voor het cognitieve elaboratieprincipe van samenwerkend leren (O'Donnell, 2006; Slavin et al., 2003; Springer et al., 1999). De resultaten suggereren dat er bepaalde condities zijn waaronder elaboratie de zelfstudie na een probleemgestuurde discussie kan bevorderen. Elaboratie door het geven van verklaringen aan anderen bevordert het onthouden van informatie op de lange termijn, maar luisteren naar verklaringen van anderen is net zo effectief als er meer tijd is om te reflecteren op deze verklaringen. Door verdiepende vragen te stellen kan een docent ervoor zorgen dat minder goede studenten meer kennis onthouden op de lange termijn. En als laatste moet elaboratie tijdens de groepsdiscussie ondersteund worden door een zeker niveau van voorkennis. Studenten kunnen concepten uit deze voorkennis gebruiken om nieuwe en betekenisvolle verbanden te leggen. 


\section{Referenties}

Albanese, M. A. (1993). Problem-based learning: A review of literature on its outcomes and implementation issues. Academic Medicine, 68(1), 52-81.

Asterhan, C. S. C., \& Schwarz, B. B. (2007). The effects of monological and dialogical argumentation on concept learning in evolutionary theory. Journal of Educational Psychology, 99(3), 626-639.

Bargh, J. A., \& Schul, Y. (1980). On the cognitive benefits of teaching. Journal of Educational Psychology, 72(5), 593-604.

Bobrow, S. A., \& Bower, G. H. (1969). Comprehension and recall of sentences. Journal of Experimental Psychology, 80(3), 455-461.

Brown, A. L., \& Palincsar, A. S. (1989). Guided, cooperative learning and individual knowledge acquisition. In L. B. Resnick (Ed.), Knowing, learning, and instruction: Essays in honor of Robert Glaser (pp. 393-451). Hillsdale, NJ: Erlbaum.

Budé, L., Imbos, T., Van der Wiel, M., Broers, N., \& Berger, M. (2009). The effect of directive tutor guidance in problem-based learning of statistics on students' perceptions and achievement. Higher Education, 57(1), 23-36.

Capon, N., \& Kuhn, D. (2004). What's so good about problem-based learning? Cognition and Instruction, 22(1), 61-79.

Chi, M. T. H. (2000). Self-explaining expository texts: The dual processes of generating inference and repairing mental models. In R. Glaser (Ed.), Advances in Instructional Psychology (Vol. 5, pp. 161-238). Mahwah, NJ, US: Erlbaum.

Chi, M. T. H. (2009). Active-constructive-interactive: A conceptual framework for differentiating learning activities. Topics in Cognitive Science, 1(1), 73-105.

Chi, M. T. H., De Leeuw, N., Chiu, M. H., \& La Vancher, C. (1994). Eliciting selfexplanations improves understanding. Cognitive Science, 18(3), 439-477.

Chi, M. T. H., Siler, S. A., Jeong, H., Yamauchi, T., \& Hausmann, R. G. (2001). Learning from human tutoring. Cognitive Science, 25(4), 471-533.

Chinn, C. A., \& Brewer, W. F. (1993). The role of anomalous data in knowledge acquisition: A theoretical framework and implications for science instruction. Review of Educational Research, 63(1), 1-49.

Cohen, J. (1988). Statistical power analysis for the behavioral sciences (2nd ed.). Hillsdale, NJ: Erlbaum.

Cohen, J. (1992). A power primer. Psychological Bulletin, 112(1), 155-159.

Colliver, J. A. (2000). Effectiveness of problem-based learning curricula: Research and theory. Academic Medicine, 75(3), 259-266.

Dansereau, D. F. (1988). Cooperative learning strategies. In C. E. Weinstein, E. T. Goetz \& P. A. Alexander (Eds.), Learning and study strategies: Issues in assessment, instruction, and evaluation (pp. 103-120). San Diego, CA: Academic Press.

Dansereau, D. F., Collins, K. W., McDonald, B. A., Holley, C. D., Garland, J., Diekhoff, G., et al. (1979). Development and evaluation of a learning strategy training program. Journal of Educational Psychology, 71(1), 64-73.

De Bruin, A. B. H., Rikers, R. M. J. P., \& Schmidt, H. G. (2007). The effect of selfexplanation and prediction on the development of principled understanding of chess in novices. Contemporary Educational Psychology, 32(2), 188-205.

De Grave, W. S., Boshuizen, H. P. A., \& Schmidt, H. G. (1996). Problem based learning: Cognitive and metacognitive processes during problem analysis. Instructional Science, 24(5), 321-341.

De Grave, W. S., Dolmans, D. H. J. M., \& Van der Vleuten, C. P. M. (1999). Profiles of effective tutors in problem-based learning: Scaffolding student learning. Medical Education, 33(12), 901-906.

De Grave, W. S., Schmidt, H. G., \& Boshuizen, H. P. A. (2001). Effects of problembased discussion on studying a subsequent text: A randomized trial among first year medical students. Instructional Science, 29(1), 33-44. 
Dillenbourg, P., \& Tchounikine, P. (2007). Flexibility in macro-scripts for computersupported collaborative learning. Journal of Computer Assisted Learning, 23(1), 1-13.

Dochy, F., Segers, M., Van den Bossche, P., \& Gijbels, D. (2003). Effects of problem-based learning: A meta-analysis. Learning and Instruction, 13(5), 533-568.

Dolmans, D. H. J. M., Gijselaers, W. H., Moust, J. H. C., De Grave, W. S., Wolfhagen, I. H. A. P., \& Van der Vleuten, C. P. M. (2002). Trends in research on the tutor in problem-based learning: Conclusions and implications for educational practice and research. Medical Teacher, 24(2), 173-180.

Dolmans, D. H. J. M., \& Schmidt, H. G. (2006). What do we know about cognitive and motivational effects of small group tutorials in problem-based learning? Advances in Health Sciences Education, 11(4), 321-336.

Durling, R., \& Schick, C. (1976). Concept attainment by pairs and individuals as a function of vocalization. Journal of Educational Psychology, 68(1), 83-91.

Eisenstaedt, R. S., Barry, W. E., \& Glanz, K. (1990). Problem-based learning: Cognitive retention and cohort traits of randomly selected participants and decliners. Academic Medicine, 65(9, Suppl.), 11-12.

Fuchs, L. S., Fuchs, D., Hamlett, C. L., \& Karns, K. (1998). High-achieving students' interactions and performance on complex mathematical tasks as a function of homogeneous and heterogeneous pairings. American Educational Research Journal, 35(2), 227-267.

Gholson, B., Witherspoon, A., Morgan, B., Brittingham, J. K., Coles, R., Graesser, A. C., et al. (2009). Exploring the deep-level reasoning questions effect during vicarious learning among eighth to eleventh graders in the domains of computer literacy and Newtonian physics. Instructional Science, 37(5), 487493.

Hamilton, R. J. (1989). The effects of learner-generated elaborations on concept learning from prose. The Journal of Experimental Education, 57(3), 205-217.

Hamilton, R. J. (2004). Material appropriate processing and elaboration: The impact of balanced and complementary types of processing on learning concepts from text. British Journal of Educational Psychology, 74(2), 221-237.

Hmelo-Silver, C. E. (2004). Problem-based learning: What and how do students learn? Educational Psychology Review, 16(3), 235-266.

Hmelo-Silver, C. E., \& Barrows, H. S. (2008). Facilitating collaborative knowledge building. Cognition and Instruction, 26, 48-94.

Hmelo-Silver, C. E., Chernobilsky, E., \& Jordan, R. (2008). Understanding collaborative learning processes in new learning environments. Instructional Science, 36(5-6), 409-430.

Johnsey, A., Morrison, G. R., \& Ross, S. M. (1992). Using elaboration strategies training in computer-based instruction to promote generative learning. Contemporary Educational Psychology, 17(2), 125-135.

King, A. (1990). Enhancing peer interaction and learning in the classroom through reciprocal questioning. American Educational Research Journal, 27(4), 664687.

King, A. (2007). Beyond literal comprehension: A strategy to promote deep understanding of text. In D. S. McNamara (Ed.), Reading comprehension strategies: Theories, interventions, and technologies (pp. 267-290). Mahwah, NJ: Erlbaum.

King, A., Staffieri, A., \& Adelgais, A. (1998). Mutual peer tutoring: Effects of structuring tutorial interaction to scaffold peer learning. Journal of Educational Psychology, 90(1), 134-152.

Krol, K., Janssen, J., Veenman, S., \& Van der Linden, J. (2004). Effects of a cooperative learning program on the elaborations of students working in dyads. Educational Research and Evaluation, 10(3), 205-237.

Larson, C. O., Dansereau, D. F., O'Donnell, A. M., Hythecker, V. I., Lambiotte, J. G., \& Rocklin, T. R. (1985). Effects of metacognitive and elaborative activity 
on cooperative learning and transfer. Contemporary Educational Psychology, 10(4), 342-348.

Lee, G.-H., Lin, Y.-H., Tsou, K.-I., Shiau, S.-J., \& Lin, C.-S. (2009). When a problem-based learning tutor decides to intervene. Academic Medicine, 84(10), 1406-1410.

Levin, J. R. (1988). Elaboration-based learning strategies: Powerful theory=powerful application. Contemporary Educational Psychology, 13(3), 191-205.

Lloyd, J., Margetson, D., \& Bligh, J. G. (1998). Problem-based learning: A coat of many colours. Medical Education, 32(5), 492-494.

Machiels-Bongaerts, M., Schmidt, H. G., \& Boshuizen, H. P. A. (1995). The effect of prior knowledge activation on text recall: An investigation of two conflicting hypotheses. British Journal of Educational Psychology, 65(4), 409-423.

Mayer, R. E. (1980). Elaboration techniques that increase the meaningfulness of technical text: An experimental test of the learning strategy hypothesis. Journal of Educational Psychology, 72(6), 770-784.

Mayer, R. E. (1985). Structural analysis of science prose: Can we increase problemsolving performance? In B. K. Britton \& J. B. Black (Eds.), Understanding expository text: A theoretical and practical handbook for analyzing explanatory text. Hillsdale, NJ: Erlbaum.

McDonald, B. A., Larson, C. O., Dansereau, D. F., \& Spurlin, J. E. (1985). Cooperative dyads: Impact on text learning and transfer. Contemporary Educational Psychology, 10(4), 369-377.

Mercer, N., Dawes, L., Wegerif, R., \& Sams, C. (2004). Reasoning as a scientist: Ways of helping children to use language to learn science. British Educational Research Journal, 30(3), 359-377.

Mercer, N., \& Sams, C. (2006). Teaching children how to use language to solve maths problems. Language and Education, 20(6), 507-528.

Moust, J. H. C., Schmidt, H. G., De Volder, M. L., Belien, J. J., \& De Grave, W. S. (1987). Effects of verbal participation in small group discussion. In J. T. E. Richardson, M. W. Eysenck \& D. W. Piper (Eds.), Student learning: Research in education and cognitive psychology (pp. 147-154). Guildford Maidenhead, BRK England: Society for Research into Higher Education, Open University Press.

Neville, A. J. (1999). The problem-based learning tutor: Teacher? Facilitator? Evaluator? Medical Teacher, 21(4), 393-401.

Nussbaum, E. M. (2008). Collaborative discourse, argumentation, and learning: Preface and literature review. Contemporary Educational Psychology, 33, 345359.

O'Donnell, A. M. (1996). Effects of explicit incentives on scripted and unscripted cooperation. Journal of Educational Psychology, 88(1), 74-86.

O'Donnell, A. M. (2006). The role of peers and group learning. In P. H. Winne \& P. A. Alexander (Eds.), Handbook of educational psychology (pp. 781-802). Mahwah, NJ: Erlbaum.

O'Donnell, A. M., Dansereau, D. F., Rocklin, T. R., Hythecker, V. I., Lambiotte, J. G., Larson, C. O., et al. (1985). Effects of elaboration frequency on cooperative learning. Journal of Educational Psychology, 77(5), 572-580.

Peeck, J. (1982). Effects of mobilization of prior knowledge on free recall. Journal of Experimental Psychology: Learning, Memory, and Cognition, 8(6), 608-612.

Peterson, P. L., \& Swing, S. R. (1985). Students' cognitions as mediators of the effectiveness of small-group learning. Journal of Educational Psychology, 77(3), 299-312.

Pichert, J. W., \& Anderson, R. C. (1977). Taking different perspectives on a story. Journal of Educational Psychology, 69(4), 309-315.

Pressley, M., McDaniel, M. A., Turnure, J. E., Wood, E., \& Ahmad, M. (1987). Generation and precision of elaboration: Effects on intentional and incidental learning. Journal of Experimental Psychology: Learning, Memory, and Cognition, 13(2), 291-300. 
Pressley, M., Symons, S., McDaniel, M. A., Snyder, B. L., \& Turnure, J. E. (1988). Elaborative interrogation facilitates acquisition of confusing facts. Journal of Educational Psychology, 80(3), 268-278.

Pressley, M., Tanenbaum, R., McDaniel, M. A., \& Wood, E. (1990). What happens when university students try to answer prequestions that accompany textbook material? Contemporary Educational Psychology, 15(1), 27-35.

Pressley, M., Wood, E., Woloshyn, V. E., Martin, V., King, A., \& Menke, D. (1992). Encouraging mindful use of prior knowledge: Attempting to construct explanatory answers facilitates learning. Educational Psychologist, 27(1), 91109.

Reder, L. M. (1980). The role of elaboration in the comprehension and retention of prose: A critical review. Review of Educational Research, 50(1), 5-53.

Renkl, A., Stark, R., Gruber, H., \& Mandl, H. (1998). Learning from worked-out examples: The effects of example variability and elicited self-explanations. Contemporary Educational Psychology, 23(1), 90-108.

Rewey, K. L., Dansereau, D. F., Skaggs, L. P., Hall, R. H., \& Pitre, U. (1989). Effects of scripted cooperation and knowledge maps on the processing of technical material. Journal of Educational Psychology, 81(4), 604-609.

Rosenshine, B., Meister, C., \& Chapman, S. (1996). Teaching students to generate questions: A review of the intervention studies. Review of Educational Research, 66(2), 181-221.

Roseth, C. J., Johnson, D. W., \& Johnson, R. T. (2008). Promoting early adolescents' achievement and peer relationships: The effects of cooperative, competitive, and individualistic goal structures. Psychological Bulletin, 134(2), 223-246.

Ross, S. M., \& Di Vesta, F. J. (1976). Oral summary as a review strategy for enhancing recall of textual material. Journal of Educational Psychology, 68(6), 689-695.

Schmidt, H. G. (1984). Activatie van voorkennis en tekstverwerking / Activation of prior knowledge and text processing. Nederlands Tijdschrift voor de Psychologie en haar Grensgebieden, 39(6), 335-347.

Schmidt, H. G. (1993). Foundation of problem-based learning: Some explanatory notes. Medical Education, 27(5), 422-432.

Schmidt, H. G., De Volder, M. L., De Grave, W. S., Moust, J. H. C., \& Patel, V. L. (1989). Explanatory models in the processing of science text: The role of prior knowledge activation through small-group discussion. Journal of Educational Psychology, 81(4), 610-619.

Schmidt, H. G., Van der Molen, H. T., Te Winkel, W. W. R., \& Wijnen, W. H. F. W. (2009). Constructivist, problem-based learning does work: A meta-analysis of curricular comparisons involving a single medical school. Educational Psychologist, 44(4), 227-249.

Schwartz, D. L., \& Bransford, J. D. (1998). A time for telling. Cognition and Instruction, 16(4), 475-522.

Slamecka, N. J., \& Graf, P. (1978). The generation effect: Delineation of a phenomenon. Journal of Experimental Psychology: Human Learning and Memory, 4(6), 592-604.

Slavin, R. E., Hurley, E. A., \& Chamberlain, A. (2003). Cooperative learning and achievement: Theory and research. In G. E. Miller \& W. M. Reynolds (Eds.), Handbook of psychology: Educational psychology (Vol. 7, pp. 177-198). Hoboken, NJ: John Wiley \& Sons.

Springer, L., Stanne, M. E., \& Donovan, S. S. (1999). Effects of small-group learning on undergraduates in science, mathematics, engineering, and technology: A meta-analysis. Review of Educational Research, 69(1), 21-51.

Spurlin, J. E., Dansereau, D. F., Larson, C. O., \& Brooks, L. W. (1984). Cooperative learning strategies in processing descriptive text: Effects of role and activity level of the learner. Cognition and Instruction, 1(4), 451-463.

Strijbos, J.-W., Martens, R. L., Prins, F. J., \& Jochems, W. M. G. (2006). Content analysis: What are they talking about? Computers \& Education, 46(1), 29-48. 
Tans, R. W., Schmidt, H. G., Schade-Hoogeveen, B. E., \& Gijselaers, W. H. (1986). Sturing van het onderwijsleerproces door middel van problemen: een veldexperiment / Problem-based learning: A field experiment. Tijdschrift voor Onderwijsresearch, 11(1), 35-46.

Teasley, S. D. (1995). The role of talk in children's peer collaborations. Developmental Psychology, 31(2), 207-220.

Van Boxtel, C., Van der Linden, J., \& Kanselaar, G. (2000). Collaborative learning tasks and the elaboration of conceptual knowledge. Learning and Instruction, $10,311-330$.

Veenman, S., Denessen, E., Van den Akker, A., \& Van der Rijt, J. (2005). Effects of a cooperative learning program on the elaborations of students during help seeking and help giving. American Educational Research Journal, 42(1), 115151.

Vernon, D. T., \& Blake, R. L. (1993). Does problem-based learning work? A metaanalysis of evaluative research. Academic Medicine, 68(7), 550-563.

Wang, M. C., Haertel, G. D., \& Walberg, H. J. (1990). What influences learning? A content analysis of review literature. Journal of Educational Research, 84(1), 30-43.

Webb, N. M. (1989). Peer interaction and learning in small groups. International Journal of Educational Research, 13(1), 21-39.

Webb, N. M., \& Farivar, S. (1999). Developing productive group interaction in middle school mathematics. In A. M. O'Donnell \& A. King (Eds.), Cognitive perspectives on peer learning (pp. 117-149). Mahwah, NJ: Erlbaum.

Webb, N. M., Franke, M. L., Ing, M., Chan, A., De, T., Freund, D., et al. (2008). The role of teacher instructional practices in student collaboration. Contemporary Educational Psychology, 33(3), 360-381.

Webb, N. M., Nemer, K. M., Chizhik, A. W., \& Sugrue, B. (1998). Equity issues in collaborative group assessment: Group composition and performance. American Educational Research Journal, 35(4), 607-651.

Webb, N. M., Troper, J. D., \& Fall, R. (1995). Constructive activity and learning in collaborative small groups. Journal of Educational Psychology, 87(3), 406-423.

Wetzels, S. A. J., Kester, L., \& van Merriënboer, J. J. G. (2011). Adapting prior knowledge activation: Mobilisation, perspective taking, and learners' prior knowledge. Computers in Human Behavior, 27(1), 16-21.

Wilkerson, L. (1994). Identification of skills for the problem-based tutor: Student and faculty perspectives. Instructional Science, 22(4), 303-315.

Willoughby, T., Waller, T. G., Wood, E., \& MacKinnon, G. E. (1993). The effect of prior knowledge on an immediate and delayed associative learning task following elaborative interrogation. Contemporary Educational Psychology, 18(1), 36-46.

Wittrock, M. C. (1992). Generative learning processes of the brain. Educational Psychologist, 27(4), 531-541.

Woloshyn, V. E., Pressley, M., \& Schneider, W. (1992). Elaborative-interrogation and prior-knowledge effects on learning of facts. Journal of Educational Psychology, 84(1), 115-124.

Yager, S., Johnson, D. W., \& Johnson, R. T. (1985). Oral discussion, group-toindividual transfer, and achievement in cooperative learning groups. Journal of Educational Psychology, 77(1), 60-66. 


\section{Dankwoord (Acknowledgements)}

Onderzoek doen betekent samenwerken. Veel mensen hebben mij geholpen met de totstandkoming van dit proefschrift en bij dezen wilde ik hen bedanken. Ik zou een tweede proefschrift kunnen schrijven over het proces achter het onderzoek en alle mensen die daaraan hebben bijdragen (sommige promovendi doen dit ook daadwerkelijk), maar heb mezelf een samenvatting van twee pagina's tot doel gesteld. Laten we beginnen.

Allereerst natuurlijk Diana, mijn dagelijkse begeleider die met afstand de meeste feedback heeft gegeven op mijn proefschrift. Diana, ik denk dat weinig promovendi de luxe ervaren van een begeleider die met zo veel tomeloze inzet je stukken nakijkt en reviseert. Werkelijk altijd en vanaf elke plek op aarde kon ik je iets toesturen. Toen ik een paper zat te typen onder de sterrenhemel van Joshua Tree National Park dacht ik nog: 'Als ik het nu naar Diana zou sturen, zou ik morgen feedback hebben.' Als ik niet midden in de woestijn had gezeten, had ik een draadloos netwerk gezocht om de proef op de som nemen. Ik heb grote bewondering voor het optimisme waarmee je me coachte en het geduld waarmee je mijn werk nakeek. Ik kwam nog wel eens met een hele stapel nieuwe onderzoeksliteratuur aanzetten, maar jij bleef me altijd op de rode draad wijzen. Hier ben ik je dankbaar voor en ik hoop dat we in de toekomst kunnen blijven samenwerken.

Henk, bedankt voor alle adviezen die ik de afgelopen vier jaar van jou mocht ontvangen. Ik ben blij dat je me de kans hebt gegeven om dit pioniersproject uit te voeren. Op enkele voorstudies in Rotterdam na was er in 2006 nog nooit een onderzoek gedaan waarbij willekeurige groepsprocessen volledig experimenteel gecontroleerd werden. De fundamenten leggen voor een nieuwe onderzoeksmethode was een uitdagende opdracht. Ik heb enorm veel geleerd en ben blij dat ik dit mooie project heb mogen uitvoeren.

Cees, ook jij bedankt voor al je adviezen en voor de mogelijkheden die je me gaf om me op andere gebieden te ontwikkelen. Met veel plezier heb ik de uitwisselingen tussen promovendi uit Maastricht en Kopenhagen georganiseerd. Dankzij jou en Lambert Schuwirth heb ik een totaal nieuwe kijk gekregen op toetsing. Dit heeft me al geholpen bij advieswerk en zal in de toekomst zeker nog van pas komen.

Jeroen, bedankt voor de tijd die je me gaf om een nieuw onderzoeksvoorstel te schrijven. De brainstormsessies voor dit onderzoek waren zeer inspirerend en hebben mijn enthousiasme nog meer aangewakkerd. Anique en Diana, jullie ook bedankt voor het meedenken.

I would like to thank Micki Chi and her grad students Muhsin, Yuning and Stephanie for feedback on my work and the good times we had in Arizona. Kashia and Ben, thanks for teaching me how to climb. 
Mereke, dank je wel voor het reviseren van het eerste artikel. Robert, bedankt voor het programmeren van belangrijke materialen voor mijn experimenten. Zonder jouw expertise was dit nooit gelukt. Jeroen (Donkers) en Jean, jullie ook bedankt voor de ICT adviezen. Jean, jij ook bedankt voor de mountainbiketochtjes die we gemaakt hebben. Dit waren mooie gelegenheden om even stoom af te blazen en elkaar beter te leren kennen.

Dominique, ik wilde jou ook bedanken als lid van het 'O\&O mountainbike team'. Nooit heb ik iemand in zo'n hoog verzet op het onverharde een heuvel op zien rijden. Oprecht bedankt voor de mogelijkheid die je me gaf om een tijdje in Saoedi-Arabië te werken. Ik heb dit met plezier gedaan en hoop dat ik in de toekomst betrokken kan blijven bij het Qassim-project.

Willem, bedankt voor je hulp bij het coderen van de data. Het codeerschema dat jij voor je studies hebt gebruikt was een enorme hulp.

Medepromovendi van O\&O, bedankt voor alle gesprekken, adviezen, kopjes koffie en gezellige borrels. Mijn werkwereld veranderde drastisch toen er in mijn tweede jaar een promovendikamer werd ingericht. Dat O\&O vrijwel alleen maar vrouwelijke promovendi heeft maakte dit alleen maar interessanter. Binnen de kortste keren leerde ik dat je nooit een kopje koffie alleen voor jezelf mag halen, dat je altijd moet onthouden wat iedereen in zijn koffie drinkt en dat die pyjama's die baby's dragen niet gewoon pyjama's heten, maar rompertjes. Jeantine, Rachelle, Janneke, Marjo, Greet, Ellen, bedankt voor de leuke tijd en ik hoop dat we contact houden. Dit geldt natuurlijk ook voor Ilske, Renée, Joost en de andere AiO's.

Het ProVUM bestuur wil ik bedanken voor haar actieve inzet voor de belangen van promovendi in Maastricht. Dit geldt voor Cynthia, Jennifer, Mirjam, Janine, Silke, Marieke, Arkady, Raffaele, Conrad en al die andere actieve leden. Marcel en Melissa, het was een genoegen met jullie samen te werken in de universiteitsraad.

Vriendjes en vriendinnetjes uit Den Haag, bedankt voor alle gezelligheid de afgelopen jaren. Dat we nog vele stedentripjes, wintersportvakanties, concerten en uitgaansavondjes met elkaar mogen beleven. Misschien zien we ADO zelfs nog een keer landskampioen worden. Erik, bedankt voor de gezellige tijd in de Heugemerstraat. Victor, bedankt voor je hulp bij het leren van Flash en je vriendschap. Veel succes met je huis.

Als laatste wilde ik mijn ouders en broer bedanken. Het is goed om te weten dat we altijd op elkaar terug kunnen vallen en inderdaad, blood is thicker than water. 


\section{Curriculum Vitae}

Floris van Blankenstein was born on January $9^{\text {th }}, 1980$ in The Hague. He received his secondary degree diploma at Dalton Voorburg secondary school in 1999. From 1999 until 2004 he studied psychology at Maastricht University and specialized in cognitive and educational psychology. After his studies, he worked for one year and taught for half a year in a PBL curriculum at the Catholic University of Mozambique. Shortly after his return to the Netherlands in 2006, he started his PhD project about the effect of elaboration during small-group, problem-based discussions on academic achievement at Maastricht University. During his PhD project, he attended Arizona State University in the United States as a visiting scholar. He also worked as an educational consultant at Sulaiman AlRajhi University in Saudi Arabia. Furthermore, he was chairman of the Maastricht PhD network ProVUM and a member of the university council. 


\section{SHE dissertation series}

In the SHE Dissertation Series dissertations are published of $\mathrm{PhD}$ candidates from the School of Health Professions Education (SHE) who defended their PhD thesis at Maastricht University. The most recent ones are listed below. For more information go to: www.maastrichtuniversity.nl /she.

De Leng, B. (8-12-2009). Wired for learning. How computers can support interaction in small group learning in higher education.

Maiorova, T. (29-05-2009). The role of gender in medical specialty choice and general practice preferences.

Bokken, L. (04-03-2009). Innovative use of simulated patients for educational purposes.

Wagenaar, A. (18-09-2008). Learning in internships. What and how students learn from experience.

Driessen, E. (25-06-2008). Educating the self-critical doctor. Using portfolio to stimulate and assess medical students' reflection.

Derkx, H. (18-06-2008). For your ears only. Quality of telephone triage at out-of-hours centres in the Netherlands.

Niessen, Th. (30-11-2007). Emerging epistemologies: making sense of teaching practice.

Budé, L. (05-10-2007). On the improvement of students' conceptual understanding in statistics education.

Niemantsverdriet, S. (26-07-2007). Learning from international internships: A reconstruction in the medical domain.

Marambe, K. (20-06-2007). Patterns of student learning in medical education - A Sri Lankan study in traditional curriculum.

Pleijers, A. (19-01-2007). Tutorial group discussion in problem-based learning.

Sargeant, J. (21-09-2006). Multi-source feedback for physician learning and change.

Dornan, T. (12-06-2006). Experience-based learning.

Wass, V. (12-05-2006). The assessment of clinical competence in high stakes examinations.

Prince, K. (21-04-2006). Problem-based learning as a preparation for professional practice. 


\section{ICO dissertation series}

In the ICO Dissertation Series dissertations are published of graduate students from faculties and institutes on educational research within the following universities: Eindhoven University of Technology, Leiden University, Maastricht University, Open University of the Netherlands, University of Amsterdam, University of Groningen, University of Twente, Utrecht University, VU University Amsterdam, and Wageningen University (and formerly Radboud University Nijmegen and Tilburg University). Below is a list of the most recent dissertations.

179. Munneke-de Vries, E.L. (11-01-2008). Arguing to learn: Supporting interactive argumentation through computer-supported collaborative learning. Utrecht: Utrecht University.

180. Nijveldt, M.J. (16-01-2008). Validity in teacher assessment. An exploration of the judgement processes of assessors. Leiden: Leiden University.

181. Jonker, H.G. (14-02-2008). Concrete elaboration during knowledge acquisition. Amsterdam: VU University Amsterdam.

182. Schuitema, J.A. (14-02-2008). Talking about values. A dialogue approach to citizenship education as an integral part of history classes. Amsterdam: University of Amsterdam.

183. Janssen, J.J.H.M. (14-03-2008). Using visualizations to support collaboration and coordination during computer-supported collaborative learning. Utrecht: Utrecht University.

184. Honingh, M.E. (17-04-2008). Beroepsonderwijs tussen publiek en privaat: Een studie naar opvattingen en gedrag van docenten en middenmanagers in bekostigde en niet-bekostigde onderwijsinstellingen in het middelbaar beroepsonderwijs. Amsterdam: University of Amsterdam.

185. Baartman, L.K.J. (24-04-2008). Assessing the assessment: Development and use of quality criteria for competence assessment programmes. Utrecht: Utrecht University.

186. Corbalan Perez, G. (25-04-2008). Shared control over task selection: Helping students to select their own learning tasks. Heerlen: Open University of the Netherlands.

187. Hendrikse, H.P. (22-05-2008). Wiskundig actief: Het ondersteunen van onderzoekend leren in het wiskunde onderwijs. Enschede: University of Twente.

188. Moonen, M.L.I. (26-09-2008). Testing the multi-feature hypothesis: Tasks, mental actions and second language acquisition. Utrecht: Utrecht University.

189. Hooreman, R.W. (18-11-2008). Synchronous coaching of the trainee teacher: An experimental approach. Eindhoven: Eindhoven University of Technology.

190. Bakker, M.E.J. (02-12-2008). Design and evaluation of video portfolios: Reliability, generalizability, and validity of an authentic performance assessment for teachers. Leiden: Leiden University. 
191. Kicken, W. (12-12-2008). Portfolio use in vocational education: Helping students to direct their learning. Heerlen: Open University of the Netherlands.

192. Kollöffel, B.J. (18-12-2008). Getting the picture: The role of external representations in simulation-based inquiry learning. Enschede: University of Twente.

193. Walraven, A. (19-12-2008). Becoming a critical websearcher: Effects of instruction to foster transfer. Heerlen: Open University of the Netherlands.

194. Radstake, H. (14-05-2009).Teaching in diversity: Teachers and pupils about tense situations in ethnically heterogeneous classes. Amsterdam: University of Amsterdam.

195. Du Chatenier, E. (09-09-2009). Open innovation competence: Towards a competence profile for inter-organizational collaboration in innovation teams. Wageningen: Wageningen University.

196. Van Borkulo, S.P. (26-06-2009). The assessment of learning outcomes of computer modelling in secondary science education. Enschede: University of Twente.

197. Handelzalts, A. (17-09-2009). Collaborative curriculum development in teacher design teams. Enschede: University of Twente.

198. Nievelstein, F.E.R.M. (18-09-2009). Learning law: Expertise differences and the effect of instructional support. Heerlen: Open University of the Netherlands.

199. Visser-Wijnveen, G.J. (23-09-2009). The research-teaching nexus in the humanities: Variations among academics. Leiden: Leiden University.

200. Van der Rijst, R.M. (23-09-2009). The research-teaching nexus in the sciences: Scientific research dispositions and teaching practice. Leiden: Leiden University.

201. Mainhard, M.T. (25-09-2009). Time consistency in teacher-class relationships. Utrecht: Utrecht University.

202. Van Ewijk, R. (20-10-2009). Empirical essays on education and health. Amsterdam: University of Amsterdam.

203. Seezink, A. (18-11-2009). Continuing teacher development for competence-based teaching. Tilburg: Tilburg University.

204. Rohaan, E.J. (09-12-2009). Testing teacher knowledge for technology teaching in primary schools. Eindhoven: Eindhoven University of Technology.

205. Kirschner, F.C. (11-12-2009). United brains for complex learning. Heerlen: Open University of the Netherlands.

206. Wetzels, S.A.J. (18-12-2009). Individualized strategies for prior knowledge activation. Heerlen: Open University of the Netherlands. 